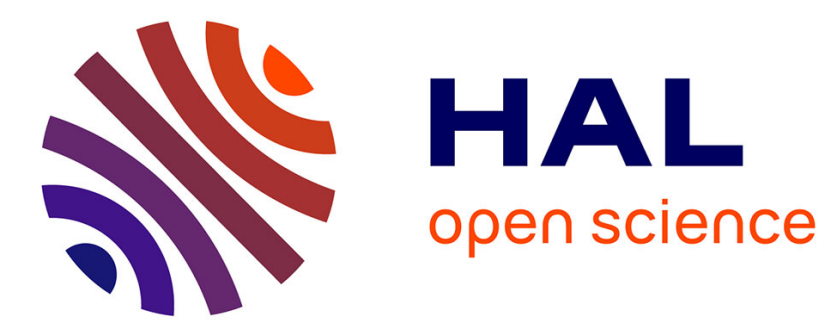

\title{
Access to Galectin3 Inhibitors from Chemoenzymatic Synthons
}

\author{
Christophe Dussouy, Stéphane Téletchéa, Annie Lambert, Cathy Charlier, \\ Iuliana Botez, Frédéric de Ceuninck, Cyrille Grandjean
}

\section{To cite this version:}

Christophe Dussouy, Stéphane Téletchéa, Annie Lambert, Cathy Charlier, Iuliana Botez, et al.. Access to Galectin3 Inhibitors from Chemoenzymatic Synthons. Journal of Organic Chemistry, 2020, 10.1021/acs.joc.0c01927 . hal-03010455

\section{HAL Id: hal-03010455 \\ https://hal.science/hal-03010455}

Submitted on 18 Nov 2020

HAL is a multi-disciplinary open access archive for the deposit and dissemination of scientific research documents, whether they are published or not. The documents may come from teaching and research institutions in France or abroad, or from public or private research centers.
L'archive ouverte pluridisciplinaire HAL, est destinée au dépôt et à la diffusion de documents scientifiques de niveau recherche, publiés ou non, émanant des établissements d'enseignement et de recherche français ou étrangers, des laboratoires publics ou privés. 


\title{
Access to Galectin-3 Inhibitors from Chemoenzymatic Synthons
}

\author{
C hristophe D ussouy, ${ }^{+}$Stéphane T életchéa, ${ }^{+}$Annie L ambert, ${ }^{+}$C athy C harlier, ${ }^{+}+{ }^{+} \mid$Iuliana Botez, ${ }^{\S}$ F rédéric De C eu- \\ ninck ${ }^{\S}$ and Cyrille Grandjean*,+ \\ + U niversité de N antes, CN RS, U nité Fonctionnalité et Ingénierie des Protéines (U FIP), U M R 6286, F-44000 N antes, F rance \\ * U niversité de N antes, CN RS, Plateforme IM PACT , U M R 6286, F- 44000 N antes, France \\ $\S$ Institut de Recherches Servier, Croissy-sur-Seine, France \\ KEYW O RDS: glycosynthase, biocatalysis, galectin-3 inhibitors, lacto-N -biose, lactose, carbohydrate, galectin, medicinal chemistry
}

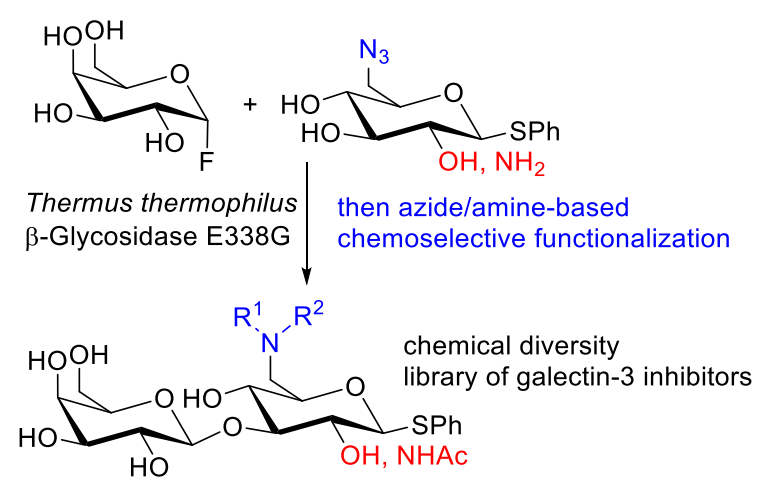

\begin{abstract}
ABST RACT: C hemo-enzymatic strategies are useful to provide both regio- and stereoselective access to bioactive oligosaccharides. We show herein that a glycosynthase mutant of a Thermus thermophilus $\alpha$-glycosidase can react with unnatural glycosides such as 6-azido-6-deoxy-Dglucose/ glucosamine to lead to $\beta$-D-galactopyranosyl-( $1 \rightarrow 3)$-D-glucopyranoside or $\beta$-D-galactopyranosyl- $(1 \rightarrow 3)$-2-acetamido-2-deoxy-D-glucopyranoside derivatives bearing a unique azide function. T aking advantage of the orthogonality between the azide and the hydroxyl functional groups, the former was next selectively reacted to give rise to a library of galectin-3 inhibitors. Combining enzyme substrate promiscuity and bioorthogonality thus appears as a powerful strategy to rapidly access to sugar-based ligands.
\end{abstract}

\section{INTRODUCTION}

By essence glycosyltransferases are designed and thus widely used to achieve glycan synthesis with incomparable selectivity and efficiency. ${ }^{1,2,3,4} \mathrm{~T}$ he transfer catalyzed by some of these enzymes can occur efficiently not only with their natural donor substrates but also with synthetic analogs. This considerably increases thescope of their applications, which is therefore not limited to the sole preparation of natural glycans. A major achievement was the advent of metabolic functionalization. ${ }^{5}$ Glycosyltransferase substrate promiscuity has now been exploited for the synthesis of complex glycans as well as for inhibitor or ligands. This was achieved starting from chemoenzymatic synthons, first enzymatically used either in cellulo or in vitro as substrates to form oligosaccharides prior to their chemical modifications. ${ }^{67,8,9}$ Interestingly a reverse strategy consisting in using temporary protecting groups on acceptor substrates to divert and control the reactivity of glycosyltransferases has been applied to synthesize complex glycoforms. ${ }^{10,11} \mathrm{~T}$ rans-glycosidases whether natural ${ }^{12}$ or mutant glycoside hydrolases obtained by directed evolution ${ }^{13}$ or rational design ${ }^{14}$ as well as glycosynthases ${ }^{15}$ are powerful tools for the synthesis of oligosaccharides or glycoconjugates. For example, the design of a trans- $\beta-\mathrm{N}$-acetylglucosaminidase engineered from a
GH 1 glycoside hydrolase able to hydrolyze galactose and glucose but not $\mathrm{N}$-acetyl-D-glucosamine has been reported. ${ }^{16}$ Glycosynthases arise from the mutation of the catalytic nucleophile residue of a retaining glycoside hydrolase to either Ala, G ly or Ser. While glycosynthases have lost their hydrolytic capacity, they are able to catalyze the selective transfer of fluoro-activated sugar donors to appropriate acceptors. ${ }^{17,15} \mathrm{H}$ owever, despite their broad interest, such enzymes have scarcely been tested for their ability to accept chemoenzymatic synthons. Withers' laboratory has recently reported the screening of glycoside hydrolase activities from the $\mathrm{GH} 1$ family (CA-zyme), for substrates bearing either an amino or an azido group at the 3, 4- or 6-position of the glucose. ${ }^{18}$ The panel of tested enzymes proved rather tolerant for the replacement of a hydroxyl with an amino group and when an azido group was present at the 6-position. They were much less permissive for 3-azido and 4-azido substrates due to the steric demand of the azido group because of the strong hydrogen bonds formed between substrates and highly conserved residues of GH 1 enzyme catalytic domains. Finally, the authors succeeded in synthesizing taggable di- and tri-saccharides from seven glycosynthases derived from these glycosidases to demonstrate the utility of this approach. Considering now the acceptor sub- 
strate, it is well-established that a wide range of aglycons are tolerated albeit with a preference for arylated substituents in line with their capability to form stabilizing hydrophobic interactions with the residues within the $+1,+2$ enzyme subsites. Furthermore the hydroxyl can be advantageously replaced by a thiol group which can next be used as the glycosylation site to give rise to thio-glycosides. ${ }^{19}$ Finally, site-specific enzymatic $\alpha$-D-glucosylation has been performed on a disaccharide whereby an acetamido group has been replaced by a trichloroacetamide at a remote position, to allow further chemical elongation of the resulting trisaccharide building block to form an important hapten for vaccination. ${ }^{20}$ As an extension of the use of chemoenzymatic synthons, we herein report that 6-azido-glycosides are effective glycosynthase acceptor substrates, useful to give access to glycan-derived inhibitors of relevant therapeutic targets. In the present work, we focused on the galectin-3 protein as a representative example. Galectins form an evolutionary conserved family of animal lectins which bind $\alpha$-galactoside motifs through one or two carbohydrate binding domains (CRDs). H uman galectin-3 is the only chimera-type galectin composed of a single CRD at its $C$ terminus and of a non-lectin collagen-like domain. ${ }^{21} \mathrm{G}$ alectin-3 is found in the nucleus, the cytoplasm, in the vicinity of the cell surface, the extracellular matrices and even in the circulation. Galectin-3 is expressed in various cell types including epithelial and endothelial cells, fibroblasts as well as immune cells. Galectin-3 has been increasingly recognized as being involved in highly diverse physiological or pathophysiological processes such as adhesion, differentiation, apoptosis, cell division, proliferation, trafficking, growth or regulation of cell signaling and gene expression..$^{22,23}$ Consequently galectin3 has emerged as a potential novel therapeutic target and sugar-derived small molecule inhibitors have been proposed as galectin specific inhibitors and beyond, as potential novel drug candidates.

\section{RESULTSAND DISCUSSION}

Rationale. Galectin-3 recognizes both $\beta-G$ alp-( $1-3)-\beta-D-G I c p N$ (lactosamine type I) and $\beta$-Galp-(1-4)- $\beta$-D-GIcpN (lactosamine type II) core structures. A close study of lactosamine I and II binding modes was performed recently. ${ }^{24}$ In their work, $\mathrm{H}$ sieh and co-workers found that galactose position for both lactosamine types was highly conserved in galectin-3. This orientation is also identical in more recent structures of di-galactoside galectin inhibitors where the galactose binding position is strictly conserved. ${ }^{25,26}$ This evolution-driven specificity for galactose recognition involves two chemical interactions. First, a characteristic direct or water-mediated hydrogen network is formed by the conserved amino acids $\mathrm{H} 158$, $\mathrm{N} 160, \mathrm{R} 162, \mathrm{~N} 174$ and $\mathrm{E} 184$ with the oxygens $03,04,05$, and 06 of the galactose moiety. Second, W 181 tightens the binding via a hydrophobic interaction with galactose atoms C 3, C4, C5 and C6. Concerning the glucose or N Ac-glucose recognition for lactosamine type I or II, the authors observed a rotation of $240^{\circ}$ around the glycosidic angle. ${ }^{24} \mathrm{~T}$ his rotation does not alter one important hydrogen bond with $\mathrm{R} 162$ and $\mathrm{E} 184$ since the lactosamine type II C4-OH and the lactosamine type I $\mathrm{C}$ 3-O H are superimposable at this oxygen position. This rotation exchanges $\mathrm{C} 2$ and $\mathrm{C} 6$ positions between the lactosamines I and II leading to differences in their binding affinities, measured $K_{d}$ being respectively $33 \mu \mathrm{M}$ and $93 \mu \mathrm{M}$, in-line with other studies. ${ }^{24,27}$ While the carbohydrate core is involved in a dense hydrogen bond network making the presence of the $4-\mathrm{O} \mathrm{H}$ and 3-O $\mathrm{H}$ groups mandatory for the recognition as described above, the careful choice of the substituents at the other positions provides significant contribution to both affinity and specificity. T remendous synthetic efforts have been devoted to the decoration of the lactose / type II lactosamine core notably at the $\mathrm{C} 2$ position of the glucose/ glucosamine residue. ${ }^{28,29} \mathrm{M}$ odifications at C2-position are key since, for example, aryl substituents have been shown to enhance the binding affinity towards galectin-3 by one order of magnitude through cation$\pi$ interactions with the residue $\mathrm{R} 186$ of the CRD.$^{30}$ By contrast, to our knowledge, only two reports describe the preparation of type I lactosamine-derived galectin inhibitors. The first one concerns the preparation of $\mathrm{N}$-acetyllactosamine type 1 oligomers by iterative enzymatic synthesis. ${ }^{31}$ The second one describes the synthesis of a series of inhibitors bearing modifications at either the 2'-OH position of the galactose or the amino position of the glucosamine residues, obtained according to a classical glycosylation strategy between a thio-glycoside donor and a 4,6-0-benzylidene protected glucosamine acceptor ${ }^{32} 0$ ur laboratory reported some years ago the preparation of the glycosynthase E338G mutant from Thermusthermophilus glycoside hydrolase (TT $\beta$ G ly E338G) which was successfully used as a catalyst for the expeditious synthesis of the $\beta$-G alp-( 1-3) $\beta$-D-GICN p / GIcp core. ${ }^{33}$ We reasoned that if this glycosynthase accepts 6 -azido-glycosides as substrate that would offer a unique opportunity to explore the effect of modifications at C6-position ( equivalent to $\mathrm{C} 2$ position on type lactosamine / lactose) on galectin-3 recognition.

Access to $\beta$-Galp(1-3)-6-azido-6-deoxy- $\beta$-D-G Icp/ G IcN p motifs. To test our working hypothesis, we first synthesized potential donor and acceptor substrates for the enzyme. $\alpha$-Galactopyranosyl fluoride 1 was thus prepared in two steps ( $90 \%$ overall yield) from galactose-pentaacetate upon HF-pyridine treatment followed by Zemplén deprotection as described ${ }^{33}$ except that we omitted the final neutralization step as we noticed that compound 1 could be stored longer at $-20^{\circ} \mathrm{C}$. Synthesis of phenyl 2-acetamido-6-azido2,6-dideoxy-1-thio- $\alpha$-D-glucopyranoside 2 was preferentially carried out from a 2-phthalimido rather than a 2-acetamido precursor. Hence, derivative $3^{34}$ was selectively mesylated at the C -6 position and next subjected to $\mathrm{S}_{\mathrm{N}} 2$ substitution using sodium azide to give compound 4. Acceptor $\mathbf{2}$ was obtained after ethylene diamine treatment to remove phthalimide protecting group from intermediate $\mathbf{4}$ ( $46 \%$ yield for the three steps) (Scheme 1). ${ }^{35}$ In parallel glucose pentaacetate $\mathbf{5}$ was glycosylated with thiophenol in the presence of boron trifluoride etherate, treated with sodium methoxide in methanol, silylated at the C-6 upon treatment with the TBDM S-imidazole complex and submitted to peracetylation to afford the intermediate 6. Selective deprotection of the 6-hydroxyl moiety of derivative $\mathbf{6}$, next subjected to mesylation followed by sodium azide nucleophile substitution, conducted to the intermediate 7. Final deacetylation of 7 gave rise to a second chemoenzymatic synthon, the phenyl 6-azido6 -deoxy-1-thio- $\beta$-D-glucopyranoside 8 in 8 steps and $45 \%$ overall yield (Scheme 1).

To our delight the reaction of $\alpha$-galactopyranosyl fluoride 1 with acceptor 2 at a 2:1 stoichiometry in phosphate buffer in the presence of T T $\beta$ G ly E338G mutant as described previously ${ }^{33}$ gave access to phenyl $\alpha$-D-galactopyranosyl-( $1 \rightarrow 3$ )-2-amino-2-deoxy-1-thio- $\alpha$-D glucopyranoside 9 as a sole product in $40 \%$ yield ( Scheme 2 and T a- 
ble 1). Addition of $5 \%$ or $10 \%$ DMSO in the reaction mixture favored the solubilization of the acceptor 2 without apparent alteration of TT $\beta$ G ly E338G activity, leading to improved $67 \%$ and $78 \%$ yields, respectively ( $\mathrm{T}$ able 1 ). Finally, compound $\mathbf{9}$ was peracetylated to give intermediate $\mathbf{1 0}$ which was then treated with sodium methoxide in methanol to afford derivative 11. The optimized enzymatic conditions were next applied to the enzymatic glycosylation between compounds $\mathbf{1}$ and $\mathbf{8}$ to give phenyl $\alpha$-D-galactopyranosyl$(1 \rightarrow 3$ )-1-thio- $\alpha$-D-glucopyranoside $\mathbf{1 2}$ in $47 \%$ isolated yield (Scheme 1 and T able 1).

Scheme 1. Preparation of the enzymatic synthons and chemoenzymatic access to $\beta-G$ alp-(1-3)-6-azido-6-deoxy- $\beta$-D-G Icp/ G IcNp motifs

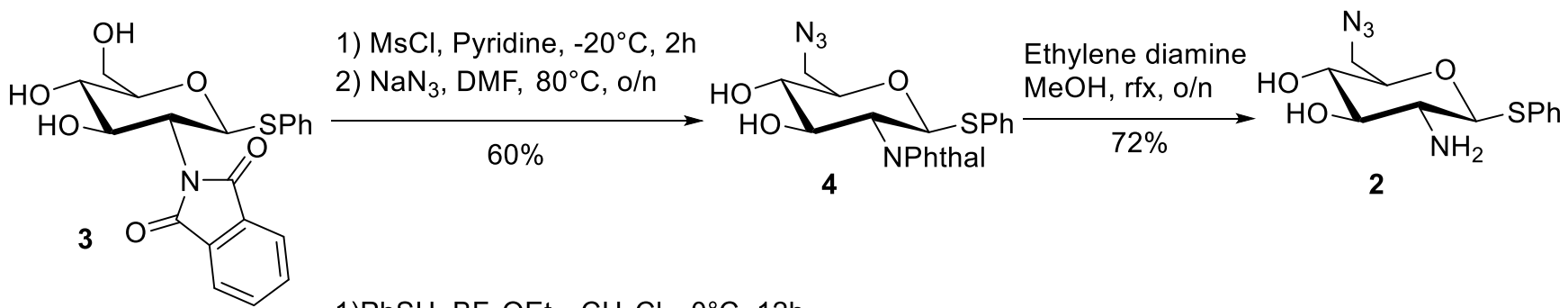

1) $\mathrm{PhSH}, \mathrm{BF}_{3} \mathrm{OEt}_{2}, \mathrm{CH}_{2} \mathrm{Cl}_{2}, 0^{\circ} \mathrm{C}, 12 \mathrm{~h}$

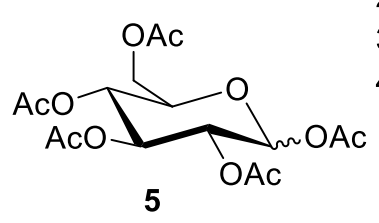

MeOHa, $\mathrm{MeOH}, 2 \mathrm{~h}$

3) TBDMSCl, Imidazole, DMF, $0^{\circ} \mathrm{C}$ to $\mathrm{rt}, 12 \mathrm{~h}$

4) $\mathrm{Ac}_{2} \mathrm{O}, \mathrm{Et}_{3} \mathrm{~N}, \mathrm{DMAP}, \mathrm{CH}_{2} \mathrm{Cl}_{2}, \mathrm{rt}, \mathrm{o} / \mathrm{n}$

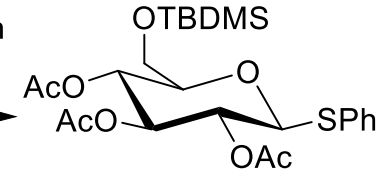

6

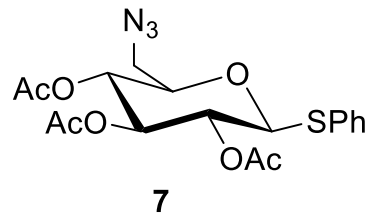

7
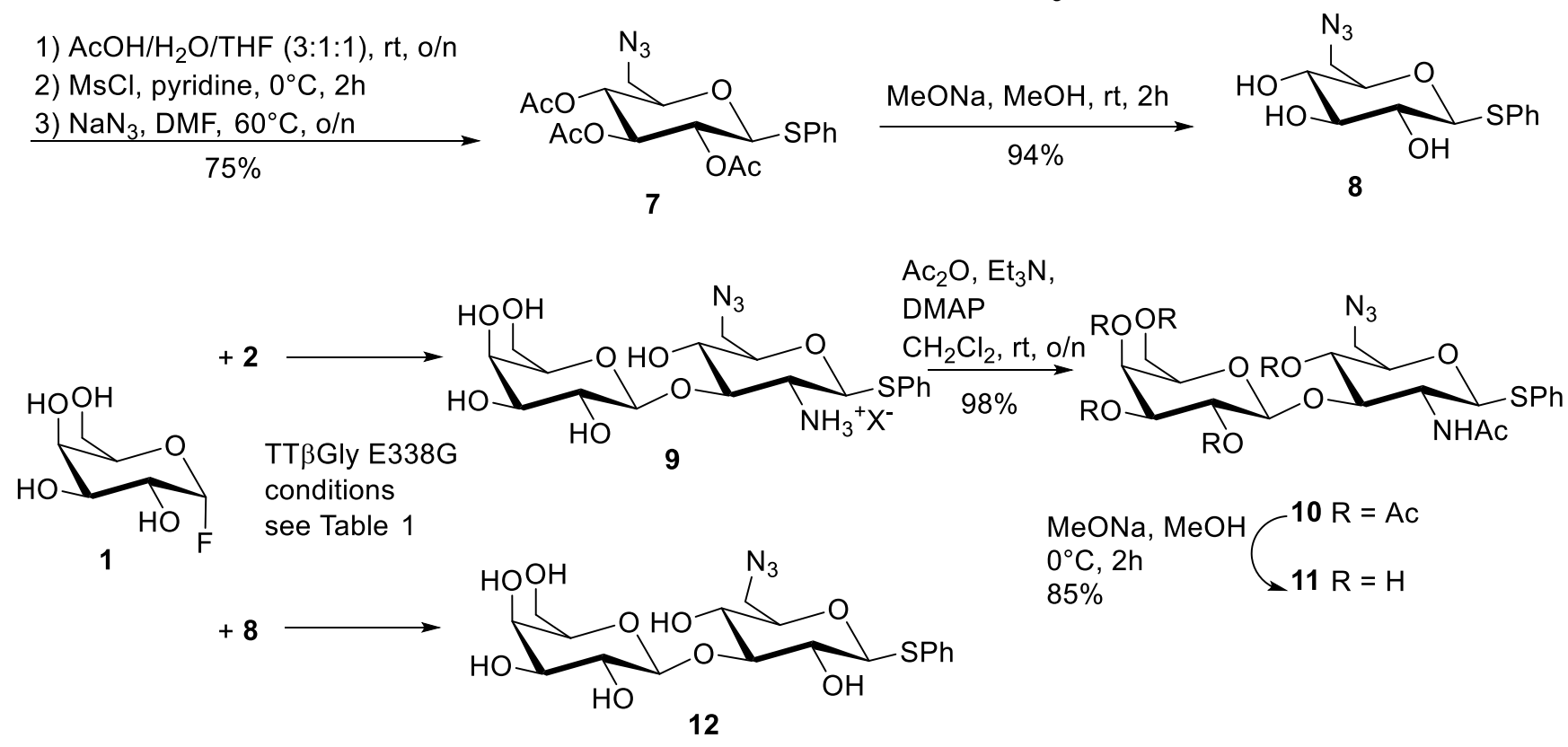

Table 1. Enzymatic glycosylation reaction ${ }^{a}$

$\begin{array}{cccc}\text { Donor (equiv) } & \text { Acceptor (equiv) } & \text { DM SO (\%) } & \text { Yield (\%) } \\ \mathbf{1}(2) & \mathbf{2}(1) & - & 40 \\ \mathbf{1}(2) & \mathbf{2}(1) & 5 & 67 \\ \mathbf{1}(2) & \mathbf{2}(1) & 10 & 78 \\ \mathbf{1}(1.5) & \mathbf{8}(1) & 10 & 47^{\mathrm{b}}\end{array}$

a TTßGly E338G (3-4.5 mg/mL), Phosphate buffer (150mM, pH 7.3), $37^{\circ} \mathrm{C}, 72 \mathrm{~h}$; ${ }^{b}+$ unseparable mixture of regioisomers and excess donor $\mathbf{1}$
Formation of by-products, presumably corresponding to the $1 \rightarrow 2$ or/ and $1 \rightarrow 4$ regioisomer disaccharides together with some unreacted fluoride donor were detectable on TLC plates. Similar reaction led to a mixture of both $\beta-(1 \rightarrow 3)$ disaccharide ( $96-94 \%)$ and $\beta$ - $(1 \rightarrow 6)$ regioisomer $(4-6 \%)$ when phenyl 1-thio- $\beta$-D-glucopyranoside was used as the acceptor substrate. While $C 6$ position is no longer reactive due to the replacement of the hydroxyl by the azide, this observation suggests that the steric demand of the azide substituent modifies the position of the acceptor within the ( +1 site). 
Along this line, our laboratory reported that the nature of the anomeric substituent could orient the regioselectivity of the glycosylation catalyzed by TT $\beta$ Gly E338G in particular towards the formation of the $\beta$ - $(1 \rightarrow 2)$ disaccharides. ${ }^{36}$

Successful enzymatic access to disaccharides $\mathbf{1 1}$ and $\mathbf{1 2}$ offered a unique opportunity to further document structure-activity relationships within a series of sugar-based derivatives that were further evaluated in a biochemical test to assess their binding affinity towards galectin-3. The syntheses could be achieved upon exploiting the unique reactivity of azide subsituent either directly using click chemistry or after its reduction to the corresponding amine.

Access to inhibitors using azide specific reactivity in $\mathbf{1 1}$. Staudinger reaction or hydrogenation $\left(\mathrm{NaBH}_{4} /\right.$ catalytic $\left.\mathrm{NiCl}_{2} \cdot 6 \mathrm{H}_{2} \mathrm{O}\right)^{37}$ was accompanied with acetate migration when carried out with intermediate $\mathbf{1 0}$. Reduction was thus attempted on deprotected disaccharide $\mathbf{1 1}$ which was treated with trimethylphosphine. Amine intermediate $\mathbf{1 3}$ was not purified but further reacted with 2,3-naphthalic anhydride to give amide 14 (19\%) together with the corresponding imide 15 (18\%) (Scheme 2).

\section{Scheme2. Synthesis of galectin-3 inhibitors from disaccharide 13}

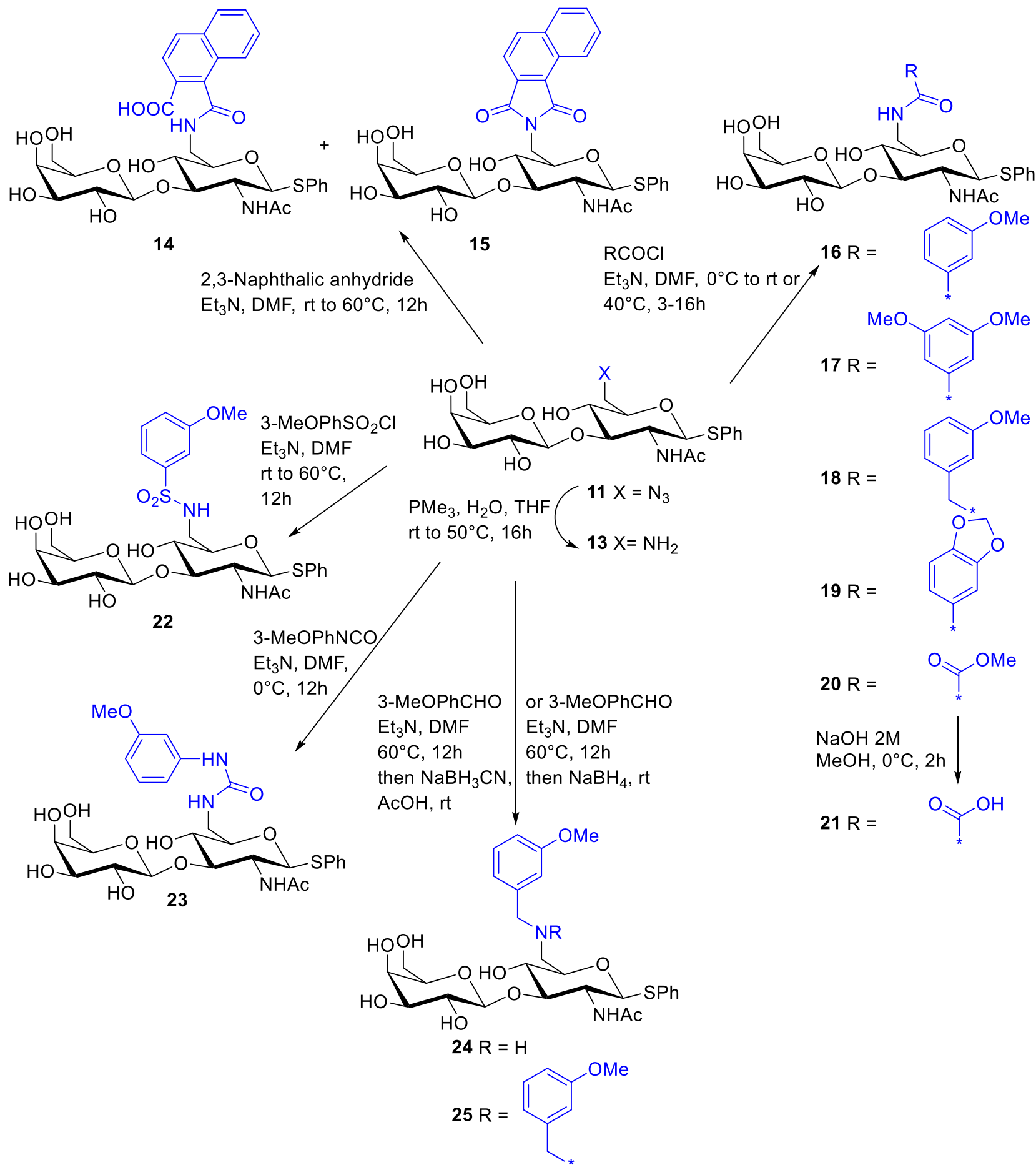


$\mathrm{N}$ ext amine 13 was reacted in parallel with a series of acyl chlorides to give amides 16 (50\%), 17 (38\%), 18 (65\%), 19 (55\%) and 20 (60\%) (Scheme 2). T he methyl ester compound 20 was further saponified to give an additional carboxylic acid derivative $\mathbf{2 1}$ in 95\% yield. 0 n the one hand a carboxylic acid substituent as in $\mathbf{2 1}$ was expected to interact with Arg186 side-chain residue of galectin-3 CRD. On the other hand, aromatic substituents at the GICN -C2 position in type II lactosamines have been shown to interact through cation$\pi$ interactions with Arg 186, contributing substantially to the affinity towards galectin-3. This effect was particularly pronounced with 1carboxy-2-naphthoyl and 3-methoxybenzoyl substituents. ${ }^{30,27,38,39}$ Based on this knowledge, the 3-methoxyaryl motif was next selected to synthesize a new set of derivatives simply differing by their connectivity to the sugar moiety. H ence, amine $\mathbf{1 3}$ was reacted with 3methoxysulfonyl chloride or 3-methoxyisocyanate to afford sulfone

\section{Scheme 3. Synthesis of compound 26 from disaccharide 11}

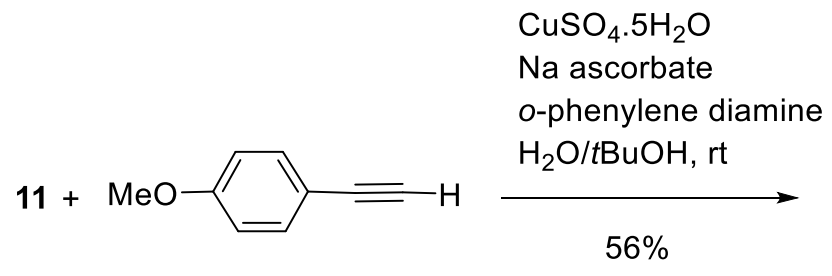

\section{Binding affinity measurements}

We next carried out biochemical experiments to measure the binding affinities of these derivatives towards galectin-3 in order to validate the value of the chemoenzymatic approach for the discovery of new galectin inhibitors. $D$ issociation constants were determined by fluorescence polarization assay using known 2-[ ( fluoresceinyl) thioureido] ethyl 4-0-[3-0-(3-methoxybenzyl)- $\beta$-D-galactopyranosyl]$\beta$-D-glucopyranoside as fluorescent probe (FigureS1) and recombinant human galectin-3 ( $\mathrm{hG} \mathrm{al}-3$ ) protein ( T able 2) ${ }^{29} \mathrm{~T}$ wo inhibitors previously described in the literature, the bis $\{3-d e o x y-3-[4-(3-f l u o r-$ ophenyl)-1H-1,2,3-triazol-1-yl]- $\beta$-d-galactopyranosyl\}sulfane (usually referred to as TD 139), ${ }^{25}$ and the phenyl $\beta$-D-galactopyranosyl- $(1 \rightarrow 3)$-2-acetamido-2-deoxy-1-thio- $\beta$-D-glucopyranoside $\mathbf{2 7}^{33}$ (Figures S1 and S2) were tested in parallel as positive controls. The head-to-head comparison towards known inhibitors allows to assessing the value of the new compounds for targeting galectin-3. T D139 is among the most potent disaccharide-based galectin-3 inhibitor developed so far. This derivative has been evaluated in a Phase II clinical trial. Derivative $\mathbf{2 7}$ is not modified at the $C 6$ position of the glucose residue representing the type I lactosamine core. This inhibitor is thus useful to assess the contribution of the substituent at the $C 6$ position of the glucose to the binding.

$K_{d}$ for reference compound 27 was found equal to $52 \mu \mathrm{M}$ by fluorescence polarization, in agreement with the value measured by isothermal microcalorimetry ( $32 \mu \mathrm{M}$ ) (See Figure S2 \& T able S1) .

The tested compounds could be ranked depending on their affinity to galectin-3: compounds with similar or less affinity than the reference 27 (e.g. methoxyphenyl amides 16, 17 and 18), those with
22 and urea $\mathbf{2 3}$ with $20 \%$ and $47 \%$ yield, respectively. M onobenzylated amine $\mathbf{2 4}$ or dibenzylated amine $\mathbf{2 5}$ were respectively obtained upon reductive amination of $\mathbf{1 3}$ with either 1.2 equivalent of 3-methoxybenzaldehyde in the presence of sodium cyanoborohydride as the reducing agent or 2.4 equivalent of the aldehyde using sodium borohydride in $56 \%$ and $37 \%$ yield. Finally, triazole derivative $\mathbf{2 6}$ was obtained with $23 \%$ yield according to a copper-catalyzed azide-alkyne cycloaddition (CuAAC) reaction from 3-methoxyphenylacetylene and disaccharide $\mathbf{1 1}$ (Scheme 3). T he low isolated yield was ascribed to intrinsic reactivity of compound $\mathbf{1 1}$ since, in our hands, these experimental conditions ${ }^{40}$ led to the quantitative transformation of azide 4 used as a model reactant. Alternatively, using copper (II) sulfate, sodium ascorbate and sodium carbonate in a $\mathrm{H}_{2} \mathrm{O}$ / T HF mixture at rt afforded an inseparable mixture of regioisomers.

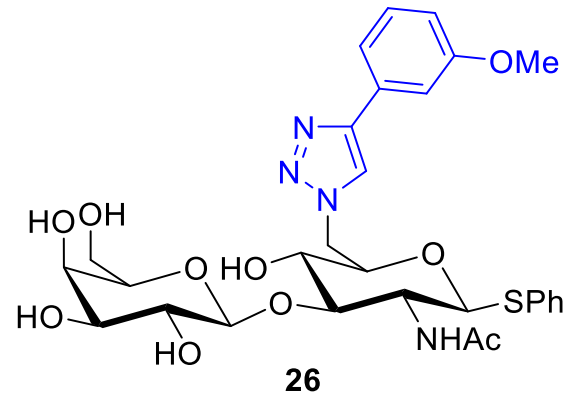

slightly improved affinities (amides 14, 19, 20 and 21, urea 23 and triazole 26 with $\mathrm{K}_{\mathrm{d}} \mathrm{s}$ in the range of $28-42 \mu \mathrm{M}$ and imide 15, amines $\mathbf{2 4}$ and $\mathbf{2 5}$ with $\mathrm{K}_{\mathrm{d}} \mathrm{S}$ in the range of $20 \mu \mathrm{M}$ ) and, finally, 3-methoxysulfonamide 22 having a $K_{d}$ equal to $10.4 \mu \mathrm{M}$.

Table 2. Dissociation constants of compounds tested against galectin-3 at rt ${ }^{a, b}$

$\begin{array}{cccc}\text { Inhibitor } & \mathrm{K}_{\mathrm{d}}(\mu \mathrm{M}) & \text { Inhibitor } & \mathrm{K}_{d}(\mu \mathrm{M}) \\ \text { TD139 } & 0.22 \pm 0.041 & \mathbf{2 7} & 51.8 \pm 10.3 \\ \mathbf{1 4} & 28.0 \pm 3.6 & \mathbf{2 5} & 22.1 \pm 3.8 \\ \mathbf{1 5} & 19.4 \pm 3.4 & \mathbf{2 6} & 40.2 \pm 6.2 \\ \mathbf{1 6} & 58.3 \pm 8.9^{c} & \mathbf{2 9} & 35.9 \pm 10.9 \\ \mathbf{1 7} & 64.5 \pm 6.8 & \mathbf{3 0} & 42.7 \pm 6.1 \\ \mathbf{1 8} & 52.2 \pm 9.0 & \mathbf{3 1} & 14.9 \pm 2.4 \\ \mathbf{1 9} & 37.6 \pm 6.7 & \mathbf{3 2} & 9.14 \pm 1.9 \\ \mathbf{2 0} & 37.6 \pm 5.2^{c} & \mathbf{3 3} & 14.6 \pm 2.6 \\ \mathbf{2 1} & 41.5 \pm 7.0 & \mathbf{3 4} & 68.5 \pm 10.5 \\ \mathbf{2 2} & 10.4 \pm 2.3^{c} & \mathbf{3 5} & 41.0 \pm 5.4 \\ \mathbf{2 3} & 36.8 \pm 6.4^{c} & \mathbf{3 6} & 225^{\mathrm{d}} \\ \mathbf{2 4} & 20.8 \pm 3.4^{c} & & \end{array}$

${ }^{a}$ Concentrations wereas follows: probe $100 \mathrm{nM}, \mathrm{hG}$ al- $31 \mu \mathrm{M}$ and inhibitors tested in serial dilutions from $800 \mu \mathrm{M}$ to $10 \mathrm{nM}$; ${ }^{\mathrm{b}}$ A ssays were carried out in duplicate; ${ }^{\mathrm{C}} \mathrm{An}$ independent assay was repeated in duplicate for this derivative and confirmed the $K_{d}$ value determined in the first experiment; $d K_{d}$ value might be overestimated as compound $\mathbf{3 6}$ precipitated during the assay. 
Introduction of aromatic substituents at the 6 position of the glucose residue does not impair the recognition between the compounds and the galectin-3CRD, suggesting that the interactions established by the disaccharide core are maintained upon binding. Such observation was expected based on the results obtained from type II lactosamine derivatives bearing aromatic substituents a the C 2 position of the glucose residue. ${ }^{30,38}$ Analogously, the overall contribution of the substituents was equally modest. H owever, the nature of the linkage between the substituent and the $C 6$ position of the glucose seems to modulate the affinity. To confirm the trends within the different structural classes we decided to synthesize analogs of representative compounds (sulfonamide, amine, urea, amide) in the $\beta$-Galp-(1-3)- $\beta$-D-G Icp series.
Access to inhibitors using azide specific reactivity of 12 . To this aim, azide $\mathbf{1 2}$ was reduced into the amine $\mathbf{2 8}$ upon treatment with trimethylphosphine and next reacted with 3-methoxybenzoyl chloride, 3-methoxyphenylisocyanate, 3-methoxybenzaldehyde and 3-methoxysulfonyl chloride to give derivatives 29, 30, 31 and $\mathbf{3 2}$ in $57 \%, 65 \%, 61 \%$ and $70 \%$ yields, respectively (Scheme 4 ). In addition, amine $\mathbf{2 8}$ was condensed with 4-phenyloxyphenylsulfonyl chloride to afford compound $\mathbf{3 3}$ in 55\% yield to further exemplify the most promising sulfonamide family of inhibitor. M oreover, it had been suggested that a phenyloxyphenyl substituent (at the $C 2$ position of the type II lactosamine), might be oriented such as to establish cation- $\pi$ interactions with both Arg186 and Arg168 residues of the galectin-3 CRD. ${ }^{41}$

\section{Scheme 4. Synthesis of galectin-3 inhibitors from disaccharide 12}

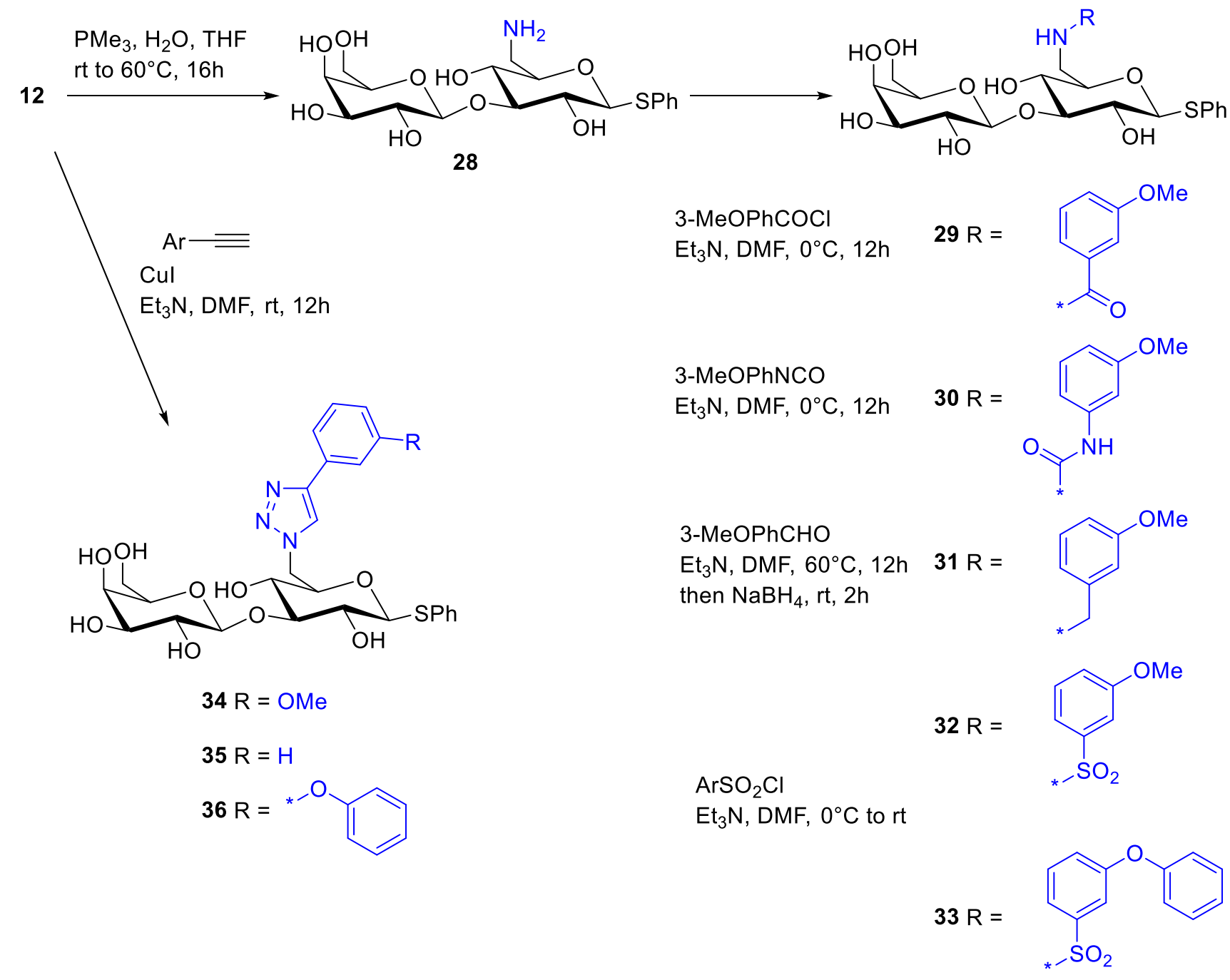

Furthermore C UAAC reactions were carried out with azide $\mathbf{1 2}$ to prepare triazole inhibitors from methoxyphenylacetylene, acetylene or 1-ethynyl-4-phenoxybenzene using either catalytic or stoichiometric amount of copper (I) iodide. ${ }^{25}$ Derivatives $\mathbf{3 4}, \mathbf{3 5}$ and $\mathbf{3 6}$ were obtained in $36 \%, 85 \%$ and $62 \%$ yields.
Galectin-3 binding affinities of the new analogues were measured by a fluorescence polarization assay as previously described ( $T$ able 2). The same ranking as that reported in the first series of compounds was observed i.e. the $K_{d} S$ of galectin- 3 for urea/ amide was 35 $45 \mu \mathrm{M}, 15-20 \mu \mathrm{M}$ for amine and decreased to 8-10 $\mu \mathrm{M}$ for sulfonamides.

\section{Binding affinity measurements}


A
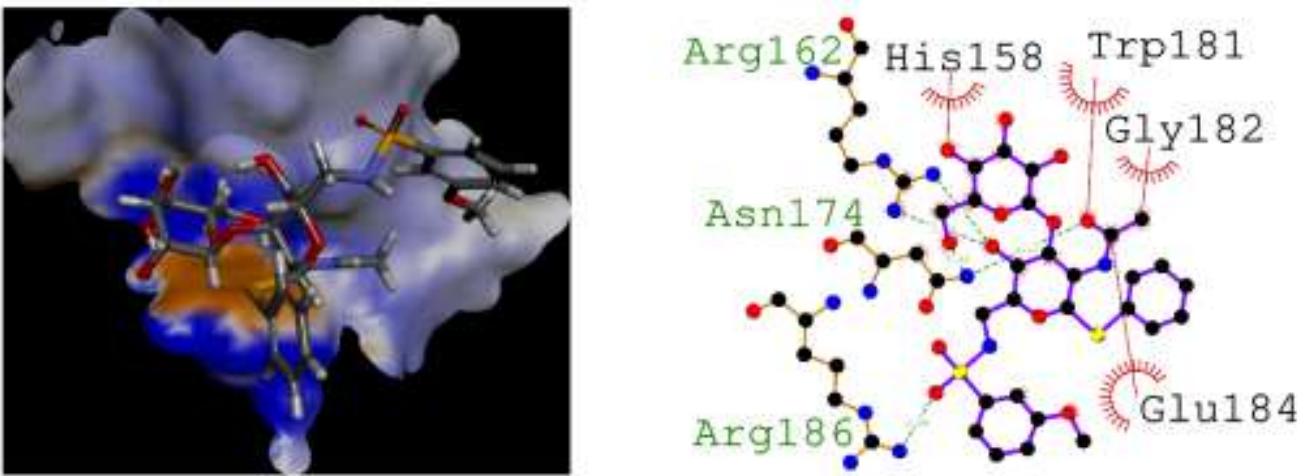

B

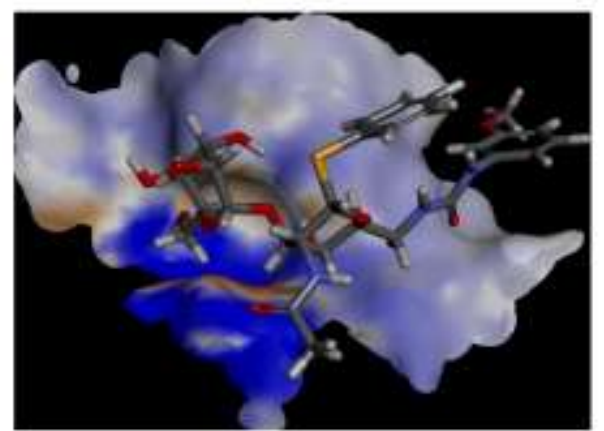

C
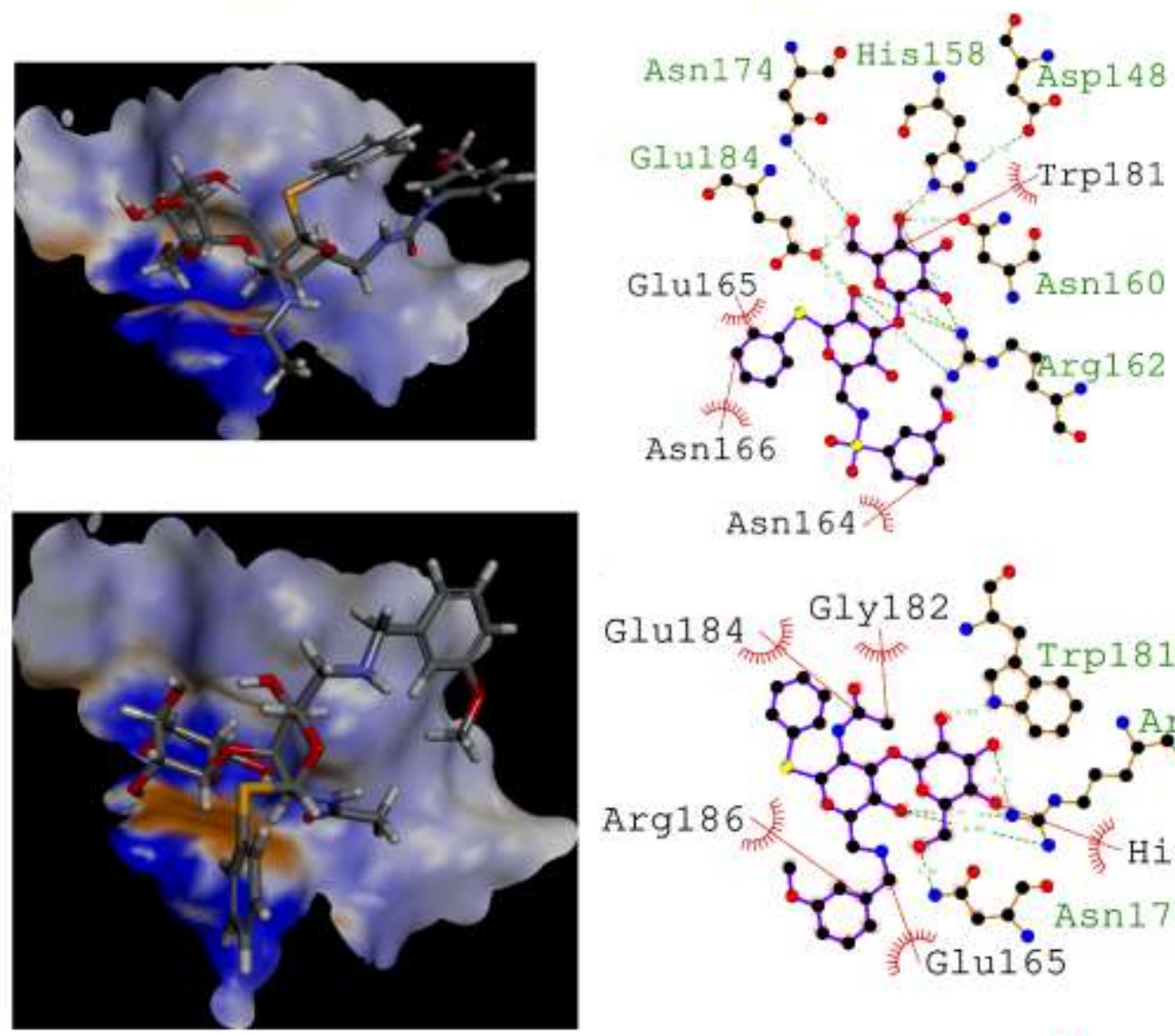

Asn 164 年

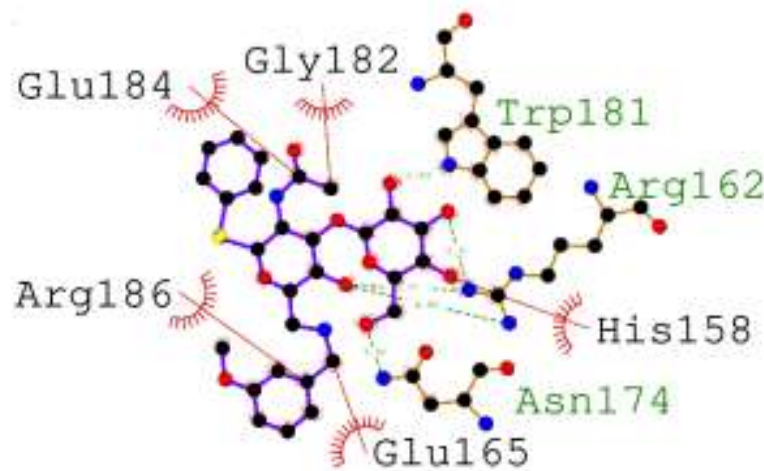

D
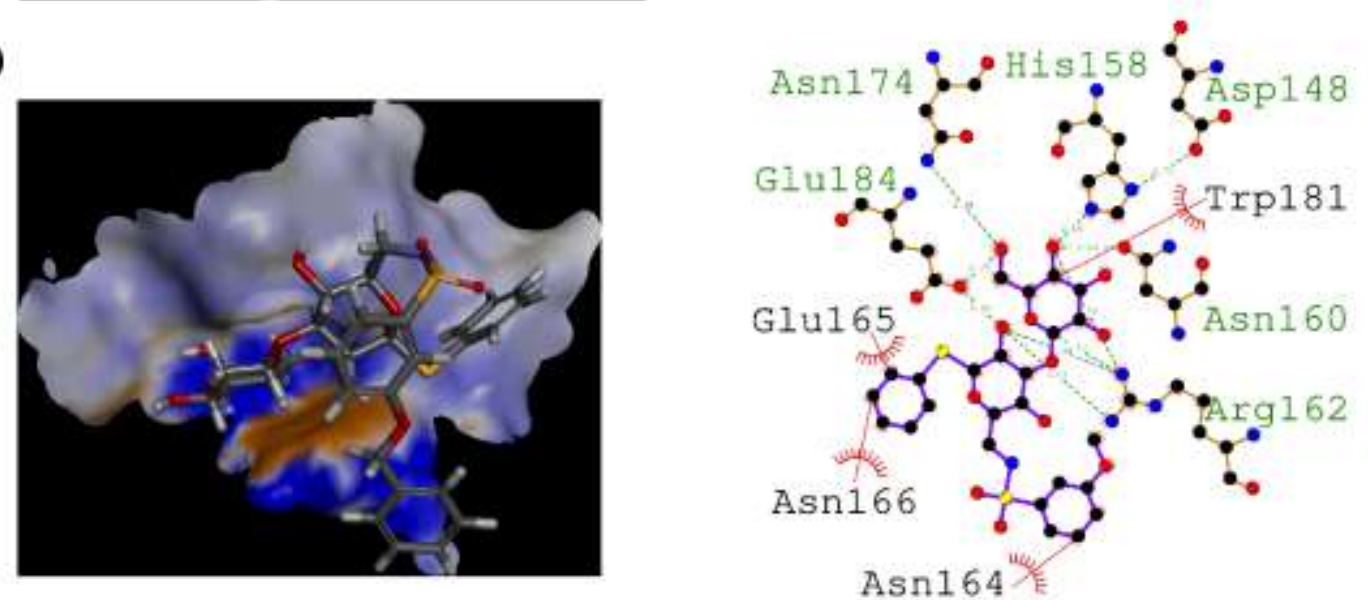

Figure 1. Molecular docking of selected compounds with the galectin-3. 0 verview of one representative binding pose after docking for 22 (A), 23 (B), 24 (C) and 32 (D). Ligands are displayed in sticks and colored by atom types: carbons in gray, hydrogen in white, oxygens in red, nitrogen in blue, sulfur in yellow. The receptor surface is colored by aromaticity with the aromatic face in orange ( W 181) and the aromatic edge in blue 
In silico analysis of docked compounds $\mathbf{2 2}$ (sulfonamide), $\mathbf{2 3}$ (urea) and $\mathbf{2 4}$ (amine) confirms that the core conserved binding motif characteristic of the lactosamine moieties is recovered via interactions of all compounds with H 158, N 160/R162, N 174 and W181 (Figure 1). In all binding modes observed, the thiophenyl anomeric modification does not seem to bring critical contacts explaining the differences in binding energies. The residue E184 is found in interaction with $\mathbf{2 2}$ and $\mathbf{2 4}$, with small additional hydrophobic interactions provided by E165 and R186 for 24. The urea part of $\mathbf{2 3}$ is also involved in E 184 targeting but through a hydrogen bond. T wo small hydrophobic interactions are detected for $\mathbf{2 3}$ with R183 and R186. In total, the number of interactions between compound $\mathbf{2 2}$ (7), 23 (9) and $\mathbf{2 4}$ (8) does not seem to be enough to explain the relative differences in binding efficiency on galectin. The galactose binding position is, however, displaced from its location in lactosamine type I structure with a RM SD of $1.58 \AA$ (22), $3.23 \AA$ (23) and $1.55 \AA$ ( 24), indicative of a counterbalance between galectin affinity provided by the galactose and by additional interaction energy provided by substituents. The equatorial substituent at the C2 position of GIC/ GICN which points outwards the CRD does not impact on the binding. The acetamido present at the $C 2$ position of the GICN is not involved in direct interactions with galectin, but it reduces the potential rotation between $\mathrm{Gal}$ and $\mathrm{GICN}$ compared to Glc. When the acetamido is removed ( 32 ), the galactose can rotate more ( Figure $1 \mathrm{D}$ ). T he susbsituent in position 6 is therefore free to get extra hydrophobic interactions with galectin (close to R 186). In this situation, the lactosamine core is less displaced with a galactose RMSD of only $0.62 \AA$. T his geometric observation could explained why compound $\mathbf{3 2}$ is measured to be (relatively) better than 22. The bulky sulfonamide $\mathbf{3 3}$ has a similar behavior as inhibitors $\mathbf{2 2}$ and $\mathbf{3 2}$. The best pose for the bulkier compound 33 is also less displaced than its acetamido counterpart with a RM SD of $0.33 \AA$ (not shown).

Sulfonamides $\mathbf{2 2}$ and $\mathbf{3 2}$ were eventually selected to document the selectivity. To this aim their dissociation constants were determined for galectin-1 C 3S (a stable mutant of galectin-1) ( hGal-1) and galectin-7 ( $\mathrm{hGal}-7$ ) ${ }^{42}$ in addition to galectin-3 ( $\mathrm{T}$ able 3)

Table 3. Dissociation constants $\left(K_{d} s\right)$ of inhibitors for galectin-1, galectin-3 and galectin-7 at $4^{\circ} \mathrm{C}$ a

$\begin{array}{cccc}\text { Inhibitor } & \text { hGal-1 } & \text { hGal-3 } & \text { hGal-7 } \\ \text { TD 139 }^{b} & 2.0 \pm 0.8 \mu \mathrm{M} & 0.01 \pm 0.003 \mu \mathrm{M} & 15.5 \pm 6.2 \mu \mathrm{M} \\ \mathbf{2 2} & 11.7 \pm 4.1 \mu \mathrm{M} & 2.66 \pm 0.5 \mu \mathrm{M} & 39.4 \pm 14.4 \mu \mathrm{M} \\ \mathbf{3 2} & 23.5 \pm 9.4 \mu \mathrm{M} & 2.51 \mu \pm 0.2 \mu \mathrm{M} & 46.1 \pm 18.0 \mu \mathrm{M}\end{array}$

${ }^{a}$ Concentrations were as follows: 2-(fluorescein-5-thiourea) ethyl [3-0( 2-naphthyl) methyl- $\beta$-D-galactopyranosyl] - (1-4)-2-deoxy-2-( 3-methoxybenzamido)- $\beta$-D-glucopyranoside ${ }^{42}$ used as probe ( $500 \mathrm{nM}$ ); hG al-1, $5 \mu \mathrm{M}$; hG al-3, 1 $\mathrm{M} ; \mathrm{hG}$ al-7, $5 \mu \mathrm{M}$ and inhibitors tested in serial dilutions from 800 $\mu \mathrm{M}$ to $10 \mathrm{nM}$; bPositive control.

Lower affinities were observed for both sulfonamides $\mathbf{2 2}$ and $\mathbf{3 2}$ for hG al-1 and hG al-7 compared with hG al-3. This resulted in selectivity factors of 4 and 14 in favor of hGal-3 for compound 22. Selectivities were further increased to 9 ( $h G$ al-3 vshGal-1) and 18 ( hG al3 vs hGal-7) for compound 32. Of note, derivatives 22 and 32 lacks substituents at the $\mathrm{C} 3$ position of the galactose, this position being known to contribute significantly to the selectivity. ${ }^{42}$

\section{CONCLUSION}

Substrate promiscuity of enzymes in particular that of glycoenzymes remains largely overlooked. Glycosyltransferases, glycoside hydrolases or transglycosidases can all show exquisite reactivity not limited to their known natural substrates but extended to sugars lightly protected or modified with biorthogonal functionalities. This peculiarity has been herein exploited and illustrated using a GH 1 glycosynthase to rapidly access to a library of potential galectin inhibitors. Further glyco-engineering will feed this enzyme toolbox, expanding the scope of chemo-enzymatic pathways to synthesize complex oligosaccharides.

\section{EXPERIMENTAL SECTION}

General. All reagents were purchased from commercial sources and used without further purification. Reactions were monitored by thin-layer chromatography (T LC) on $0.25 \mathrm{~mm}$ silica gel plates with fluorescent indicator ( GF254) and visualized under UV light. Detection was further achieved by charring with vanillin (1.5 g) in sulfuric acid/ ethanol ( 1.5:95 mL). Flash chromatography purifications were carried out on silica gel columns ( 4 to $80 \mathrm{~g}, 240-400$ mesh) using an automated $C$ hromatography System equipped by both ELS (Evaporative Light Scattering) and UV/diode array allowing the simultaneous use of two customizable wavelengths detectors.

All N M R experiments were performed at $400.13 \mathrm{M} \mathrm{H}$ z using a 400 M H z spectrometer equipped with a DUAL + 1H/13C ATM A grad $5 \mathrm{~mm}$ probe. Structural assignments were made with additional information from gCOSY and $\mathrm{gHSQ} \mathrm{C}$ experiments using standard pulse programs from the Bruker library. Chemical shifts are given relative to external TMS with calibration involving the residual solvent signals. H igh-resolution mass spectra were recorded in positive mode on Waters SYN APT G2-Si HDM S with detection with a hybrid quadripole time of flight ( Q -T OF) detector. The compounds were individually dissolved in $\mathrm{MeOH}$ at a concentration of 1 $\mathrm{mg} \cdot \mathrm{mL}^{-1}$ and then infused into the electrospray ion source at a flow rate of $10 \mu \mathrm{L} \cdot \mathrm{min}^{-1}$ at $100{ }^{\circ} \mathrm{C}$. The mass spectrometer was operated at $3 \mathrm{kV}$ whilst scanning the magnet at a typical range of 4000-100 D a. Themass spectra were collected as continuum profile data. Accurate mass measurement was achieved based on every five second autocalibration using leucine-enkephalin $\left([\mathrm{M}+\mathrm{H}]^{+}=556.2771 \mathrm{~m} / \mathrm{z}\right)$.

Phenyl 6-azido-2,6-dideoxy-2-phthalimido-1-thio- $\beta$-D-glucopyranoside 4. Phenyl 2-deoxy-2-phthalimido-1-thio- $\beta$-D-glucopyranoside 3 ( $2.5 \mathrm{~g}, 6.25 \mathrm{mmol}, 1 \mathrm{eq})$ was dissolved in anhydrous pyridine $(120 \mathrm{~mL})$ and the solution was cooled to $-20{ }^{\circ} \mathrm{C}$. M esyl chloride ( $2.90 \mathrm{~mL}, 18.75 \mathrm{mmol}, 3 \mathrm{eq}$ ) was added dropwise. After $2 \mathrm{~h}$, the reaction was quenched upon addition of methanol and the solvent was removed under reduced pressure. The residue was diluted with EtO Ac ( $125 \mathrm{~mL})$, washed with aqueous $1 \mathrm{~N} \mathrm{H} \mathrm{Cl}(125 \mathrm{~mL})$, sat. aq. $\mathrm{NaHCO}_{3}(125 \mathrm{~mL})$ and brine $(125 \mathrm{~mL})$. The organic layer was dried over $\mathrm{Na}_{2} \mathrm{SO}_{4}$ and concentrated under reduced pressure. The residue was purified by flash chromatography ( $C$ yclohexane/ EtO Ac $5 / 5)$ to give the mesylated intermediate as a yellow oil ( $1.93 \mathrm{~g}, 65 \%$ ). $R_{f} 0.48$ (Cyclohexane/EtO Ac 2/8). This compound was directly dissolved in anhydrous DM F ( $25 \mathrm{~mL}$ ) and treated with $\mathrm{N} \mathrm{aN}_{3}(1.31$ $\mathrm{mg}, 20.1 \mathrm{mmol}, 5 \mathrm{eq})$. The resulting mixture was stirred at $80^{\circ} \mathrm{C}$ for $16 \mathrm{~h}$ then was diluted by EtO Ac ( $125 \mathrm{~mL}$ ) and washed with $\mathrm{H}_{2} \mathrm{O}$ ( 2 $\times 60 \mathrm{~mL})$ and sat. aq. $\mathrm{NaH} \mathrm{CO}_{3}(60 \mathrm{~mL})$. Theorganic layer was dried over $\mathrm{N} \mathrm{a}_{2} \mathrm{SO}_{4}$ and concentrated under reduced pressure. The residue was purified by flash chromatography ( Cyclohexane/ EtO Ac 7/ 3) to 
give compound 4 as a yellow oil ( $1.54 \mathrm{~g}, 92 \%) . R_{f} 0.45$ (Cyclohexane/ EtO Ac 3/ 7) ; ${ }^{1} \mathrm{H}$ N M R ( $\left.400 \mathrm{M} \mathrm{Hz} \mathrm{CDCl}_{3}\right) \delta 7.87$ (dd, J = 3.0,

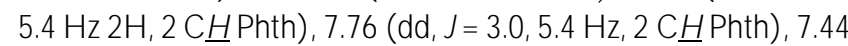
$-7.41(\mathrm{~m}, 2 \mathrm{H}, \mathrm{C} \underline{\mathrm{H}} \mathrm{SPh}), 7.32-7.25(\mathrm{~m}, 3 \mathrm{H}, \mathrm{C} \underline{\mathrm{H}} \mathrm{SPh}), 5.59(\mathrm{~d}, \mathrm{~J}=$ $10.2 \mathrm{~Hz}, 1 \mathrm{H}, \mathrm{H} 1), 4.28(\mathrm{t}, \mathrm{J}=9.7 \mathrm{~Hz}, 1 \mathrm{H}, \mathrm{H} \mathrm{3}), 4.16(\mathrm{t}, \mathrm{J}=10.2 \mathrm{~Hz}$, $1 \mathrm{H}, \mathrm{H} 2), 3.63-3.58(\mathrm{~m}, 2 \mathrm{H}, \mathrm{H} \mathrm{5}, \mathrm{H} \mathrm{6a}), 3.52(\mathrm{t}, \mathrm{J}=8.8 \mathrm{~Hz}, 1 \mathrm{H}, \mathrm{H} 4)$, 3.48 ( dd, J =6.2, $13.6 \mathrm{~Hz}, 1 \mathrm{H}, \mathrm{H} \mathrm{6b}) .{ }^{13} \mathrm{C} \mathrm{NMR}\left(101 \mathrm{M} \mathrm{Hz} \mathrm{CDCl}_{3}\right)$ $\delta 162.9$ ( $2 \underline{\mathrm{C}}(\mathrm{O})$ ) Phth), 134.3 ( $2 \underline{\mathrm{CH}}, \mathrm{Phth}, 1 \underline{\mathrm{C}}$ quat, SPh), 133.1 (2 $\underline{\mathrm{CH}}, \mathrm{SPh}), 131.6$ ( $2 \underline{\mathrm{C}}_{\text {quat, }}$ Phth), 128.9 ( $\left.2 \underline{\mathrm{C}} \mathrm{H}, \mathrm{SPh}\right), 128.2$ (1 $\underline{\mathrm{C}} \mathrm{H}$, SPh), 123.9 and 123.4 (2 $\underline{\mathrm{CH}}$, Phth), 83.7 (C1), 78.9 (C5), 72.9 (C3), 72.1 (C4) , 55.6 (C6), 51.6 (C2); HRM S (ESI-T OF) m/ z: [ M $+\mathrm{Na}]^{+} \mathrm{Calcd}$ for $\mathrm{C}_{20} \mathrm{H}_{18} \mathrm{~N}_{4} \mathrm{O}{ }_{5} \mathrm{SN}$ a 449.0896; Found 449.0902 .

Phenyl 2-amino-6-azido-2,6-dideoxy-1-thio- $\beta$-D-glucopyranoside 2. Compound $\mathbf{4}$ ( $1.49 \mathrm{~g}, 3.5 \mathrm{mmol}, 1 \mathrm{eq}$ ) was stirred with a solution of ethylene diamine $0.8 \mathrm{M}$ in $\mathrm{M} \mathrm{eO} \mathrm{H}(7.4 \mathrm{~mL}, 5.94 \mathrm{mmol}$, $1.7 \mathrm{eq})$. The mixture was heated at $65^{\circ} \mathrm{C}$ for $16 \mathrm{~h}$ and then the solvent was removed under reduced pressure. The residue was purified by flash chromatography $\left(\mathrm{CH}_{2} \mathrm{Cl}_{2} / \mathrm{M} \mathrm{eOH} \mathrm{95/5)}\right.$ to give compound 2 as a yellow oil ( $750 \mathrm{mg}, 72 \%) \cdot \mathrm{R}_{\mathrm{f}} 0.81\left(\mathrm{CH}_{2} \mathrm{Cl}_{2} / \mathrm{M} \mathrm{eOH} \mathrm{9/1)}{ }^{1} \mathrm{H}\right.$ NMR (400 M Hz, CD 3 OD) $\delta 7.63-7.59(\mathrm{~m}, 2 \mathrm{H}, \mathrm{C} \underline{\mathrm{H}} \mathrm{SPh}), 7.37$ $7.31(\mathrm{~m}, 3 \mathrm{H}, \mathrm{C} \underline{\mathrm{H}} \mathrm{SPh}), 4.54(\mathrm{~d}, \mathrm{~J}=9.8 \mathrm{~Hz}, 1 \mathrm{H}, \mathrm{H} 1), 3.57$ (dd, J = 1.7, $12.7 \mathrm{~Hz}, 1 \mathrm{H}, \mathrm{H} 6 \mathrm{a}), 3.47-3.42(\mathrm{~m}, 1 \mathrm{H}, \mathrm{H} 5), 3.41$ (dd, J = 5.7, $12.7 \mathrm{~Hz}, 1 \mathrm{H}, \mathrm{H} \mathrm{6b}), 3.30-3.20(\mathrm{~m}, 2 \mathrm{H}, \mathrm{H} 3, \mathrm{H} 4), 2.64-2.57(\mathrm{~m}, 1 \mathrm{H}$, $\mathrm{H} 2) .{ }^{13} \mathrm{C}\left\{{ }^{1} \mathrm{H}\right\}$ NMR (101 MHz, CD $\left.3 \mathrm{OD}\right) \delta 132.6$ (2드, SPh),

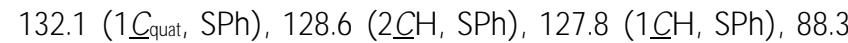
(C1), 79.1 (C5), 77.5 (C3), 70.8 (C4), 55.6 (C2), 51.6 (C6); HRMS (ESI-TOF) m/ z: [M + Na] ${ }^{+}$Calcd for $\mathrm{C}_{12} \mathrm{H}_{16} \mathrm{~N}_{4} \mathrm{O}_{3} \mathrm{SNa}$ 319.0840; Found 319.0834.

Phenyl 2,3,4-tri-O-acetyl-6-O-tet-butyldimethylsilyl-1-thio$\beta$-D-glucopyranoside $6 .{ }^{43} \mathrm{Thiophenol}(6 \mathrm{~mL}, 61.50 \mathrm{mmol}, 1.2 \mathrm{eq}$ ) and $\mathrm{BF}_{3} \mathrm{OEt}$ ( $4.21 \mathrm{~mL}, 35.86 \mathrm{mmol}, 0.7 \mathrm{eq}$ ) were added to a stirred solution of $\beta$-D-glucosapyranose pentaacetate 5 ( $20 \mathrm{~g}, 51.2 \mathrm{mmol}, 1$ eq) in $\mathrm{CH}_{2} \mathrm{Cl}_{2}(200 \mathrm{~mL})$ at $0^{\circ} \mathrm{C}$. After $12 \mathrm{~h}$, the reaction mixture was quenched by addition of sat. aq. $\mathrm{NaHCO}_{3}(150 \mathrm{~mL})$. The aqueous layer was separated and extracted with $\mathrm{CH}_{2} \mathrm{Cl}_{2}(3 \times 75 \mathrm{~mL})$. The combined organic layer was washed with brine, dried over $\mathrm{N} \mathrm{a}_{2} \mathrm{SO}_{4}$ and evaporated under reduced pressure. The residue was purified by precipitation in a mixture of warm EtO Ac/ Cyclohexane to give phenyl 2,3,4,6-tetra-0-acetyl-1-thio- $\beta$-D-glucopyranoside (18.2 g, $80 \%) ; \mathrm{Rf}=0.50$ (Cyclohexane/ EtO Ac 7/3). To a solution of this intermediate ( $18.2 \mathrm{~g}, 41.2 \mathrm{mmol}$, 1eq) in $\mathrm{M} \mathrm{eOH}(220 \mathrm{~mL})$, a solution of sodium methoxide $5.4 \mathrm{M}(8.24 \mathrm{mmol}, 1.5 \mathrm{~mL}, 0.2 \mathrm{eq})$ was added at $r$ and stirred for $2 \mathrm{~h}$. Then the mixture was neutralized with an acidic resin (Amberlyte IR $120-\mathrm{H}^{+}$), filtrated and the solvent was removed under reduced pressure to give crude phenyl 1-thio- $\beta$-D glucopyranoside which was further used without purification.

The triol was solubilized in anhydrous DM F ( $100 \mathrm{~mL})$, then a solution of tert-butyldimethylsilyl chloride (TBDM SCl, $6.8 \mathrm{~g}, 45.3$ $\mathrm{mmol}, 1.1 \mathrm{eq})$ and imidazole $(7.0 \mathrm{~g}, 103.0 \mathrm{mmol}, 2.5 \mathrm{eq})$ in anhydrous $D M F\left(40 \mathrm{~mL}\right.$ ) was added at $0^{\circ} \mathrm{C}$. After stirring for $12 \mathrm{~h}$, the mixture was diluted by EtO $\mathrm{Ac}(150 \mathrm{~mL})$, washed with $\mathrm{H}_{2} \mathrm{O}(2 \times 100$ $\mathrm{mL}$ ) and sat. aq. $\mathrm{NaHCO}_{3}(100 \mathrm{~mL})$. The organic layer was dried over $\mathrm{N}_{2} \mathrm{SO}_{4}$ and concentrated under reduced pressure; $\mathrm{R}_{f} 0.57$ ( $\mathrm{Cy}$ clohexane/ EtO Ac 1/9). Then the residue was solubilized in $\mathrm{CH}_{2} \mathrm{Cl}_{2}$ $(100 \mathrm{~mL})$ at $0^{\circ} \mathrm{C}$, treated with $\mathrm{AC}_{2} \mathrm{O}(17.5 \mathrm{~mL}), \mathrm{Et}_{3} \mathrm{~N}(20.1 \mathrm{~mL})$, DMAP (cat.) and stirred for $16 \mathrm{~h}$. The mixture was diluted by
$\mathrm{CH}_{2} \mathrm{Cl}_{2}(100 \mathrm{~mL})$, washed with $\mathrm{H}_{2} \mathrm{O}(2 \times 100 \mathrm{~mL})$ and sat. aq. Na$\mathrm{HCO}_{3}(100 \mathrm{~mL})$. The organic layer was dried over $\mathrm{N}_{2} \mathrm{SO}_{4}$ and concentrated under reduced pressure. The residue was purified by flash chromatography (Cyclohexane/ Eto Ac 9/1) to give phenyl 2,3,4tri-0-acetyl-6-0 -tert-butyldimethylsilyl-1-thio- $\beta$-D-glucopyranoside 6 as a white solid ( $16.64 \mathrm{~g}, 65 \%$ over 4 steps). $R_{f} 0.71$ (Cyclohexane/ EtO Ac 7/ 3); $\left.{ }^{1} \mathrm{H} \mathrm{N} \mathrm{M} \mathrm{R} \mathrm{(} 400 \mathrm{M} \mathrm{Hz}, \mathrm{CDCl}_{3}\right) \delta 7.51-7.49$ (m, $2 \mathrm{H}, \mathrm{C} \underline{\mathrm{H}} \mathrm{SPh}), 7.30-7.28(\mathrm{~m}, 3 \mathrm{H}, \mathrm{C} \underline{\mathrm{H}} \mathrm{SPh}), 5.22(\mathrm{t}, \mathrm{J}=9.3 \mathrm{~Hz}, 1 \mathrm{H}$, H 3), $5.03(\mathrm{t}, J=9.8 \mathrm{~Hz}, 1 \mathrm{H}, \mathrm{H} 4), 4.96(\mathrm{t}, J=9.3,10.0 \mathrm{~Hz}, 1 \mathrm{H}, \mathrm{H} 2)$, $4.72(\mathrm{~d}, \mathrm{~J}=10.0 \mathrm{~Hz}, 1 \mathrm{H}, \mathrm{H} 1), 3.75(\mathrm{dd}, J=2.5,11.6 \mathrm{~Hz}, 1 \mathrm{H}, \mathrm{H} \mathrm{6a}$ ), $3.70(\mathrm{dd}, \mathrm{J}=5.0,11.6 \mathrm{~Hz}, 1 \mathrm{H}, \mathrm{H} 6 \mathrm{~b}), 3.58(\mathrm{ddd}, \mathrm{J}=2.5,5.0,10.0 \mathrm{~Hz}$, $1 \mathrm{H}, \mathrm{H} 5), 2.07\left(\mathrm{~s}, 3 \mathrm{H}, \mathrm{COCH}_{3}\right), 2.01\left(\mathrm{~s}, 3 \mathrm{H}, \mathrm{COCH}_{3}\right), 1.98(\mathrm{~s}, 3 \mathrm{H}$, $\left.\mathrm{COCH}_{3}\right), 0.90\left(\mathrm{~s}, 9 \mathrm{H}, 3 \mathrm{CCH}_{3}\right), 0.07\left(\mathrm{~s}, 3 \mathrm{H}, \mathrm{CH}_{3}, \mathrm{TBDMS}\right), 0.05$ ( $\mathrm{s}$, $\left.3 \mathrm{H}, \mathrm{CH}_{3}, \mathrm{TBDMS}\right) ;{ }^{13} \mathrm{C}\left\{{ }^{1} \mathrm{H}\right\}$ NMR $\left(101 \mathrm{MHz}, \mathrm{CDCl}_{3}\right) \delta 170.2$, 169.2, 169.2 (3C quat, $\mathrm{COCH}_{3}$ ), $132.6(2 \underline{\mathrm{CH}}, \mathrm{SPh}), 133.2$ (1 $\mathrm{C}_{\text {quat, }}$

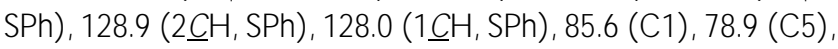
$74.4(\mathrm{C} 3), 70.1$ ( C2) , $68.6(\mathrm{C} 4), 62.4(\mathrm{C} 6), 25.8\left(3 \mathrm{CCH}_{3}\right), 20.7$, $20.6\left(3 \mathrm{CO} \underline{\mathrm{CH}}_{3}\right), 18.4\left(1 \mathrm{CCH}_{3}\right),-5.4,-5.4\left(2 \mathrm{CH}_{3}, \mathrm{TBDMS}\right)$; HRMS (ESI-TOF) m/z: [M $+\mathrm{Na}]^{+} \mathrm{Calcd}$ for $\mathrm{C}_{24} \mathrm{H}_{36} \mathrm{O}_{8} \mathrm{SiSN}$ a 535.1798; Found 535.1790.

Phenyl 2,3,4-tri-O-acetyl-6-O-azido-1-thio- $\beta$-D-glucopyranoside $7 .^{44} \mathrm{Compound} 6(2.96 \mathrm{~g}, 5.77 \mathrm{mmol}$, 1eq) was stirred for 16 $h$ in a solution of $\mathrm{ACOH} / \mathrm{H}_{2} \mathrm{O} / \mathrm{THF}(3 / 1 / 1 ; 100 \mathrm{~mL})$ at rt. Then TH F was removed under reduced pressureand the mixture was neutralized with sat. aq. $\mathrm{NaHCO}_{3}(3 \times 70 \mathrm{~mL})$. The organic layer was dried over $\mathrm{N} \mathrm{a}_{2} \mathrm{SO}_{4}$ and concentrated under reduced pressure. $\mathrm{R}_{\mathrm{f}} 0.57$ (Cyclohexane/ EtO Ac 1/9). The residue was purified by flash chromatography (Cyclohexane/ EtO Ac 75/25) to give phenyl 2,3,4-tri0 -acetyl-1-thio- $\beta$-D -glucopyranoside as a colorless oil (1.94 g, 85\%). Rf 0.32 (Cyclohexane/ EtO Ac 7/3). This intermediate was dissolved in anhydrous pyridine $(32 \mathrm{~mL})$ and the solution was cooled to $0^{\circ} \mathrm{C}$. M esyl chloride ( $750 \mu \mathrm{L}, 9.7 \mathrm{mmol}, 2$ eq) was added dropwise. After $2 \mathrm{~h}$, the reaction was quench by adding methanol and the solvent was removed under reduced pressure. $R_{f} 0.88(\mathrm{Cy}$ clohexane/ EtO Ac 5/5). The residue was directly dissolved in anhydrous D M F ( $50 \mathrm{~mL}$ ) and treated with $\mathrm{N} \mathrm{aN}_{3}(944 \mathrm{mg}, 14.5 \mathrm{mmol}, 3$ eq). The resulting mixture was stirred at $60^{\circ} \mathrm{C}$ for $16 \mathrm{~h}$, then diluted in EtO AC ( $100 \mathrm{~mL})$ and washed with $\mathrm{H}_{2} \mathrm{O}(2 \times 50 \mathrm{~mL})$ and sat. aq.N aH CO ${ }_{3}(50 \mathrm{~mL})$. The organic layer was dried over $\mathrm{N} \mathrm{a}_{2} \mathrm{SO}_{4}$ and concentrated under reduced pressure. The residue was purified by flash chromatography (Cyclohexane/ EtO Ac 8/2) to give phenyl 2,3,4-tri-0 -acetyl-6-azido-6-deoxy-1-thio- $\beta$-D-glucopyranoside $\mathbf{7}$ as a white solid ( $1.8 \mathrm{~g}, 88 \%$ over 2 steps). $R_{f} 0.43$ (C yclohexane/ EtO Ac 5/5). ${ }^{1 H}$ N M R ( $\left.400 \mathrm{M} \mathrm{Hz}_{2} \mathrm{CDCl}_{3}\right) \delta 7.56-7.50(\mathrm{~m}, 2 \mathrm{H}, \mathrm{C} \underline{\mathrm{H}} \mathrm{SPh})$, $7.37-7.32(\mathrm{~m}, 3 \mathrm{H}, \mathrm{C} \underline{\mathrm{H}} \mathrm{SPh}), 5.23(\mathrm{t}, \mathrm{J}=9.3 \mathrm{~Hz}, 1 \mathrm{H}, \mathrm{H} 3), 4.99 \_4.92$ $(\mathrm{m}, 2 \mathrm{H}, \mathrm{H} 2, \mathrm{H} 4), 4.73(\mathrm{~d}, \mathrm{~J}=10.0 \mathrm{~Hz}, 1 \mathrm{H}, \mathrm{H} 1), 3.70-3.64(\mathrm{~m}, 1 \mathrm{H}$, H 5), 3.37 (dd, J =2.5, 11.5 Hz, 1H, H 6a), 3.31 (dd, J $=5.0,11.5 \mathrm{~Hz}$, $1 \mathrm{H}, \mathrm{H} 6 \mathrm{~b}), 2.10\left(\mathrm{~s}, 3 \mathrm{H}, \mathrm{COCH}_{3}\right), 2.03\left(\mathrm{~s}, 3 \mathrm{H}, \mathrm{COCH}_{3}\right), 2.00(\mathrm{~s}, 3 \mathrm{H}$, $\left.\mathrm{COCH}_{3}\right) ;{ }^{13} \mathrm{C}\left\{{ }^{1} \mathrm{H}\right\}$ N M R $\left.\left(101 \mathrm{MHz}_{2} \mathrm{CDCl}\right)_{3}\right) \delta 170.1,169.4,169.2$ ( $\left.3 \underline{\mathrm{C}}_{\text {quat, }} \underline{\mathrm{C}} \mathrm{CCH}_{3}\right), 133.7(2 \underline{\mathrm{C}} \mathrm{H}, \mathrm{SPh}), 130.9$ ( $\left.\underline{\mathrm{C}}_{\text {quat, }} \mathrm{SPh}\right), 129.0$ (2다, $\mathrm{SPh}), 128.7$ ( $1 \mathrm{CH}, \mathrm{SPh}), 85.7$ (C1), 77.0 (C5), 73.8 (C3), 69.9 and 69.3 ( $\mathrm{C} 2$ and $\mathrm{C} 4), 51.3(\mathrm{C} 6), 20.7,20.6$ and $20.6\left(3 \mathrm{CH}_{3}\right)$; HRM S (ESI-TOF) m/ z: [M + Na] ${ }^{+} \mathrm{Calcd}$ for $\mathrm{C}_{18} \mathrm{H}_{21} \mathrm{~N}_{3} \mathrm{O}{ }_{7} \mathrm{SNa}$ 446.0998; Found 446.1019.

Phenyl 6-O-azido-1-thio- $\beta$-D-glucopyranoside $8 .{ }^{45} \mathrm{~T}$ o a solution of compound 7 (690 $\mathrm{mg}, 1.63 \mathrm{mmol}$, 1eq) in $\mathrm{MeOH}(10 \mathrm{~mL}$ ) was added a solution of sodium methoxide $5.4 \mathrm{M}(0.49 \mathrm{mmol}, 90 \mu \mathrm{L}$, 
$0.1 \mathrm{eq})$ at $0^{\circ} \mathrm{C}$ and stirred for $2 \mathrm{~h}$. Then the mixture was neutralized with an acidic resin (Amberlyte IR $120-\mathrm{H}^{+}$), filtrated and the solvent removed under reduced pressure. The residue was purified by flash chromatography ( Cyclohexane/ AcO Et 45/ 55) to give phenyl 6-azido-6-deoxy-1-thio- $\beta$-D -glucopyranoside 8 as a white solid ( $455 \mathrm{mg}$, 94\%). Rf 0.28 (Cyclohexane/ AcO Et 4/6); ${ }^{1} \mathrm{H}$ NMR (400 M Hz, $\left.\mathrm{CD}_{3} \mathrm{OD}\right) \delta 7.62-7.57(\mathrm{~m}, 2 \mathrm{H}, \mathrm{C} \underline{\mathrm{H}} \mathrm{SPh}), 7.35-7.27(\mathrm{~m}, 3 \mathrm{H}, \mathrm{C} \underline{\mathrm{H}}$ $\mathrm{SPh}), 4.60(\mathrm{~d}, \mathrm{~J}=9.7 \mathrm{~Hz}, 1 \mathrm{H}, \mathrm{H} 1), 3.56(\mathrm{dd}, \mathrm{J}=2.0,12.9 \mathrm{~Hz}, 1 \mathrm{H}$, H 6a) , 3.46-3.35 (m, 3H, H 5, H 6b, H 3) , $3.27(t, 1 H, J=9.0 H z, H 4)$, $3.22(\mathrm{dd}, \mathrm{J}=8.7,9.8 \mathrm{~Hz}, 1 \mathrm{H}, \mathrm{H} 2) ;{ }^{13} \mathrm{C}\left\{{ }^{1} \mathrm{H}\right\} \quad \mathrm{NMR}(101 \mathrm{MHz}$, MeOD) $\delta 132.9$ ( $\left.\underline{\mathrm{C}}_{\text {quat, }} \mathrm{SPh}\right), 132.4(2 \underline{\mathrm{CH}}, \mathrm{SPh}), 128.5(2 \underline{\mathrm{CH}}, \mathrm{SPh})$, 127.4 ( $\mathrm{CH}, \mathrm{SPh}$ ), 87.8 (C1), 78.9 (C5) , 78.0 (C 3) , 72.2 (C2), 70.6 (C4), 51.6 (C6); HRMS (ESI-TOF) m/ z: [M + Na] ${ }^{+}$Calcd for $\mathrm{C}_{12} \mathrm{H}_{15} \mathrm{~N}_{3} \mathrm{O}{ }_{4} \mathrm{SN}$ a 320.0681; Found 320.0694.

Phenyl $\quad \beta$-D-galactopyranosyl- $(1 \rightarrow 3)$-2-amino-6-azido-2,6dideoxy-1-thio- $\beta$-D-glucopyranoside 9 . Donor 1 (184 mg, 1.0 mmol, 2 eq) and acceptor 2 ( $150 \mathrm{mg}, 0.5 \mathrm{mmol}, 1 \mathrm{eq}$ ), were dis-

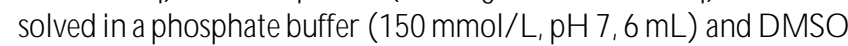
( $1 \mathrm{~mL}$ ). Then, $3 \mathrm{~mL}$ of glycosynthase E338G $\left(4.2 \mathrm{mg} \cdot \mathrm{mL}^{-1}\right.$ ) was added and the reaction was allowed to proceed at $37^{\circ} \mathrm{C}$ until complete consumption of the fluoride (about $72 \mathrm{~h}$ ). The mixture was acidified with $\mathrm{HCl} 1 \mathrm{M}$ to $\mathrm{pH} 1$ and stirred for $4 \mathrm{~h}$ before neutralization with $\mathrm{NaOH} 1 \mathrm{M}$. After removal of the solvent under reduced pressure, the crude residue was purified by flash chromatography $\left(\mathrm{CH}_{2} \mathrm{Cl}_{2} / \mathrm{M} \mathrm{eOH} \mathrm{90/10)}\right.$ to afford disaccharide 9 as a white solid (180 mg, 78\%). Rf $0.75\left(\mathrm{CHCl}_{3} / \mathrm{MeOH} / \mathrm{H}_{2} \mathrm{O} / \mathrm{CH}_{3} \mathrm{COOH}\right.$ $60 / 30 / 5 / 3) .{ }^{1} \mathrm{H}$ NMR ( $\left.400 \mathrm{MHz}, \mathrm{D}_{2} \mathrm{O}\right) \delta 7.57-7.52(\mathrm{~m}, 2 \mathrm{H}, \mathrm{CH}$ $\mathrm{SPh}), 7.36-7.28(\mathrm{~m}, 3 \mathrm{H}, \mathrm{CH} \mathrm{SPh}), 4.66(\mathrm{~d}, \mathrm{~J}=8.3 \mathrm{~Hz}, 1 \mathrm{H}, \mathrm{H} 1)$, $4.51\left(\mathrm{~d}, \mathrm{~J}=7.7 \mathrm{~Hz}, 1 \mathrm{H}, \mathrm{H} 1^{\prime}\right), 3.89$ ( $\left.\mathrm{d}, \mathrm{J}=3.3 \mathrm{~Hz}, 1 \mathrm{H}, \mathrm{H} 4^{\prime}\right), 3.76$ 3.66 ( $\mathrm{m}, 3 \mathrm{H}, \mathrm{H5}$ ', H6a', H6b'), 3.65 (dd, J = 3.3, 9.9 Hz, 1H, H3'), 3.62-3.52 (m, 4H, H2', H6a, H5, H3), 3.49 ( dd, J = 8.1, 18.5 H z, 1H, H4) , $3.44\left(d d, J=5.7,12.9 \mathrm{~Hz}, 1 \mathrm{H}, \mathrm{H} 6 \mathrm{~b}^{\prime}\right), 2.83(\mathrm{dd}, \mathrm{J}=8.3,11.1 \mathrm{~Hz}$, $1 \mathrm{H}, \mathrm{H} 2) ;{ }^{13} \mathrm{C}\left\{{ }^{1} \mathrm{H}\right\}$ NMR $\left(101 \mathrm{MHz}_{1} \mathrm{D}_{2} \mathrm{O}\right) \delta 132.7(2 \underline{\mathrm{CH}}, \mathrm{SPh})$,

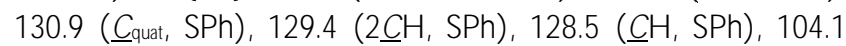
(C1'), 87.8(C1), 87.6(C3), 78.2 (C5), 75.5 (C5'), 72.8 (C3'), 71.2 (C2'), 69.0 (C4), 68.6 (C4'), 60.9 (C6'), 54.6 (C2), 51.3 (C6); HRMS (ESI-TOF) m/ z: [M + Na] ${ }^{+}$Calcd for $\mathrm{C}_{18} \mathrm{H}_{26} \mathrm{~N}_{4} \mathrm{O}_{8} \mathrm{SNa}$ 459.1550; Found 459.1558.

Phenyl 2,3,4,6-tetra-O-acetyl- $\beta$-D-galactopyranosyl- $(1 \rightarrow 3)$-4O-acetyl-2-acetamido-6-azido-2,6-dideoxy-1-thio- $\beta$-D-glucopyranoside 10. A solution of compound $\mathbf{9}$ ( $150 \mathrm{mg}, 0.33 \mathrm{mmol}$, leq) in $\mathrm{CH}_{2} \mathrm{Cl}_{2}(2.5 \mathrm{~mL})$ was treated with $\mathrm{Ac}_{2} \mathrm{O}(350 \mu \mathrm{L}), \mathrm{Et}_{3} \mathrm{~N}$ $(350 \mu \mathrm{L}), \mathrm{DM}$ AP $(0.03 \mathrm{mmol}, 4 \mathrm{mg}, 0.1 \mathrm{eq})$ and stirred for $16 \mathrm{~h}$. The mixture was diluted by $\mathrm{CH}_{2} \mathrm{Cl}_{2}(25 \mathrm{~mL})$, washed by $\mathrm{H}_{2} \mathrm{O}(2 \times 12$ $\mathrm{mL})$ and sat. aq. $\mathrm{NaH} \mathrm{CO}_{3}(12 \mathrm{~mL})$. Theorganic layer was dried over $\mathrm{N} \mathrm{a}_{2} \mathrm{SO}_{4}$ and concentrated under reduced pressure. The residue was purified by flash chromatography (Cyclohexane/ EtOAc 6/4) to give compound 10 as a yellow oil ( $233 \mathrm{mg}, 98 \%$ ); $R_{f} 0.50$ (Cyclohexane/ EtO Ac 3/ 7); ${ }^{1} \mathrm{H}$ N M R ( $\left.400 \mathrm{M} \mathrm{Hz} \mathrm{CDCl}_{3}\right) \delta 7.52-7.45$ (m, $2 \mathrm{H}, \mathrm{C} \underline{\mathrm{H}} \mathrm{SPh}), 7.33-7.27$ ( $\mathrm{m}, 3 \mathrm{H}, \mathrm{C} \underline{\mathrm{H}} \mathrm{SPh}), 6.07(\mathrm{~d}, \mathrm{~J}=8.1 \mathrm{~Hz}, 1 \mathrm{H}$, $\mathrm{N} \underline{\mathrm{H}}$ ) , 5.33 (dd, J = 1.1, 3.4 Hz, 1H, H4) $5.12(\mathrm{~d}, \mathrm{~J}=10.2 \mathrm{~Hz}, 1 \mathrm{H}$, H 1) , 5.03 (dd, J = 7.5, $\left.10.4 \mathrm{~Hz}, 1 \mathrm{H}, \mathrm{H} 2^{\prime}\right), 4.97$ (dd, J = 3.3, $10.4 \mathrm{~Hz}$, $\left.1 \mathrm{H}, \mathrm{H3} 3^{\prime}\right), 4.81(\mathrm{t}, \mathrm{J}=9.2 \mathrm{~Hz}, 1 \mathrm{H}, \mathrm{H} 4), 4.62(\mathrm{~d}, \mathrm{~J}=7.6 \mathrm{~Hz}, 1 \mathrm{H}, \mathrm{H} 1)$, $4.33(\mathrm{t}, \mathrm{J}=9.2 \mathrm{~Hz}, 1 \mathrm{H}, \mathrm{H} 3), 4.14-4.02\left(\mathrm{~m}, 2 \mathrm{H}, \mathrm{H6a}, \mathrm{H} 6 \mathrm{~b}^{\prime}\right), 3.88$ ( td, J = 1.02, 6.6 Hz, 1H, H5'), 3.63 (ddd, J = 3.0,6.8, 9.7 Hz, 1H, H5), $3.51(\mathrm{dd}, \mathrm{J}=8.1,9.4 \mathrm{~Hz}, 1 \mathrm{H}, \mathrm{H} 2), 3.33(\mathrm{dd}, \mathrm{J}=6.8,13.4 \mathrm{~Hz}$, $1 \mathrm{H}, \mathrm{H} 6 \mathrm{a}), 3.27$ (dd, J = 3.0, $13.4 \mathrm{~Hz}, 1 \mathrm{H}, \mathrm{H} 6 \mathrm{~b}), 2.13(\mathrm{~s}, 3 \mathrm{H}$,
$\left.\mathrm{COC}_{3}\right), 2.05\left(\mathrm{~s}, 3 \mathrm{H}, \mathrm{COC} \underline{\mathrm{H}}_{3}\right), 2.04\left(\mathrm{~s}, 3 \mathrm{H}, \mathrm{COC} \underline{\mathrm{H}}_{3}\right), 2.04(\mathrm{~s}, 3 \mathrm{H}$, $\left.\mathrm{COC} \underline{\mathrm{H}}_{3}\right), 2.03\left(\mathrm{~s}, 3 \mathrm{H}, \mathrm{COC} \underline{\mathrm{H}}_{3}\right), 1.95\left(\mathrm{~s}, 3 \mathrm{H}, \mathrm{COC} \underline{\mathrm{H}}_{3}\right) ;{ }^{13} \mathrm{C}\left\{{ }^{1} \mathrm{H}\right\}$ $\mathrm{NMR}(100 \mathrm{MHz}, \mathrm{CDCl}) \delta 170.5\left(\mathrm{COCH}_{3}\right), 170.4\left(\mathrm{COCH}_{3}\right)$, $170.1(2 \underline{\mathrm{COCH}})_{3}, 169.4\left(\mathrm{COCH}_{3}\right), 169.2(\underline{\mathrm{COCH}} 3), 132.8(2 \underline{\mathrm{CH}}$, SPh), 132.1 ( $\underline{C}_{\text {quat }}$ SPh) , 129.0 ( $\left.2 \underline{\mathrm{CH}}, \mathrm{SPh}\right), 128.2$ ( $\left.\underline{\mathrm{CH}}, \mathrm{SPh}\right), 100.6$ (C1'), 85.4 (C 1) , 78.0 (C3) , 77.2 (C5), 70.0 (C3'), 70.6 (C5'), 70.1 (C4) , 69.3 (C2'), 66.9 (C4'), 61.0 (C6'), 55.9 (C2), 51.6 (C 6), 23.6 $\left(\mathrm{CO} \underline{C H}_{3}\right), 20.8\left(2 \mathrm{CO}_{\mathrm{CH}}\right)_{3}, 20.7\left(\mathrm{CO} \underline{C H}_{3}\right), 20.6\left(\mathrm{CO} \underline{C H}_{3}\right), 20.5$ $\left(\mathrm{COCH}_{3}\right) ;$ HRMS (ESI-TOF) m/ $\mathrm{Z}:[\mathrm{M}+\mathrm{Na}]^{+} \mathrm{Calcd}$ for $\mathrm{C}_{30} \mathrm{H}_{38} \mathrm{~N}_{4} \mathrm{O}_{14} \mathrm{SN}$ a 733.2003.; Found 733.2011.

Phenyl $\quad \beta$-D-galactopyranosyl- $(1 \rightarrow 3)$-2-acetamido-6-azido2,6-dideoxy-1-thio- $\beta$-D-glucopyranoside 11. To a solution of compound 10 ( $233 \mathrm{mg}, 0.32 \mathrm{mmol}, 1 \mathrm{eq}$ ) in $\mathrm{MeOH}(3.5 \mathrm{~mL}$ ), a solution of sodium methoxide $5.4 \mathrm{M}(0.035 \mathrm{mmol}, 8 \mu \mathrm{L}, 0.1 \mathrm{eq})$ was added at $0^{\circ} \mathrm{C}$ and stirred for $2 \mathrm{~h}$. T hen the mixture was neutralized with an acidic resin ( amberlyte IR $120-\mathrm{H}^{+}$), filtrated and the solvent was removed under reduced pressure. The crude residue was purified by flash chromatography $\left(\mathrm{CH}_{2} \mathrm{Cl}_{2} / \mathrm{MeOH} 8 / 2\right)$ to give compound $\mathbf{1 1}$ as a white solid (135 mg, 85\%); $\mathrm{R}_{\mathrm{f}} 0.78$ $\left(\mathrm{CHCl}_{3} / \mathrm{MeOH} / \mathrm{H}_{2} \mathrm{O} / \mathrm{CH}_{3} \mathrm{COOH} 60 / 30 / 5 / 3\right) ;{ }^{1} \mathrm{H} \mathrm{NMR}(400$ M Hz, DMSO - $\left.d_{6}\right) \delta 7.93\left(d_{,} J=7.6 \mathrm{~Hz}, 1 \mathrm{H}, \mathrm{N} \underline{\mathrm{H}}\right), 7.46-7.44(\mathrm{~m}, 2 \mathrm{H}$,

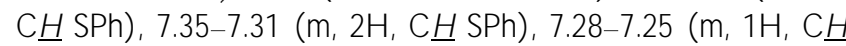
$\mathrm{SPh}), 5.01(\mathrm{~d}, \mathrm{~J}=7.7 \mathrm{~Hz}, 1 \mathrm{H}, \mathrm{H} 1), 4.89(\mathrm{~d}, \mathrm{~J}=1.6 \mathrm{~Hz}, 1 \mathrm{H}, \mathrm{O} \underline{\mathrm{H}})$, 4.79 (br s, $1 \mathrm{H}, \mathrm{OH}), 4.64$ (t, J $=5.4 \mathrm{~Hz}, 1 \mathrm{H}, \mathrm{OH}), 4.48(\mathrm{~m}, 2 \mathrm{H}, 2 \times$ $\mathrm{O} \underline{\mathrm{H}}), 4.17\left(\mathrm{~d}, \mathrm{~J}=6.3 \mathrm{~Hz}, 1 \mathrm{H}, \mathrm{H} 1^{\prime}\right), 3.68-3.59\left(\mathrm{~m}, 3 \mathrm{H}, \mathrm{H} 2, \mathrm{H} 3, \mathrm{H} 4{ }^{\prime}\right)$, 3.56-3.49 ( m, 4H, H6a, H5, H6a', H6b'), 3.49-3.39 (m, 2H, H5', H 6b), 3.37-3.22 (m, 3H, H2', H3', H4), $1.84\left(\mathrm{~s}, 3 \mathrm{H}, \mathrm{COCH}_{3}\right)$; ${ }^{13} \mathrm{C}\left\{{ }^{1} \mathrm{H}\right\}$ N MR $\left.(101 \mathrm{MHz}, \mathrm{DMSO}) \delta 170.4(\underline{\mathrm{COCH}})_{3}\right), 134.4$ ( $\underline{\mathrm{C}}_{\text {quat }}$, SPh), 130.6 (2다, $\mathrm{SPh}), 129.4(2 \underline{\mathrm{CH}}, \mathrm{SPh}), 127.4(\underline{\mathrm{CH}}, \mathrm{SPh})$, 104.3 (C1'), 85.8 (C1), 85.1 (C3), 78.6 (C5), 76.3 (C5'), 73.5 (C3'), 71.0 (C2'), 70.0 (C4), 68.7 (C4'), 61.1 (C6'), 51.9 (C2) , 51.4 (C6), 23.5 $\left(\mathrm{CO}_{\mathrm{CH}}\right) ; \mathrm{HRM} \mathrm{S}(\mathrm{ESI}-\mathrm{TOF}) \mathrm{m} / \mathrm{z}:[\mathrm{M}+\mathrm{Na}]^{+} \mathrm{Calcd}$ for $\mathrm{C}_{20} \mathrm{H}_{28} \mathrm{~N}_{4} \mathrm{O}$ 9SN a 523.1474; Found 523.1506.

Phenyl $\quad \beta$-D-galactopyranosyl- $(1 \rightarrow 3)$-6-azido-6-dideoxy-1thio- $\beta$-D-glucopyranoside 12. D onor 1 ( $115 \mathrm{mg}, 0.63 \mathrm{mmol}, 1.5$ eq) and acceptor 8 ( $125 \mathrm{mg}, 0.42 \mathrm{mmol}, 1 \mathrm{eq}$ ), were dissolved in a phosphate buffer $(200 \mathrm{mmol} / \mathrm{L}, \mathrm{pH} 6.8,6.5 \mathrm{~mL}$ ) and DMSO (1 $\mathrm{mL})$. T hen glycosynthase E338G $\left(2.5 \mathrm{~mL}, \mathrm{c}=4.0 \mathrm{mg}^{\mathrm{mL}}{ }^{-1}\right)$ was added and the reaction was allowed to proceed at $37^{\circ} \mathrm{C}$ for $72 \mathrm{~h}$. T he mixture was acidified with $\mathrm{HCl} 1 \mathrm{M}$ to $\mathrm{pH} 1$ and stirred for $4 \mathrm{~h}$ before neutralization with $\mathrm{NaOH} 1 \mathrm{M}$. After removal of the solvent under reduced pressure, the crude residue was purified by flash chromatography $\left(\mathrm{CH}_{2} \mathrm{Cl}_{2} / \mathrm{M} \mathrm{eOH} \mathrm{90/10)}\right.$ to afford a mixture of phenyl $\beta$-Dgalactopyranosyl-( $1 \rightarrow 3$ )-6-azido-6-deoxy-1-thio- $\beta$-D-glucopyranoside, unreacted phenyl 6-azido-6-deoxy-1-thio- $\beta$-D-glucopyranoside. To facilitate the purification, the crude reaction mixture was suspended in $\mathrm{CH}_{2} \mathrm{Cl}_{2}(5 \mathrm{~mL})$, treated with $\mathrm{AC}_{2} \mathrm{O}(1 \mathrm{~mL}), \mathrm{Et}_{3} \mathrm{~N}$ (1 $\mathrm{mL}$ ), DM AP (cat) and stirred for $16 \mathrm{~h}$. Then the reaction mixture was diluted in $\mathrm{CH}_{2} \mathrm{Cl}_{2}(25 \mathrm{~mL})$, washed with $\mathrm{H}_{2} \mathrm{O}(2 \times 15 \mathrm{~mL})$ and sat. aq. $\mathrm{NaH} \mathrm{CO}_{3}(15 \mathrm{~mL})$. T he organic layer was dried over $\mathrm{N} \mathrm{a}_{2} \mathrm{SO}_{4}$ and concentrated under reduced pressure. The crude residue was purified first by flash chromatography (Cyclohexane/ EtOAC $65 / 35)$ then by reverse phase $\mathrm{C}-18$ flash chromatography $\left(\mathrm{H}_{2} \mathrm{O} / \mathrm{M} \mathrm{eOH} \mathrm{4/6)}\right.$ to give phenyl 2,3,4,6-tetra-0 -acetyl- $\beta$-D-galactopyranosyl-( $1 \rightarrow 3)$-2,4-di-0 -acetyl-6-azido-6-deoxy-1-thio- $\beta$-Dglucopyranoside as a colorless oil ( $141 \mathrm{mg}, 48 \%$ over 2 steps); Rf 0.50 (C yclohexane/ EtO Ac 5/ 5); ${ }^{1} \mathrm{H}$ N M R ( $\left.400 \mathrm{M} \mathrm{Hz}, \mathrm{CD}_{3} \mathrm{OD}\right) \delta$ 


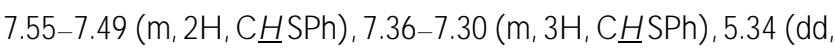
$\mathrm{J}=1.1,3.4 \mathrm{~Hz}, 1 \mathrm{H}, \mathrm{H} 4), 5.21(\mathrm{t}, \mathrm{J}=9.0 \mathrm{~Hz}, 1 \mathrm{H}, \mathrm{H} 3), 5.10(\mathrm{dd}, \mathrm{J}=$ 3.5, $\left.10.4 \mathrm{~Hz}, 1 \mathrm{H}, \mathrm{H} 3^{\prime}\right), 4.98\left(\mathrm{dd}, \mathrm{J}=7.9,10.4 \mathrm{~Hz}, 1 \mathrm{H}, \mathrm{H} 2^{\prime}\right), 4.92(\mathrm{~d}$, $\mathrm{J}=10.4 \mathrm{~Hz}, 1 \mathrm{H}, \mathrm{H} \mathrm{1}), 4.81$ (dd, J = 9.1, $10.1 \mathrm{~Hz}, 1 \mathrm{H}, \mathrm{H} 2), 4.69$ (d, J $\left.=7.9 \mathrm{~Hz}, 1 \mathrm{H}, \mathrm{H1} 1^{\prime}\right), 4.16-4.06$ (m, 3H, H5', H6a', H6b'), 3.79 (dd, J $=8.9,9.8 \mathrm{~Hz}, 1 \mathrm{H}, \mathrm{H} 4), 3.73(\mathrm{ddd}, \mathrm{J}=2.1,5.3,9.8 \mathrm{~Hz}, 1 \mathrm{H}, \mathrm{H} 5), 3.63$ ( $d d, J=2.2,13.5 \mathrm{~Hz}, 1 \mathrm{H}, \mathrm{H} 6 \mathrm{a}), 3.42(\mathrm{dd}, \mathrm{J}=5.3,13.5 \mathrm{~Hz}, 1 \mathrm{H}, \mathrm{H} 6 \mathrm{~b})$, $2.12\left(\mathrm{~s}, 3 \mathrm{H}, \mathrm{COC} \underline{\mathrm{H}}_{3}\right), 2.06\left(\mathrm{~s}, 3 \mathrm{H}, \mathrm{COC \underline {H } _ { 3 }}\right), 2.04\left(\mathrm{~s}, 3 \mathrm{H}, \mathrm{COC \textrm {H } _ { 3 }}\right)$, $2.02\left(\mathrm{~s}, 3 \mathrm{H}, \mathrm{COC} \underline{\mathrm{H}}_{3}\right), 2.02\left(\mathrm{~s}, 3 \mathrm{H}, \mathrm{COC \underline {H } _ { 3 }}\right), 1.92\left(\mathrm{~s}, 3 \mathrm{H}, \mathrm{COC} \underline{\mathrm{H}}_{3}\right)$; ${ }^{13} \mathrm{C}\left\{{ }^{1} \mathrm{H}\right\}$ NMR (101 MHz, CD $\left.3 \mathrm{OD}\right) \delta 172.0\left(\mathrm{COCH}_{3}\right), 171.9$ $\left.\left(\mathrm{COCH}_{3}\right), 171.7\left(\underline{\mathrm{COCH}}_{3}\right), 171.4\left(\mathrm{COCH}_{3}\right), 171.1(\underline{\mathrm{COCH}})_{3}\right)$, $171.0\left(\underline{\mathrm{COCH}}_{3}\right), 134.5$ ( $\left.2 \underline{\mathrm{CH}}, \mathrm{SPh}\right), 132.6$ ( $\left.\underline{\mathrm{C}}_{\text {quat }}, \mathrm{SPh}\right), 130.0(2 \underline{\mathrm{CH}}$, $\mathrm{SPh}$ ), 129.5 (ㄷH, SPh), 101.9 (C1'),86.1 (C1), 79.2 (C5), 77.5 (C4), 75.5 (C3), $72.4\left(\mathrm{C} 3^{\prime}\right), 71.8$ and 71.7 (C2 and $\mathrm{C} 5$ '), 70.7 (C2'), 68.6 (C4'), $62.3\left(\mathrm{C}^{\prime}\right), 51.9(\mathrm{C} 6), 21.1\left(\mathrm{COCH}_{3}\right), 20.8$ $\left(\mathrm{CO} \underline{\mathrm{CH}}_{3}\right), 20.7\left(\underline{\mathrm{CH}}_{3}\right), 20.6\left(\underline{\mathrm{CH}}_{3}\right), 20.5\left(\underline{\mathrm{CH}}_{3}\right) ; \mathrm{HRM} \mathrm{S}(\mathrm{ESI}-\mathrm{TOF})$ $\mathrm{m} / \mathrm{z}:[\mathrm{M}+\mathrm{Na}]^{+} \mathrm{Calcd}$ for $\mathrm{C}_{18} \mathrm{H}_{25} \mathrm{~N}_{3} \mathrm{O}{ }_{9} \mathrm{SN}$ a 734.1843; Found 734.1854 .

To a solution of phenyl 2,3,4,6-tetra-0 -acetyl- $\beta$-D-galactopyranosyl-( $1 \rightarrow 3)$-2,4-0 -di-acetyl-6-azido-6-deoxy-1-thio- $\beta$-D-glucopyranoside ( $141 \mathrm{mg}, 0.20 \mathrm{mmol}, 1 \mathrm{eq})$ in $\mathrm{M} \mathrm{eOH}(2 \mathrm{~mL}$ ), a solution of sodium methoxide $5.4 \mathrm{M}(0.02 \mathrm{mmol}, 3 \mu \mathrm{L}, 0.1 \mathrm{eq})$ wasadded at $0^{\circ} \mathrm{C}$ and stirred for $2 \mathrm{~h}$. Then the solvent was removed under reduced pressure and the residue was purified by flash chromatography $\left(\mathrm{CH}_{2} \mathrm{Cl}_{2} / \mathrm{M} \mathrm{eOH} \mathrm{9/1)}\right.$ to giveto give disaccharide 12 as a white solid ( $90 \mathrm{mg}, 100 \%) ; \mathrm{R}_{\mathrm{f}} 0.60\left(\mathrm{CH}_{2} \mathrm{Cl}_{2} / \mathrm{M} \mathrm{eOH} \mathrm{9/1);}{ }^{1} \mathrm{H} \mathrm{NMR}(400 \mathrm{M} \mathrm{Hz}\right.$, $\left.\mathrm{CD}_{3} \mathrm{OD}\right) \delta 7.61-7.57(\mathrm{~m}, 2 \mathrm{H}, \mathrm{C} \underline{\mathrm{H}} \mathrm{SPh}), 7.36-7.30(\mathrm{~m}, 3 \mathrm{H}, \mathrm{C} \underline{\mathrm{H}}$ $\mathrm{SPh}), 4.64(\mathrm{~d}, \mathrm{~J}=9.8 \mathrm{~Hz}, 1 \mathrm{H}, \mathrm{H} 1), 4.53\left(\mathrm{~d}, \mathrm{~J}=7.7 \mathrm{~Hz}, 1 \mathrm{H}, \mathrm{H1}{ }^{\prime}\right)$, $3.81\left(\mathrm{dd}, \mathrm{J}=1.0,3.3 \mathrm{~Hz}, 1 \mathrm{H}, \mathrm{H} 4^{\prime}\right), 3.78(\mathrm{dd}, \mathrm{J}=7.6,11.4 \mathrm{~Hz}, 1 \mathrm{H}$, H6a'), 3.69 (dd, J = 4.5, $\left.11.4 \mathrm{~Hz}, 1 \mathrm{H}, \mathrm{H} 6 \mathrm{~b}^{\prime}\right), 3.63-3.55$ ( $\mathrm{m}, 4 \mathrm{H}, \mathrm{H} 2$ ', H3, H5', H 6a ), 3.54-3.47 (m, 2H, H3', H5), 3.44-3.33 (m, 3H, $\mathrm{H} 6 \mathrm{~b}, \mathrm{H} 2, \mathrm{H} 4) ;{ }^{13} \mathrm{C}\left\{{ }^{1} \mathrm{H}\right\} \mathrm{N} \mathrm{M} \mathrm{R}\left(101 \mathrm{M} \mathrm{H} z, \mathrm{DM} \mathrm{SO}-\mathrm{d}_{6}\right) \delta 132.7(2 \underline{\mathrm{CH}}$, $\mathrm{SPh}$ ), 132.4 ( $\left.\underline{\mathrm{C}}_{\text {quat }}, \mathrm{SPh}\right), 128.5$ (2대, $\left.\mathrm{SPh}\right), 127.5$ ( $\left.\underline{\mathrm{CH}}, \mathrm{SPh}\right), 104.2$ (C1'), 87.4 (C3), 87.1 (C1), 78.6 (C5) , 75.7 (C5), 73.3 (C3'), 71.6 (C2'), 17.3 (C2), 69.3 and 68.9 (C4 and C4'), 61.1 (C6), 51.6 (C6); HRMS (ESI-TOF) m/z: $[\mathrm{M}+\mathrm{Na}]^{+}$Calcd for $\mathrm{C}_{18} \mathrm{H}_{25} \mathrm{~N}_{3} \mathrm{O}$ 9SN a 482.1209; Found 482.1181.

\section{General procedure for the reduction of azide derivative 11}

To a solution of disaccharide $\mathbf{1 1}$ ( $50 \mathrm{mg}, 0.1 \mathrm{mmol}, 1 \mathrm{eq}$ ) in THF ( $5 \mathrm{ml}$ ), under an atmosphere of argon, $\mathrm{PM}_{3} 1 \mathrm{M}$ in THF ( $200 \mu \mathrm{L}$, $0.2 \mathrm{mmol}, 2 \mathrm{eq}$ ) was added. T he reaction was stirred at rt and monitored by TLC $\left(\mathrm{CHCl}_{3} / \mathrm{MeOH} / \mathrm{H}_{2} \mathrm{O} / \mathrm{CH}_{3} \mathrm{COOH} \mathrm{60/30/5/3).} \mathrm{Af-}\right.$ ter completion, $\mathrm{H}_{2} \mathrm{O}(10 \mu \mathrm{L})$ was added and the mixture was heated to $50^{\circ} \mathrm{C}$ in an oil bath for $16 \mathrm{~h}$. Then solvent was removed under reduced pressure to give crude phenyl $\beta$-D -galactopyranosyl- $(1 \rightarrow 3)$ 2-acetylamino-6-amino-2,6-dideoxy-1-thio- $\beta$-D-glucopyranoside 13 used without further purification; $\mathrm{R}_{\mathrm{f}} 0.78$ ( $\mathrm{CHCl}_{3} / \mathrm{MeOH} / \mathrm{H}_{2} \mathrm{O} / \mathrm{CH}_{3} \mathrm{COOH} \mathrm{60/30/5/3).}$

Phenyl $\beta$-D-galactopyranosyl- $(1 \rightarrow 3)$-2-acetamido-2,6-dideoxy-6-(1-carboxy-2-naphtoyl) amino-1-thio- $\beta$-D -glucopyranoside 14 and phenyl $\beta$-D-galactopyranosyl-( $1 \rightarrow 3)$-2-acetamido-2,6-dideoxy-6-(2,3-naphtal) imido-1-thio- $\beta$-D-glucopyranoside 15

Amine $\mathbf{1 3}$ was dissolved in anhydrous DMF $(2 \mathrm{ml})$ at $0^{\circ} \mathrm{C}$ and treated with 2,3-naphtalic anhydride ( $34 \mathrm{mg}, 0.17 \mathrm{mmol}, 1.7 \mathrm{eq}$ ) and $\mathrm{Et}_{3} \mathrm{~N}(27 \mu \mathrm{L}, 0.2 \mathrm{mmol}, 2.0 \mathrm{eq})$. The mixture was stirred 12 hours at rt and then heated at $60^{\circ} \mathrm{C}$ in an oil bath. After $12 \mathrm{~h}$ formation of two products was observed. The reaction was stopped and concentrated under reduced pressure. The residue was purified by reverse phase $\mathrm{C}$-18 flash chromatography using $\mathrm{H}_{2} \mathrm{O} / \mathrm{M} \mathrm{eO} \mathrm{H}$ gradient mixture as eluant to successively give $\mathbf{1 4}$ as a white solid ( $11.7 \mathrm{mg}, \mathbf{1 9 \%}$ ) and $\mathbf{1 5}$ as a white solid (12.3 mg, 18\%); Compound 14: $\mathrm{R}_{\mathrm{f}} 0.67$ $\left(\mathrm{CHCl}_{3} / \mathrm{MeOH} / \mathrm{H}_{2} \mathrm{O} / \mathrm{CH}_{3} \mathrm{COOH} 60 / 30 / 5 / 3\right) ;{ }^{1} \mathrm{H} \mathrm{NMR}(400$ $\mathrm{MHz}$, DMSO - d 6 ) 88.64 (br s, $1 \mathrm{H}, \mathrm{N} \underline{\mathrm{HCON}}$ apht) , 8.36 (s, $1 \mathrm{H}, \mathrm{C} \underline{\mathrm{H}}$

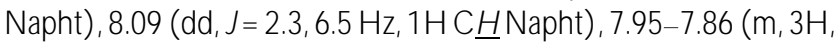

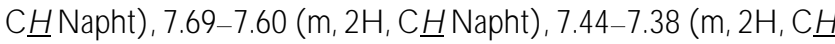
$\mathrm{SPh})$, 7.11-6.98 (m, 3H, SPh), 5.06-4.88 (m, 2H, H 1, O프), 4.81 ( br s, 2H, $2 \times 0 \underline{\mathrm{H}}), 4.51(\mathrm{~d}, \mathrm{~J}=3.3 \mathrm{~Hz}, 2 \mathrm{H}, 2 \times 0 \mathrm{H}), 4.28 \mathrm{4.19}(\mathrm{m}$, $1 \mathrm{H}, \mathrm{H1}$ ') 3.88 (dd, J = 7.2, $13.2 \mathrm{~Hz}, 1 \mathrm{H}, \mathrm{H} \mathrm{6a}), 3.78-3.45(\mathrm{~m}, 7 \mathrm{H}$, H2, H3, H5, H4', H6'a, H6'b, H5'), 3.45-3.14 (m, 4H, H2', H3', H4, H 6b) , $1.83\left(\mathrm{~s}, 3 \mathrm{H} \mathrm{COC} \underline{\mathrm{H}}_{3}\right) ;{ }^{13} \mathrm{C}\left\{{ }^{1} \mathrm{H}\right\}$ N M R ( $\left.101 \mathrm{M} \mathrm{Hz}, \mathrm{DMSO}-\mathrm{d}_{6}\right)$ $\delta, 170.4$ (2 $\underline{\mathrm{C}}_{\text {quat, }} \mathrm{COCH}_{3}, \underline{\mathrm{COOH}}$ ), 169.0 ( $\underline{\mathrm{C}}_{\text {quat, }}, \underline{\mathrm{CON}}$ apht), 135.3, $134.9,133.3,132.7$ (4C quat, N apht, SPh) , 130.0 ( $\underline{\mathrm{C}} \mathrm{H}, \mathrm{N}$ apht) , 129.5

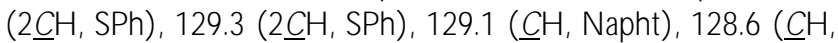
Napht), 128.4 ( $\underline{\mathrm{CH}}, \mathrm{N}$ apht), 128.0 ( $\underline{\mathrm{CH}}, \mathrm{N}$ apht), $127.6(\underline{\mathrm{CH}}$, $\mathrm{N}$ apht), 126.6 ( $\mathrm{CH}, \mathrm{SPh}), 104.3$ (C1'), 85.6 (C1), 85.3 (C 3) , 78.4 (C5) , 76.3 (C5'), 73.6 (C3'), 71.1, 71.0 (C2',C4), 68.8 (C4'), 61.1 (C6), 53.5 ( C2) , 41.7 (C6), $23.5\left(\mathrm{COCH}_{3}\right)$; HRMS (ESI-TOF) $\mathrm{m} / \mathrm{z}$ : [M - H ] Calcd for $\mathrm{C}_{32} \mathrm{H}_{35} \mathrm{~N}_{2} \mathrm{O}_{12} \mathrm{~S} 671.1911$; Found 671.1920.

Compound 15: $\mathrm{R}_{\mathrm{f}} 0.88\left(\mathrm{CHCl}_{3} / \mathrm{MeOH} / \mathrm{H}_{2} \mathrm{O} / \mathrm{CH}_{3} \mathrm{COOH}\right.$ $60 / 30 / 5 / 3) ;{ }^{1} \mathrm{H}$ NMR (400 MHz, DMSO-d $) \delta 8.52$ (s, 2H, CH N apht) , 8.29 (dd, J = 3.3, $6.2 \mathrm{~Hz}, 2 \mathrm{H}, \mathrm{C} \underline{\mathrm{H}} \mathrm{N}$ apht) , 7.87 ( $\mathrm{d}, \mathrm{J}=8.2$

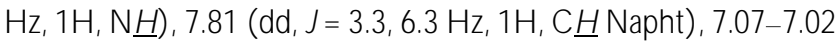
( $\mathrm{m}, 2 \mathrm{H}, \mathrm{C} \underline{\mathrm{H}} \mathrm{SPh}), 6.54-6.45(\mathrm{~m}, 3 \mathrm{H}, \mathrm{C} \underline{\mathrm{H}} \mathrm{SPh}), 5.03(\mathrm{~d}, \mathrm{~J}=1.7 \mathrm{~Hz}$, $1 \mathrm{H}, 0 \underline{\mathrm{H}}), 4.82(\mathrm{~d}, \mathrm{~J}=4.9 \mathrm{~Hz}, 1 \mathrm{H}, 0 \underline{\mathrm{H}}), 4.78(\mathrm{~d}, \mathrm{~J}=8.0 \mathrm{~Hz}, 1 \mathrm{H}, \mathrm{H} 1)$, $4.70(\mathrm{t}, \mathrm{J}=5.1 \mathrm{~Hz}, 1 \mathrm{H}, 0 \underline{\mathrm{H}}), 4.56(\mathrm{~d}, \mathrm{~J}=3.7 \mathrm{~Hz}, 1 \mathrm{H}, 0 \underline{\mathrm{H}}), 4.53(\mathrm{~d}$, $\mathrm{J}=4.7 \mathrm{~Hz}, 1 \mathrm{H}, \mathrm{O} \underline{\mathrm{H}}), 4.21\left(\mathrm{~d}, \mathrm{~J}=6.8 \mathrm{~Hz}, 1 \mathrm{H}, \mathrm{H1} 1^{\prime}\right), 3.96(\mathrm{dd}, \mathrm{J}=3.4$, $14.0 \mathrm{~Hz}, 1 \mathrm{H}, \mathrm{H} \mathrm{6a}$ ) , 3.89 (dd, J = 9.6, $14.1 \mathrm{~Hz}, 1 \mathrm{H}, \mathrm{H} \mathrm{6b}), 3.75-3.59$ ( $\left.\mathrm{m}, 4 \mathrm{H}, \mathrm{H} 2, \mathrm{H} 3, \mathrm{H} 5, \mathrm{H} 4^{\prime}\right), 3.57-3.46$ ( $\mathrm{m}, 3 \mathrm{H}, \mathrm{H6}$ 'a, H6’b, H5'), $3.40-3.30\left(\mathrm{~m}, 3 \mathrm{H}, \mathrm{H} 2{ }^{\prime}, \mathrm{H} 3{ }^{\prime}, \mathrm{H} 4\right), 1.83(\mathrm{~s}, 3 \mathrm{H} \mathrm{COCH} 3) ;{ }^{13} \mathrm{C}\left\{{ }^{1} \mathrm{H}\right\}$

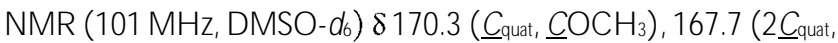
$\mathrm{N}(\underline{\mathrm{CO}})_{2}$ ) , 135.5 (2C, 2C quat, N apht) , 134.4 (1C, 1C quat, SPh) , 130.8

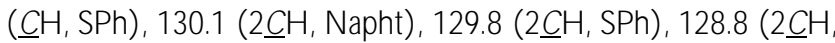

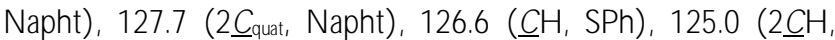
N apht) , 104.4 (C1'), 86.0 (C 1) , 85.3 (C 3) , 76.3 (C5), 76.2 (C5'), $73.6\left(\mathrm{C}^{\prime}\right), 71.8$ and 71.0 (C2' and C4), 68.8 (C4'), 61.5 (C6'), 53.3 (C2) , 40.6 (C6), $23.5\left(\mathrm{COCH}_{3}\right)$; HRMS (ESI-TOF) m/ z: [M + $\mathrm{Na}{ }^{+} \mathrm{C}$ alcd for $\mathrm{C}_{32} \mathrm{H}_{34} \mathrm{~N}_{2} \mathrm{O}_{11} \mathrm{SN}$ a 677.1781; Found 677.1773.

Phenyl $\beta$-D-galactopyranosyl-( $1 \rightarrow 3)$-2-acetamido-2,6-dideoxy-6-(3-methoxybenzamido)-1-thio- $\beta$-D-glucopyranoside 16

Amine 13 was dissolved in anhydrous DMF $(2 \mathrm{ml})$ at $0^{\circ} \mathrm{C}$ and treated with 3-methoxybenzoyl chloride ( $15 \mu \mathrm{L}, 0.11 \mathrm{mmol}, 1.1 \mathrm{eq}$ ) and $\mathrm{Et}_{3} \mathrm{~N}$ ( $\left.15 \mu \mathrm{L}, 0.11 \mathrm{mmol}, 1.1 \mathrm{eq}\right)$. The mixture was stirred $2 \mathrm{~h}$ and concentrated under reduced pressure. The residue was purified by flash chromatography $\left(\mathrm{CH}_{2} \mathrm{Cl}_{2} / \mathrm{M} \mathrm{eOH} \mathrm{9/1)}\right.$ to give derivative 16 as a white solid (29 mg, 50\%); $\mathrm{R}_{\mathrm{f}} 0.72$ $\left(\mathrm{CHCl}_{3} / \mathrm{MeOH} / \mathrm{H}_{2} \mathrm{O} / \mathrm{CH}_{3} \mathrm{COOH} 60 / 30 / 5 / 3\right) ;{ }^{1} \mathrm{H} \mathrm{NMR}(400$ $\mathrm{MHz}$, DM SO $\left.-\mathrm{d}_{6}\right) \delta 8.55(\mathrm{t}, \mathrm{J}=5.7 \mathrm{~Hz}, 1 \mathrm{H}, \mathrm{N} \underline{\mathrm{H}}(3 \mathrm{M} \mathrm{eO} \mathrm{Bz})$ ), 7.98 ( d, $\mathrm{J}=8.3 \mathrm{~Hz}, 1 \mathrm{H}, \mathrm{N} \underline{\mathrm{HAC}}), 7.50-7.44(\mathrm{~m}, 2 \mathrm{H}, \mathrm{CH} 3 \mathrm{M} \mathrm{eO} \mathrm{Bz}), 7.40$ ( $\mathrm{t}$, J $=7.9 \mathrm{~Hz}, 1 \mathrm{H}, \mathrm{C} \underline{\mathrm{H}} 3 \mathrm{M} \mathrm{eO} \mathrm{Bz}), 7.32$ (t, J $=4.5 \mathrm{~Hz}, 2 \mathrm{H}, \mathrm{C} \underline{\mathrm{H}} \mathrm{SPh}), 7.13$ ( $d d, J=3.4,8.5 \mathrm{~Hz}, 1 \mathrm{H}, \mathrm{C} \underline{\mathrm{H}} 3 \mathrm{M} \mathrm{eO} \mathrm{Bz}), 7.04$ (t, J $=7.4 \mathrm{~Hz}, 1 \mathrm{H}, \mathrm{C} \underline{\mathrm{H}}$ $\mathrm{SPh}), 6.91(\mathrm{t}, \mathrm{J}=7.6 \mathrm{~Hz}, 2 \mathrm{H}, \mathrm{C} \underline{\mathrm{H}} \mathrm{SPh}), 4.92-4.90(\mathrm{~m}, 1 \mathrm{H}, \mathrm{O} \underline{\mathrm{H}})$, $4.86(d, J=9.5 \mathrm{~Hz}, 1 \mathrm{H}, \mathrm{H} 1), 4.81(\mathrm{~d}, \mathrm{~J}=4.4 \mathrm{~Hz}, 1 \mathrm{H} \mathrm{O} \underline{\mathrm{H}}), 4.69$ (t, J 
$=5.2 \mathrm{~Hz}, 1 \mathrm{H}, \mathrm{O} \underline{\mathrm{H}}), 4.52(\mathrm{~d}, \mathrm{~J}=4.7 \mathrm{~Hz}, 1 \mathrm{H}, 0 \underline{\mathrm{H}}), 4.49(\mathrm{~d}, \mathrm{~J}=3.3 \mathrm{~Hz}$, $1 \mathrm{H}, \mathrm{O} \underline{\mathrm{H}}), 4.22\left(\mathrm{~d}, \mathrm{~J}=6.4 \mathrm{~Hz}, 1 \mathrm{H}, \mathrm{H1} 1^{\prime}\right), 3.90-3.82(\mathrm{~m}, 1 \mathrm{H}, \mathrm{H} \mathrm{6a})$, 3.80 ( $\left.\mathrm{s}, 3 \mathrm{H}, \mathrm{CH}_{3} 3 \mathrm{M} \mathrm{eO} \mathrm{Bz}\right), 3.77-3.44(\mathrm{~m}, 7 \mathrm{H}, \mathrm{H} 2, \mathrm{H} 3, \mathrm{H} 4$ ', H5, H6a', H6’b, H5'), 3.42-3.22 (m, 4H, H2', H3', H6b, H4), 1.84 ( $\mathrm{s}$, $\left.3 \mathrm{H}, \mathrm{COC} \underline{\mathrm{H}}_{3}\right) ;{ }^{13} \mathrm{C}\left\{{ }^{1} \mathrm{H}\right\}$ N M R ( $101 \mathrm{M} \mathrm{H}$, DM SO - $\left.\mathrm{d}_{6}\right) \delta 170.3$ ( $\underline{\mathrm{C}}_{\text {quat, }}$ $\underline{\mathrm{COCH}}_{3}$ ) , 166.3 ( $\underline{\mathrm{C}}_{\text {quat, }} \underline{\mathrm{COPh}}$ ), 159.6 ( $\underline{\mathrm{C}}_{\text {quat, }}, 3 \mathrm{M} \mathrm{eO}-\underline{\mathrm{C}}$ ) , 136.2 ( $\underline{\mathrm{C}}_{\text {quat, }}$ 3M eO Bz) , 135.5 ( $\underline{\mathrm{C}}_{\text {quat, }} \mathrm{SPh}$ ) , 129.8 ( $\left.\underline{\mathrm{CH}}, 3 \mathrm{M} \mathrm{eO} \mathrm{Bz}\right), 129.6$ (2다 , SPh), 129.1 (2대 , SPh), 126.7 ( $\underline{\mathrm{CH}}, \mathrm{SPh}), 120.0$ ( $\underline{\mathrm{CH}}, 3 \mathrm{M} \mathrm{eOBz})$, 117.5 ( $\underline{\mathrm{CH}}, 3 \mathrm{M} \mathrm{eO} \mathrm{Bz}), 113.0$ ( $\underline{\mathrm{CH}}, 3 \mathrm{M} \mathrm{eO} \mathrm{Bz}), 104.3$ (C1'), 86.2 (C1) , 85.5 (C 3), 78.0 (C5) , 76.2 (C5), 73.6 (C3'), 71.5 (C4) , 71.1 (C2'), 68.7 (C4'), 61.1 (C6'), 55.8 ( $\left.\underline{\mathrm{CH}}_{3}, 3 \mathrm{M} \mathrm{eO} \mathrm{Bz}\right), 53.5$ ( C 2) , 41.7 (C6), $23.5\left(\mathrm{COCH}_{3}\right) ; \mathrm{HRM} \mathrm{S}\left(\mathrm{ESI}-\mathrm{T}\right.$ OF ) m/ z: [M + Na] ${ }^{+} \mathrm{Calcd}$ for $\mathrm{C}_{28} \mathrm{H}_{36} \mathrm{~N}_{2} \mathrm{O}_{11} \mathrm{SN}$ a 631.1938; Found 631.1941.

Phenyl $\beta$-D-galactopyranosyl-( $1 \rightarrow 3)$-2-acetamido-2,6-dideoxy-6-(3,5-dimethoxybenzamido)-1-thio- $\beta$-D-glucopyranoside 17

Amine 13 was dissolved in anhydrous DMF $(2 \mathrm{ml})$ at $0^{\circ} \mathrm{C}$ and treated with 3,5-dimethoxybenzoyl chloride ( $80 \mathrm{mg}, 0.44 \mathrm{mmol}, 4$ eq) and $\mathrm{Et}_{3} \mathrm{~N}(60 \mu \mathrm{L}, 0.44 \mathrm{mmol}, 4 \mathrm{eq})$. The mixture was stirred $8 \mathrm{~h}$ at rt where $20 \%$ of conversion was observed and at $40{ }^{\circ} \mathrm{C}$ for $16 \mathrm{~h}$ where all the starting product was converted. Then the mixture was concentrated under reduced pressure and the residue was purified by flash chromatography $\left(\mathrm{CH}_{2} \mathrm{Cl}_{2} / \mathrm{MeOH}\right.$ 9/1) to give derivative 17 as a white solid (22 mg, 38\%); $\mathrm{R}_{\mathrm{f}} 0.67$ $\left(\mathrm{CHCl}_{3} / \mathrm{MeOH} / \mathrm{H}_{2} \mathrm{O} / \mathrm{CH}_{3} \mathrm{COOH} 60 / 30 / 5 / 3\right) ;{ }^{1} \mathrm{H} \mathrm{NMR}(400$ $\mathrm{MHz}$, DM SO $\left.-\mathrm{d}_{6}\right) \delta 8.56(\mathrm{t}, \mathrm{J}=5.7 \mathrm{~Hz}, 1 \mathrm{H}, \mathrm{N} \underline{\mathrm{H}}(3 \mathrm{M} \mathrm{eOBz})$ ) , $7.98(\mathrm{~d}$, $\mathrm{J}=8.3 \mathrm{~Hz}, 1 \mathrm{H}, \mathrm{N} \underline{\mathrm{H}}(\mathrm{Ac})), 7.32(\mathrm{~d}, \mathrm{~J}=7.4 \mathrm{~Hz}, 2 \mathrm{H}, \mathrm{C} \underline{\mathrm{H}} \mathrm{SPh}), 7.08(\mathrm{~d}$, $\mathrm{J}=2.3 \mathrm{~Hz}, 2 \mathrm{H}, \mathrm{C} \underline{\mathrm{H}} 3 \mathrm{M} \mathrm{eO} \mathrm{Bz}), 7.05(\mathrm{t}, \mathrm{J}=7.7 \mathrm{~Hz}, 1 \mathrm{H}, \mathrm{C} \underline{\mathrm{H}} \mathrm{SPh}), 6.92$ $(\mathrm{t}, \mathrm{J}=7.7 \mathrm{~Hz}, 2 \mathrm{H}, \mathrm{C} \underline{\mathrm{H}} \mathrm{SPh}), 6.69(\mathrm{t}, \mathrm{J}=2.3 \mathrm{~Hz}, 1 \mathrm{H}, \mathrm{C} \underline{\mathrm{H}} 3 \mathrm{M} \mathrm{eOBz})$, $4.92-4.90(\mathrm{~m}, 1 \mathrm{H}, \mathrm{O} \underline{\mathrm{H}}), 4.86(\mathrm{~d}, \mathrm{~J}=9.3 \mathrm{~Hz}, 1 \mathrm{H}, \mathrm{H} 1), 4.81(\mathrm{~d}, \mathrm{~J}=$ $4.9 \mathrm{~Hz}, 1 \mathrm{H} \mathrm{O} \underline{\mathrm{H}}), 4.69(\mathrm{t}, \mathrm{J}=5.2 \mathrm{~Hz}, 1 \mathrm{H}, 0 \underline{\mathrm{H}}), 4.51(\mathrm{~d}, \mathrm{~J}=4.7 \mathrm{~Hz}$, $1 \mathrm{H}, 0 \underline{\mathrm{H}}), 4.48(\mathrm{~d}, \mathrm{~J}=3.2 \mathrm{~Hz}, 1 \mathrm{H}, \mathrm{O} \underline{\mathrm{H}}), 4.21(\mathrm{~d}, \mathrm{~J}=6.6 \mathrm{~Hz}, 1 \mathrm{H}, \mathrm{H1})^{\prime}$, $3.90-3.81$ ( $\mathrm{m}, 1 \mathrm{H}, \mathrm{H} 6 \mathrm{a}), 3.78$ ( $\left.\mathrm{s}, 6 \mathrm{H}, 2 \times \mathrm{C}_{3} 3 \mathrm{M} \mathrm{eO} \mathrm{Bz}\right), 3.75-3.45$ ( $\mathrm{m}, 7 \mathrm{H}, \mathrm{H} 2, \mathrm{H} 3, \mathrm{H} 4$ ', H5, H6a', H6b', H5'), 3.41-3.30 (m, 2H, H2', H3'), 3.30-3.19 (m, 2H, H 4, H 6b) , $1.83\left(\mathrm{~s}, 3 \mathrm{H}, \mathrm{COCH}_{3}\right) ;{ }^{13} \mathrm{C}\left\{{ }^{1} \mathrm{H}\right\}$ N M R (101 M Hz, D M SO-d $) \delta 170.4$ (1C, 1ㅁquat, $\left.\mathrm{COCH}_{3}\right), 166.1$ ( $\left.\underline{C}_{\text {quat }}, \underline{\mathrm{C} O P h}\right), 160.8$ ( $\left.2 \underline{\mathrm{C}}_{\text {quat }}, 3 \mathrm{M} \mathrm{eO}-\underline{\mathrm{C}}\right), 136.8$ ( $\left.\underline{\mathrm{C}}_{\text {quat }}, 3 \mathrm{M} \mathrm{eOBz}\right)$,

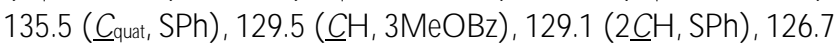
$\left.(\underline{\mathrm{CH}}, \mathrm{SPh}), 105.8(2 \underline{\mathrm{CH}}, 3 \mathrm{M} \mathrm{eOBz}), 104.4(\mathrm{C})^{\prime}\right), 103.6(\underline{\mathrm{CH}}$, $3 \mathrm{M} \mathrm{eO} \mathrm{Bz}), 85.5(2 \underline{\mathrm{CH}}, \mathrm{C} 1$ and $\mathrm{C} 3), 78.0$ (C5), 76.3 (C5), 73.6 (C3'), 71.5 (C4), 71.1 (C2'), 68.7 (C4'), 61.1 (C6), $55.9\left(2 \mathrm{CH}_{3}\right.$, 3M eO Bz), 52.9 (C2), 41.8 (C6), $23.5\left(\mathrm{CO}_{\mathrm{CH}}\right)$; HRM S (ESITOF ) $\mathrm{m} / \mathrm{z}:[\mathrm{M}+\mathrm{Na}]^{+} \mathrm{C}$ alcd for $\mathrm{C}_{29} \mathrm{H}_{38} \mathrm{~N}_{2} \mathrm{O}{ }_{12} \mathrm{SN}$ a 661.2043; F ound 661.2037.

Phenyl $\beta$-D-galactopyranosyl-( $1 \rightarrow 3)$-2-acetamido-2,6-dideoxy-6-(3-methoxyphenylacetamido)-1-thio- $\beta$-D-glucopyranoside 18

Amine 13 was dissolved in anhydrous DMF $(2 \mathrm{ml})$ at $0^{\circ} \mathrm{C}$ and treated with 3-methoxyphenylacetyl chloride ( $16 \mu \mathrm{L}, 0.10 \mathrm{mmol}, 1.1$ eq) and $\mathrm{Et}_{3} \mathrm{~N}(14 \mu \mathrm{L}, 0.10 \mathrm{mmol}, 1.1 \mathrm{eq})$. T he mixture was stirred 3 $\mathrm{h}$ and concentrated under reduced pressure. The residue was purified by flash chromatography $\left(\mathrm{CH}_{2} \mathrm{Cl}_{2} / \mathrm{M} \mathrm{eOH} \mathrm{9/1)}\right.$ to give derivative 18 as a white solid (37 mg, 66\%). $\mathrm{R}_{\mathrm{f}} 0.65$ $\left(\mathrm{CHCl}_{3} / \mathrm{MeOH} / \mathrm{H}_{2} \mathrm{O} / \mathrm{CH}_{3} \mathrm{COOH} 60 / 30 / 5 / 3\right) ;{ }^{1} \mathrm{H} \mathrm{NMR}(400$ MHz, DM SO $\left.-\mathrm{d}_{6}\right) \delta 8.11(\mathrm{t}, \mathrm{J}=5.8 \mathrm{~Hz}, 1 \mathrm{H}, \mathrm{N} \underline{\mathrm{H}}(3 \mathrm{M} \mathrm{eOPh})), 8.01(\mathrm{~d}$, $J=8.0 \mathrm{~Hz}, 1 \mathrm{H}, \mathrm{N} \underline{\mathrm{HAC}}), 7.42(\mathrm{~d}, \mathrm{~J}=7.1 \mathrm{~Hz}, 2 \mathrm{H}, \mathrm{C} \underline{\mathrm{H}} \mathrm{SPh}), 7.29$ (d, J $=8.0 \mathrm{~Hz}, 2 \mathrm{H}, \mathrm{C} \underline{\mathrm{H}} \mathrm{SPh}), 7.23(\mathrm{~d}, \mathrm{~J}=7.0 \mathrm{~Hz}, 1 \mathrm{H}, \mathrm{C} \underline{\mathrm{H}} \mathrm{SPh}), 7.17$ (t, J
$=7.8 \mathrm{~Hz}, 1 \mathrm{H}, \mathrm{C} \underline{\mathrm{H}} 3 \mathrm{M} \mathrm{eOPh}), 6.83-6.79(\mathrm{~m}, 2 \mathrm{H}, \mathrm{C} \underline{\mathrm{H}} 3 \mathrm{M} \mathrm{eOPh})$, $6.78(\mathrm{dd}, \mathrm{J}=3.1,8.1 \mathrm{~Hz}, 1 \mathrm{H}, \mathrm{C} \underline{\mathrm{H}} 3 \mathrm{M} \mathrm{eOPh}), 4.91(\mathrm{~d}, \mathrm{~J}=9.8 \mathrm{~Hz}, 1 \mathrm{H}$, $\mathrm{H}$ 1),4.86 $4.79(\mathrm{~m}, 2 \mathrm{H}, 2 \times 0 \underline{\mathrm{H}}), 4.68(\mathrm{t}, \mathrm{J}=5.3 \mathrm{~Hz}, 1 \mathrm{H}, 0 \underline{\mathrm{H}}), 4.51$ $(\mathrm{d}, \mathrm{J}=4.7 \mathrm{~Hz}, 1 \mathrm{H}, \mathrm{OH}), 4.48(\mathrm{~d}, \mathrm{~J}=3.7 \mathrm{~Hz}, 1 \mathrm{H}, 0 \underline{\mathrm{H}}), 4.19(\mathrm{~d}, \mathrm{~J}=$ $6.3 \mathrm{~Hz}, 1 \mathrm{H}, \mathrm{H1}$ '), 3.71 (s, 3H, $\left.\underline{\mathrm{H}}_{3} 3 \mathrm{M} \mathrm{eOPh}\right), 3.69-3.56(\mathrm{~m}, 4 \mathrm{H}$, H2, H3, H6a, H4'), 3.55-3.37 (m, 6H, H6a', H6b', H5', H5, CH2 $\left.3 \mathrm{MeOPhCH}_{2}\right), 3.37-3.28\left(\mathrm{~m}, 2 \mathrm{H}, \mathrm{H} 2^{\prime}, \mathrm{H}^{\prime}\right), 3.243 .17(\mathrm{~m}, 1 \mathrm{H}$, $\mathrm{H}^{\prime}$ ), $3.11(\mathrm{dd}, \mathrm{J}=5.9,14.0 \mathrm{~Hz}, 1 \mathrm{H}, \mathrm{H} 6 \mathrm{~b}), 1.84\left(\mathrm{~s}, 3 \mathrm{H} \mathrm{COC} \underline{\mathrm{H}}_{3}\right)$; ${ }^{13} \mathrm{C}\left\{{ }^{1} \mathrm{H}\right\}$ N M R (101 M Hz, DM SO- $\left.\mathrm{d}_{6}\right) \delta 170.1$ ( $\left.\underline{\mathrm{C}}_{\text {quat, }} \mathrm{COCH}_{2} \mathrm{Ph}\right)$, 170.4 ( $\underline{\mathrm{C}}_{\text {quat }}, \underline{\mathrm{COCH}} \mathrm{CH}_{3}$ ), 159.6 ( $\underline{\mathrm{C}}_{\text {quat }}, 3 \mathrm{M} \mathrm{eO}-\underline{\mathrm{C}}$ ), 138.3 ( $\underline{\mathrm{C}}_{\text {quat, }}$ 3M e-

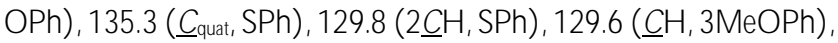
129.4 (2다 , SPh) , 127.0 ( $\underline{\mathrm{CH}}, \mathrm{SPh}), 121.7$ ( $\underline{\mathrm{CH}}, 3 \mathrm{M} \mathrm{eOPh}), 115.2$ (다 , 3M eO Ph), 112.3 ( $\underline{\mathrm{CH}}, 3 \mathrm{M} \mathrm{eOPh}), 104.3$ ( $\left.\mathrm{Cl}^{\prime}\right), 86.0$ (C 1), 85.3 (C 3) , 78.4 (C 5) , 76.3 ( $\mathrm{C5}^{\prime}$ ), 73.6 ( C3'), 71.0 ( C2'), 70.8 (C4), 68.7 ( C4'), 61.0 ( $\left.\mathrm{C}^{\prime}\right), 55.4\left(\underline{\mathrm{CH}}_{3}, 3 \mathrm{M} \mathrm{eO} \mathrm{Ph}\right), 53.4(\mathrm{C} 2), 45.9\left(\underline{\mathrm{CH}}_{2}\right.$, $3 \mathrm{MeOPhCH} 2), 40.9(\mathrm{C} 6), 23.5\left(\mathrm{COCH}_{3}\right) ; \mathrm{HRMS}$ (ESI-TOF) $\mathrm{m} / \mathrm{z}:[\mathrm{M}+\mathrm{Na}]^{+} \mathrm{Calcd}$ for $\mathrm{C}_{29} \mathrm{H}_{38} \mathrm{~N}_{2} \mathrm{O}{ }_{11} \mathrm{SN}$ a 645.2094; Found 645.2088 .

Phenyl $\beta$-D-galactopyranosyl-( $1 \rightarrow 3)$-2-acetamido-6-(piperonyloyl)amido-2,6-dideoxy-1-thio- $\beta$-D-glucopyranoside 19

Amine 13 was dissolved in anhydrous DMF $(2 \mathrm{ml})$ at $0^{\circ} \mathrm{C}$ and treated with piperonyloyl chloride ( $20 \mathrm{mg}, 0.11 \mathrm{mmol}, 1.1 \mathrm{eq}$ ) and $\mathrm{Et}_{3} \mathrm{~N}$ ( $15 \mu \mathrm{L}, 0.11 \mathrm{mmol}, 1.1 \mathrm{eq}$ ). The mixture was stirred $12 \mathrm{~h}$ and concentrated under reduced pressure. The residue was first purified by flash chromatography $\left(\mathrm{CH}_{2} \mathrm{Cl}_{2} / \mathrm{MeOH} \mathrm{75/25)}\right.$ then by reverse phase $\mathrm{C}-18$ flash chromatography using a $\mathrm{H}_{2} \mathrm{O} / \mathrm{MeOH}$ gradient mixture as eluent to give derivative 19 as a white solid ( $33 \mathrm{mg}, 55 \%$ ); $\mathrm{R}_{\mathrm{f}} 0.65\left(\mathrm{CHCl}_{3} / \mathrm{MeOH} / \mathrm{H}_{2} \mathrm{O} / \mathrm{CH}_{3} \mathrm{COOH} \mathrm{60/30/5/3);}{ }^{1} \mathrm{H} \mathrm{NMR}\right.$ $\left(400 \mathrm{MHz}, \mathrm{DMSO}-\mathrm{d}_{6}\right) \delta 8.38(\mathrm{t}, \mathrm{J}=5.7 \mathrm{~Hz}, 1 \mathrm{H}, \mathrm{N} \underline{\mathrm{H}}(\mathrm{C}(\mathrm{O}) \mathrm{Ph})$ ), $8.02(\mathrm{~d}, \mathrm{~J}=8.2 \mathrm{~Hz}, 1 \mathrm{H}, \mathrm{N} \underline{\mathrm{H}}(\mathrm{Ac})), 7.47(\mathrm{~d}, \mathrm{~J}=8.0 \mathrm{~Hz}, 1 \mathrm{H}, \mathrm{Ph}), 7.41$ ( br s, 1H, Ph) , 7.33 (d, J = 7.7 Hz, 2H, C $\underline{H} S P h), 7.08$ (t, J = 7.4 Hz, $1 \mathrm{H}, \mathrm{C} \underline{\mathrm{H}} \mathrm{SPh}), 7.03-6.93(\mathrm{~m}, 3 \mathrm{H}, \mathrm{C} \underline{\mathrm{H}}, \mathrm{SPh}, \mathrm{Ph}), 6.11(\mathrm{~s}, 2 \mathrm{H}$, $\left.\mathrm{OC} \underline{\mathrm{H}}_{2} \mathrm{O}\right), 4.98-4.79(\mathrm{~m}, 3 \mathrm{H}, 2 \times \mathrm{O} \underline{\mathrm{H}}, \mathrm{H} 1), 4.71$ (br s, $\left.1 \mathrm{H}, \mathrm{O} \underline{\mathrm{H}}\right)$, $4.52-4.50(\mathrm{~m}, 2 \mathrm{H}, 2 \mathrm{OH}), 4.21\left(\mathrm{~d}, \mathrm{~J}=6.4 \mathrm{~Hz}, 1 \mathrm{H}, \mathrm{H} 1^{\prime}\right), 3.82$ ( dd, J $=6.3,12.8 \mathrm{~Hz}, 1 \mathrm{H}, \mathrm{H} \mathrm{6a}), 3.76-3.60\left(\mathrm{~m}, 3 \mathrm{H}, \mathrm{H} 2, \mathrm{H} 3, \mathrm{H} 4{ }^{\prime}\right), 3.60-$ 3.44 (m, 4H, H5, H6'a, H6'b, H5'), 3.44-3.29 (m, 2H, H2', H3'), $3.29-3.18(\mathrm{~m}, 2 \mathrm{H}, \mathrm{H} 4, \mathrm{H} 6 \mathrm{~b}), 1.84\left(\mathrm{~s}, 3 \mathrm{H}, \mathrm{COCH}_{3}\right) ;{ }^{13} \mathrm{C}\left\{{ }^{1} \mathrm{H}\right\} \mathrm{N} M \mathrm{R}$ (101 MHz, DMSO-d $) \delta 170.4$ ( $\underline{\mathrm{C}}_{\text {quat }}, \underline{\mathrm{COCH}}_{3}$ ), 165.7 ( $\underline{\mathrm{C}}_{\text {quat }}$,

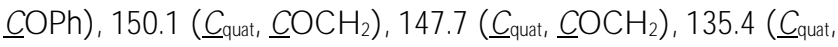
$\mathrm{SPh}), 129.6(2 \underline{\mathrm{CH}}, \mathrm{SPh}), 129.1(2 \underline{\mathrm{CH}}, \mathrm{SPh}), 128.8$ ( $\underline{\mathrm{C}}_{\text {quat, }}$ C $\underline{C} O N H), 126.8(\underline{\mathrm{CH}}, \mathrm{SPh}), 122.7(\underline{\mathrm{CH}}, \mathrm{Ph}), 108.2(\underline{\mathrm{CH}}, \mathrm{Ph})$, 107.9 ( $\mathrm{CH}, \mathrm{Ph}), 104.3$ ( $\mathrm{C} 1$ '), $102.1\left(\mathrm{CH}_{2}, \mathrm{OCH}_{2} \mathrm{O}\right), 86.1$ (C 1$), 85.5$ (C3) , 78.0 (C 5) , 76.3 (C5), 73.6 (C3'), 71.5 (C4), 71.0 (C2'), 68.7 (C4'), 61.0 (C6'), 53.5 (C2), 41.3 (C6), 23.5 ( $\left.\mathrm{COC} \mathrm{CH}_{3}\right)$; HRM S (ESI-TOF) m/ z: [M + Na] ${ }^{+} \mathrm{Calcd}$ for $\mathrm{C}_{28} \mathrm{H}_{34} \mathrm{~N}_{2} \mathrm{O}_{12} \mathrm{SN}$ a 645.1730; Found 645.1738 .

Phenyl $\beta$-D-galactopyranosyl- $(1 \rightarrow 3)$-2-acetamido-6-( methoxyoxoacetamido)-2,6-dideoxy-1-thio- $\beta$-D-glucopyranoside 20

Amine 13 was dissolved in anhydrous DMF $(2 \mathrm{ml})$ at $0^{\circ} \mathrm{C}$ and treated with methyl chlorooxoacetate ( $10 \mu \mathrm{L}, 0.11 \mathrm{mmol}, 1.1 \mathrm{eq})$ and $\mathrm{Et}_{3} \mathrm{~N}$ ( $15 \mu \mathrm{L}, 0.11 \mathrm{mmol}, 1.1 \mathrm{eq}$ ). The mixture was stirred $12 \mathrm{~h}$ and concentrated under reduced pressure. The residue was purified firstly by flash chromatography $\left(\mathrm{CH}_{2} \mathrm{Cl}_{2} / \mathrm{MeOH} 7 / 3\right)$ then by reverse phase $\mathrm{C}$ - 18 flash chromatography using a $\mathrm{H}_{2} \mathrm{O} / \mathrm{M} \mathrm{eO} \mathrm{H}$ gradient as eluent to give derivative 20 as a white solid ( $33 \mathrm{mg}, 60 \%$ ); $\mathrm{R}_{\mathrm{f}}$ $0.75\left(\mathrm{CHCl}_{3} / \mathrm{MeOH} / \mathrm{H}_{2} \mathrm{O} / \mathrm{CH}_{3} \mathrm{COOH} \mathrm{60/30/5/3);}{ }^{1} \mathrm{H} \mathrm{NMR}\right.$ $(400 \mathrm{MHz}$, DMSO-d $) \quad \delta 8.91(\mathrm{t}, \mathrm{J}=6.1 \mathrm{~Hz}, 1 \mathrm{H}$, 
$\left.\mathrm{N} \underline{\mathrm{H}}\left(\mathrm{C}(\mathrm{O}) \mathrm{CO}_{2} \mathrm{Me}\right)\right), 7.90(\mathrm{~d}, \mathrm{~J}=7.8 \mathrm{~Hz}, 1 \mathrm{H}, \mathrm{N} \underline{\mathrm{H}} \mathrm{Ac}), 7.38-7.32(\mathrm{~m}$, $2 \mathrm{H}, \mathrm{C} \underline{\mathrm{H}} \mathrm{SPh}), 7.25-7.21(\mathrm{~m}, 3 \mathrm{H}, \mathrm{CH} \mathrm{SPh}), 4.90(\mathrm{br} \mathrm{s}, 1 \mathrm{H}, \mathrm{OH})$, $4.85-4.80(\mathrm{~m}, 2 \mathrm{H}, \mathrm{H} 1$ and $\mathrm{OH}), 4.68(\mathrm{t}, \mathrm{J}=5.0 \mathrm{~Hz}, 1 \mathrm{H}, \mathrm{OH}), 4.17$ $\left.(\mathrm{d}, \mathrm{J}=6.8 \mathrm{~Hz}, 1 \mathrm{H}, \mathrm{Hl})^{\prime}\right), 3.79\left(\mathrm{~s}, 3 \mathrm{H}, \mathrm{C}_{3} \mathrm{MeO}\right), 3.72-3.44(\mathrm{~m}, 8 \mathrm{H}$, H3, H4', H6a, H2, H5', H6'a, H6’b, H5), 3.34-3.22 (m, 3H, H2', $\mathrm{H} 3$ ', H6b), 3.22 (t, J = 8.6 Hz, $1 \mathrm{H}, \mathrm{H} 4), 1.83\left(\mathrm{~s}, 3 \mathrm{H}, \mathrm{COC} \underline{\mathrm{H}}_{3}\right)$; ${ }^{13} \mathrm{C}\left\{{ }^{1} \mathrm{H}\right\} \mathrm{NMR}\left(101 \mathrm{MHz}, \mathrm{DMSO}-\mathrm{d}_{6}\right) \delta 170.3\left(\underline{\mathrm{C}}_{\text {quat, }} \underline{\mathrm{COCH}}_{3}\right)$, 161.5 ( $\underline{C}_{\text {quat, }} \underline{\mathrm{COOOMe}}$ ), 157.3 ( $\underline{\mathrm{C}}_{\text {quat, }} \mathrm{N} \mathrm{H} \underline{\mathrm{COCO}}_{2} \mathrm{Me}$ ), 135.1 ( $\underline{\mathrm{C}}_{\text {quat, }}$

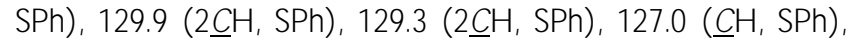
104.4 (C1'), 85.8 (C 1) , 85.5 (C 3), 77.4, 76.3 (C5', C5), 73.5 (C3'), 71.2 (C4), $71.0\left(\mathrm{C}^{\prime}\right), 68.7\left(\mathrm{C} 4^{\prime}\right), 61.1(\mathrm{C} 6), 53.3\left(\underline{\mathrm{C}}_{3}, \mathrm{MeO}\right)$, 50.9 (C2) , 41.4 (C6) , $23.5\left(\mathrm{COCH}_{3}\right)$; HRM S (ESI-T OF) m/ z: [ M $+\mathrm{Na}]^{+} \mathrm{C}$ alcd for $\mathrm{C}_{23} \mathrm{H}_{32} \mathrm{~N}_{2} \mathrm{O}_{12} \mathrm{SN}$ a 583.1574; Found 583.1582.

\section{Phenyl $\quad \beta$-D-galactopyranosyl-( $1 \rightarrow 3)$-2-acetamido-6-(car- boxyoxoacetamido-2,6-dideoxy-1-thio- $\beta$-D-glucopyranoside 21}

A solution of ester derivative $\mathbf{2 0}$ ( $15 \mathrm{mg}, 0.027 \mathrm{mmol}, 1 \mathrm{eq}$ ) in a mixture of aq. $\mathrm{NaOH} 2 \mathrm{M}(1 \mathrm{ml})$ and $\mathrm{M} \mathrm{eOH}(1 \mathrm{ml})$ was stirred $2 \mathrm{~h}$ at $0^{\circ} \mathrm{C}$. Then the mixture was acidified with $\mathrm{HCl} 1 \mathrm{M}$ to $\mathrm{pH} 1$ and concentrated under reduced pressure. The residue was purified by reverse phase $\mathrm{C}$ - 18 flash chromatography using a $\mathrm{H}_{2} \mathrm{O} / \mathrm{M} \mathrm{eO} \mathrm{H}$ gradient mixture to give acid $\mathbf{2 1}$ as a colorless solid (14 mg, 95\%); $\mathrm{R}_{\mathrm{f}}$ $0.25\left(\mathrm{CHCl}_{3} / \mathrm{MeOH} / \mathrm{H}_{2} \mathrm{O} / \mathrm{CH}_{3} \mathrm{COOH} 60 / 30 / 5 / 3\right) ;{ }^{1} \mathrm{H} N M R$ $\left(400 \mathrm{MHz}, \mathrm{DMSO}-\mathrm{d}_{6}\right) \delta 8.31$ (br s, $1 \mathrm{H}, \mathrm{NH}\left(\mathrm{C}(\mathrm{O}) \mathrm{CO}_{2} \mathrm{Na}\right.$ ) ), 7.95 $(\mathrm{d}, \mathrm{J}=8.2 \mathrm{~Hz}, 1 \mathrm{H}, \mathrm{N} \underline{\mathrm{HAC}}), 7.40(\mathrm{~d}, \mathrm{~J}=7.6 \mathrm{~Hz}, 2 \mathrm{H}, \mathrm{C} \underline{\mathrm{H}} \mathrm{SPh}), 7.31$ $(t, J=7.5 \mathrm{~Hz}, 2 \mathrm{H}, \mathrm{C} \underline{\mathrm{H} S P h}), 7.22(\mathrm{t}, \mathrm{J}=7.2 \mathrm{~Hz}, 1 \mathrm{H}, \mathrm{C} \underline{\mathrm{H}} \mathrm{SPh}), 4.92$ $4.83(\mathrm{~m}, 2 \mathrm{H}, \mathrm{H} \mathrm{l}$ and $\mathrm{OH}), 4.52(\mathrm{br} \mathrm{s}, 1 \mathrm{H}, \mathrm{OH}), 4.17(\mathrm{~d}, \mathrm{~J}=6.4 \mathrm{~Hz}$, H1'), 3.73-3.55 (m, 4H, H3, H4', H6a, H2) , 3.55-3.41 (m, 4H, H5', H6'a, H6'b, H5), 3.40-3.28 (m, 2H, H2', H3'), 3.26-3.14 ( $\mathrm{m}, 2 \mathrm{H}$, $\mathrm{H} 4, \mathrm{H} 6 \mathrm{~b}), 1.83\left(\mathrm{~s}, 3 \mathrm{H}, \mathrm{COC} \underline{\mathrm{H}}_{3}\right) ;{ }^{13} \mathrm{C}\left\{{ }^{1} \mathrm{H}\right\} \mathrm{NMR}(101 \mathrm{MHz}$, DMSO-d $)_{6} \delta 170.3\left(2 \underline{\mathrm{C}}_{\text {quat }}, \underline{\mathrm{COCH}} 3, \underline{\mathrm{COONa}}\right), 165.9$ ( $\underline{\mathrm{C}}_{\text {quat, }}$ $\mathrm{NHCOCO}{ }_{2} \mathrm{Na}$ ) , 135.0 ( $\left.\underline{\mathrm{C}}_{\text {quat }}, \mathrm{SPh}\right), 130.2$ ( $\left.2 \underline{\mathrm{CH}}, \mathrm{SPh}\right), 129.6(2 \underline{\mathrm{CH}}$, $\mathrm{SPh}), 127.1$ ( $\underline{\mathrm{CH}}, \mathrm{SPh}), 104.4$ ( C1'), 86.1 (C1), 85.3 (C 3), 78.0 (C5), 76.3 (C5'), $73.4\left(\mathrm{C}^{\prime}\right), 71.0$ (2C, C4 and C2'), 68.6 (C4'), 61.0 (C6), 53.5 (C2), 41.1 (C6), $\left.23.4\left(\mathrm{CO}_{\mathrm{CH}}\right)_{3}\right)$; HRM S (ESITOF) $\mathrm{m} / \mathrm{z}$ : [M - Na] ${ }^{-} \mathrm{Calcd}$ for $\mathrm{C}_{22} \mathrm{H}_{28} \mathrm{~N}_{2} \mathrm{O}_{12} \mathrm{~S} 545.1441$; Found 545.1437.

\section{Phenyl $\beta$-D-galactopyranosyl-( $1 \rightarrow 3)$-2-acetamido-2,6-dide- oxy-6-(3-methoxyphenylsulfonamido)-1-thio- $\beta$-D-glucopyra- noside 22}

Amine 13 was dissolved in anhydrous DMF $(2 \mathrm{ml})$ at $0^{\circ} \mathrm{C}$ and treated with 3-methoxyphenylsulfonyl chloride ( $24 \mu \mathrm{L}, 0.17 \mathrm{mmol}$, $1.6 \mathrm{eq})$ and $\mathrm{Et}_{3} \mathrm{~N}(24 \mu \mathrm{L}, 0.17 \mathrm{mmol}, 1.6 \mathrm{eq})$. T hemixturewas stirred $24 \mathrm{~h}$ at $\mathrm{rt}$ and concentrated under reduced pressure. The residue was purified by flash chromatography $\left(\mathrm{CH}_{2} \mathrm{Cl}_{2} / \mathrm{MeOH} 9 / 1\right)$ to give derivative 22 as a white solid (14 mg, 21\%); $R_{f} 0.70$ $\left(\mathrm{CHCl}_{3} / \mathrm{MeOH} / \mathrm{H}_{2} \mathrm{O} / \mathrm{CH}_{3} \mathrm{COOH} 60 / 30 / 5 / 3\right) ;{ }^{1} \mathrm{H} \mathrm{NMR}(400$

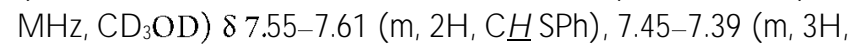

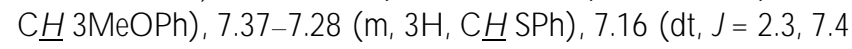
$\mathrm{Hz}, 1 \mathrm{H}, \mathrm{C} \underline{\mathrm{H}} 3 \mathrm{M} \mathrm{eOPh}), 4.74(\mathrm{~d}, \mathrm{~J}=10.5 \mathrm{~Hz}, 1 \mathrm{H}, \mathrm{H} 1), 4.27(\mathrm{~d}, \mathrm{~J}=$ $\left.7.4 \mathrm{~Hz}, 1 \mathrm{H}, \mathrm{H} 1^{\prime}\right), 3.86\left(\mathrm{~s}, 3 \mathrm{H}, \mathrm{CL}_{3} 3 \mathrm{M} \mathrm{eOPh}\right), 3.82-3.73(\mathrm{~m}, 3 \mathrm{H}$, H2, H4', H6a'), 3.73-3.61 (m, 2H, H6b', H3), 3.59-3.49 (m, 2H, H5', H2'), 3.49-3.40 (m, 2H, H3', H6a), 3.38-3.33 ( $\mathrm{m}, 1 \mathrm{H}, \mathrm{H} 5$ ), $3.22(\mathrm{dd}, \mathrm{J}=8.1,9.4 \mathrm{~Hz}, 1 \mathrm{H}, \mathrm{H}$ 4) , $3.02(\mathrm{dd}, \mathrm{J}=7.6,13.8 \mathrm{~Hz}, 1 \mathrm{H}$, $\mathrm{H} 6 \mathrm{~b}), 1.99\left(\mathrm{~s}, 3 \mathrm{H}, \mathrm{COC} \underline{\mathrm{H}}_{3}\right) ;{ }^{13} \mathrm{C}\left\{{ }^{1} \mathrm{H}\right\} \mathrm{NMR}\left(101 \mathrm{MHz}, \mathrm{CD}_{3} \mathrm{OD}\right) \delta$ 172.6 ( $\underline{\mathrm{C}}_{\text {quat }}, \underline{\mathrm{COCH}} \underline{\mathrm{CH}}_{3}$ ), 160.1 ( $\underline{\mathrm{C}}_{\text {quat, }} 3 \mathrm{M} \mathrm{eO}-\underline{\mathrm{C}}$ ), 141.8 ( $\underline{\mathrm{C}}_{\text {quat, }} 3 \mathrm{M} \mathrm{e}-$

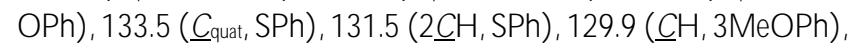

128.6 ( $2 \underline{\mathrm{C}} \mathrm{H}, \mathrm{SPh}), 127.2$ ( $\underline{\mathrm{C}} \mathrm{H}, \mathrm{SPh}), 118.7(\underline{\mathrm{C}} \mathrm{H}, 3 \mathrm{M} \mathrm{eOPh}), 118.2$ ( $\underline{\mathrm{CH}}, 3 \mathrm{M} \mathrm{eO} \mathrm{Ph}), 111.6$ ( $\underline{\mathrm{CH}}, 3 \mathrm{M} \mathrm{eOPh}), 104.2$ (C1'), 86.4 ( C1), 84.3 (C3), 78.4 (C 5) , 75.7 (C5'), 73.2 (C3'), 70.9 (C2'), 70.4 (C4), 68.8 (C4), 61.1 (C6'), 54.8 ( $\mathrm{CH}_{3}, 3 \mathrm{M} \mathrm{eO} \mathrm{Ph),} 55.0$ (C2) , 44.2 (C 6 ), $21.7\left(\mathrm{COCH}_{3}\right) ;$ HRMS (ESI-TOF) m/ $\mathrm{z}:[\mathrm{M}+\mathrm{Na}]^{+} \mathrm{Calcd}$ for $\mathrm{C}_{27} \mathrm{H}_{36} \mathrm{~N}_{2} \mathrm{O}_{12} \mathrm{~S}_{2} \mathrm{Na}$ 667.1607; Found 667.1614.

Phenyl $\beta$-D-galactopyranosyl-( $1 \rightarrow 3)$-2-acetamido-2,6-dideoxy-6-(3-methoxyphenylureido)-1-thio- $\beta$-D-glucopyranoside 23

Amine 13 was dissolved in anhydrous DMF $(2 \mathrm{ml})$ at $0^{\circ} \mathrm{C}$ and treated with 3-methoxyphenyl isocyanate ( $16 \mu \mathrm{L}, 0.12 \mathrm{mmol}, 1.2$ eq) and $\mathrm{Et}_{3} \mathrm{~N}(17 \mu \mathrm{L}, 0.12 \mathrm{mmol}, 1.1 \mathrm{eq})$. The mixture was stirred for $12 \mathrm{~h}$ and concentrated under reduced pressure. The residue was first purified by flash chromatography $\left(\mathrm{CH}_{2} \mathrm{Cl}_{2} / \mathrm{MeOH} 85 / 15\right)$ then by reverse phase $\mathrm{C}-18$ flash chromatography using a $\mathrm{H}_{2} \mathrm{O} / \mathrm{M} \mathrm{eOH}$ gradient mixture to give derivative $\mathbf{2 3}$ as a white solid $(29 \mathrm{mg}, 47 \%) ; \mathrm{R}_{\mathrm{f}} 0.89 \quad\left(\mathrm{CHCl}_{3} / \mathrm{MeOH} / \mathrm{H}_{2} \mathrm{O} / \mathrm{CH}_{3} \mathrm{COOH}\right.$ $60 / 30 / 5 / 3) ;{ }^{1} H$ NMR (400 MHz, DMSO-d $)$ \& $8.77(s, 1 H$, $\mathrm{N} \underline{\mathrm{H}}(3 \mathrm{M} \mathrm{eO} \mathrm{Ph})), 7.99(\mathrm{~d}, \mathrm{~J}=8.0 \mathrm{~Hz}, 1 \mathrm{H}, \mathrm{N} \underline{\mathrm{H} A c}), 7.44-7.38(\mathrm{~m}, 2 \mathrm{H}$,

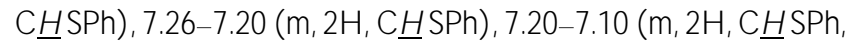

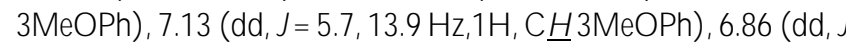
$=1.9,8.1 \mathrm{~Hz}, 1 \mathrm{H}, \mathrm{CH} 3 \mathrm{M} \mathrm{eOPh}), 6.48(\mathrm{dd}, \mathrm{J}=2.5,8.2 \mathrm{~Hz}, 1 \mathrm{H}, \mathrm{C} \underline{\mathrm{H}}$ $3 \mathrm{M} \mathrm{eOPh}), 6.33(\mathrm{t}, \mathrm{J}=6.0 \mathrm{~Hz}, 1 \mathrm{H}, \mathrm{N} \underline{\mathrm{HCONH}}), 4.94-4.77(\mathrm{~m}, 3 \mathrm{H}$, $\mathrm{H} 1,2 \times 0 \underline{\mathrm{H}}), 4.764 .64(\mathrm{~m}, 1 \mathrm{H}, \mathrm{OH}), 4.52(\mathrm{~d}, \mathrm{~J}=11.8 \mathrm{~Hz}, 2 \mathrm{H}, 2 \times$ $\mathrm{O} \underline{\mathrm{H}}), 4.20\left(\mathrm{~d}, \mathrm{~J}=5.2 \mathrm{~Hz}, 1 \mathrm{H}, \mathrm{H} 1^{\prime}\right), 3.71\left(\mathrm{~s}, 3 \mathrm{H}, \mathrm{C}_{3} 3 \mathrm{M} \mathrm{eOPh}\right)$, 3.68-3.58 (m, 4H, H2, H3, H6a, H4'), 3.52 (d, J = 6.1 Hz, 2H, H6' a, H6'b), 3.49-3.28 (m, 4H, H5', H5, H2', H3'), 3.22 (t, J = 9.3 H z, 1H, $\mathrm{H} 4), 3.19-3.10(\mathrm{~m}, 1 \mathrm{H}, \mathrm{H} 6 \mathrm{~b}), 1.83\left(\mathrm{~s}, 3 \mathrm{H} \mathrm{COC} \underline{H}_{3}\right) ;{ }^{13} \mathrm{C}\left\{{ }^{1} \mathrm{H}\right\} \mathrm{N} \mathrm{MR}$

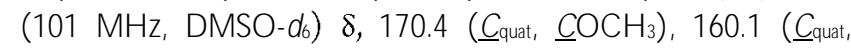
3M eO $-\underline{C}$ ) , 155.6 ( $\underline{C}_{\text {quat, }} \underline{\mathrm{CO}}$ N H Ph), 142.3 ( $\underline{\mathrm{C}}_{\text {quat, }}$ 3M eO Ph), 135.2 ( $\left.\underline{\mathrm{C}}_{\text {quat, }}, \mathrm{SPh}\right), 130.0(2 \underline{\mathrm{CH}}, \mathrm{SPh}), 129.9$ ( $\left.\underline{\mathrm{CH}}, 3 \mathrm{M} \mathrm{eOPh}\right), 129.4(2 \underline{\mathrm{CH}}$, SPh), 127.0 ( $\underline{\mathrm{CH}}, \mathrm{SPh}), 110.3(\underline{\mathrm{CH}}, 3 \mathrm{M} \mathrm{eOPh}), 106.9$ ( $\underline{\mathrm{CH}}, 3 \mathrm{M} \mathrm{e}-$ OPh), 104.3 (C1'), 103.7 ( $\underline{\mathrm{CH}}, 3 \mathrm{M} \mathrm{eOPh}), 86.2$ (C1), 85.4 (C3), 78.6(C5), 76.3 (C5'), 73.5 (C3'), 71.0 (C2'), 70.7 (C4), 68.7 (C4'), 61.0 (C6), 55.3 ( $\left.\underline{\mathrm{CH}}_{3}, 3 \mathrm{M} \mathrm{eOPh}\right), 53.4$ (C2), 41.1 (C6), 23.5 $\left(\mathrm{COCH}_{3}\right) ;$ HRMS (ESI-TOF) m/z: [M + Na] ${ }^{+} \mathrm{Calcd}$ for $\mathrm{C}_{28} \mathrm{H}_{37} \mathrm{~N}_{3} \mathrm{O}_{11} \mathrm{SN}$ a 646.2046; F ound 646.2043.

\section{Phenyl $\quad \beta$-D-galactopyranosyl-(1 $\rightarrow 3)-2$-acetamido-6-N-(3- methoxybenzyl)amino-2,6-dideoxy-1-thio- $\beta$-D-glucopyra- noside 24}

Amine 13 was dissolved in anhydrous DMF ( $1 \mathrm{ml})$ and treated with 3-methoxybenzaldehyde ( $7.3 \mu \mathrm{L}, 0.06 \mathrm{mmol}, 1.2 \mathrm{eq}$ ) and $\mathrm{Et}_{3} \mathrm{~N}$ ( $7 \mu \mathrm{L}, 0.05 \mathrm{mmol}, 1 \mathrm{eq}$ ). The mixture was stirred for $12 \mathrm{~h}$ at $60^{\circ} \mathrm{C}$ and the reaction was monitored by tlc. When all starting product was consumed, the mixture was cooled to rt and $\mathrm{NaBH}_{4}(2.3 \mathrm{mg}, 0.06$ $\mathrm{mmol}, 1.2 \mathrm{eq}$ ) was added. After completion of the reaction ( $2 \mathrm{~h}$ ), the mixture was concentrated under reduced pressure. The residue was first purified by flash chromatography $\left(\mathrm{CH}_{2} \mathrm{Cl}_{2} / \mathrm{MeOH} 8 / 2\right)$ then by reverse phase $\mathrm{C}$-18 flash chromatography using a $\mathrm{H}_{2} \mathrm{O} / \mathrm{M} \mathrm{eO} \mathrm{H}$ gradient mixture to give derivative $\mathbf{2 4}$ as a white solid $(16.7 \mathrm{mg}$, $56 \%) ; \mathrm{Rf}_{\mathrm{f}} 0.76\left(\mathrm{CHCl}_{3} / \mathrm{MeOH} / \mathrm{H}_{2} \mathrm{O} / \mathrm{CH}_{3} \mathrm{COOH} \mathrm{60/30/5/3);}{ }^{1} \mathrm{H}\right.$ NMR (400 MHz, DMSO-d $\left.\mathrm{d}_{6}\right) \delta 7.92(\mathrm{~d}, \mathrm{~J}=8.1 \mathrm{~Hz}, 1 \mathrm{H}, \mathrm{N} \underline{\mathrm{HAC}})$,

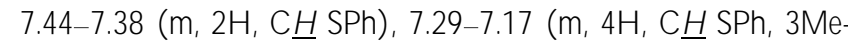
OPh) , $6.88(\mathrm{dd}, \mathrm{J}=1.4,2.8 \mathrm{~Hz}, 1 \mathrm{H}, \mathrm{C} \underline{\mathrm{H}} 3 \mathrm{M} \mathrm{eO} \mathrm{Ph}), 6.85$ (dt, J = 1.2, $7.6 \mathrm{~Hz}, 1 \mathrm{H}, \mathrm{C} \underline{\mathrm{H}} 3 \mathrm{M} \mathrm{eO} \mathrm{Ph}$ ), 6.80 (ddd, J = 1.0, 2.7, 8.3 Hz, $1 \mathrm{H}, \mathrm{C} \underline{\mathrm{H}}$ $3 \mathrm{M} \mathrm{eOPh}), 4.95(\mathrm{~d}, \mathrm{~J}=9.5 \mathrm{~Hz}, 1 \mathrm{H}, \mathrm{H} 1), 4.85-4.72\left(\mathrm{~m}, 2 \mathrm{H}, \mathrm{N} \underline{\mathrm{HCH}} \mathrm{CH}_{2}\right.$ $\mathrm{OH}), 4.62(\mathrm{t}, \mathrm{J}=5.1 \mathrm{~Hz}, 1 \mathrm{H}, \mathrm{OH}), 4.48(\mathrm{~d}, \mathrm{~J}=4.7 \mathrm{~Hz}, 1 \mathrm{H}, \mathrm{OH})$, 
4.46 (br s, 1H, O H ) , 4.17 (d, J = $\left.7.1 \mathrm{~Hz}, 1 \mathrm{H}, \mathrm{Hl} 1^{\prime}\right), 3.73\left(\mathrm{~s}, 3 \mathrm{H}, \mathrm{C}_{3}\right.$ $3 \mathrm{M} \mathrm{eO} \mathrm{Ph),} \mathrm{3.71-3.56} \mathrm{(} \mathrm{m}, 5 \mathrm{H}, \mathrm{NHC}_{2}, \mathrm{H} 2, \mathrm{H} 3, \mathrm{H} 4$ '), 3.55-3.38 ( $\mathrm{m}, 4 \mathrm{H}, \mathrm{H} 6$ 'a, H6'b, H5', H5), 3.38-3.28 (m, 2H, H2', H3'), $3.22(\mathrm{t}$, $J=8.8 \mathrm{~Hz}, 1 \mathrm{H}, \mathrm{H} 4), 2.92(\mathrm{dd}, \mathrm{J}=2.6,12.7 \mathrm{~Hz}, 1 \mathrm{H}, \mathrm{H} 6 \mathrm{a}), 2.64(\mathrm{dd}$, $\mathrm{J}=7.8,12.7 \mathrm{~Hz}, 1 \mathrm{H}, \mathrm{H} 6 \mathrm{~b}), 1.83\left(\mathrm{~s}, 3 \mathrm{H} \mathrm{COC \textrm {H } _ { 3 }}\right) ;{ }^{33} \mathrm{C}\left\{{ }^{1} \mathrm{H}\right\} \mathrm{NMR}$ (101 MHz, DMSO-d $)) \delta, 170.4\left(\underline{\mathrm{C}}_{\text {quat }}, \underline{\mathrm{COCH}}_{3}\right), 159.7$ ( $\underline{\mathrm{C}}_{\text {quat, }}$

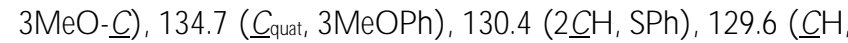

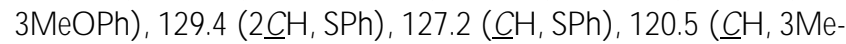
OPh) , 113.8 ( $\underline{\mathrm{CH}}, 3 \mathrm{M} \mathrm{eOPh}), 112.6$ ( $\underline{\mathrm{CH}}, 3 \mathrm{M} \mathrm{eOPh}), 104.3$ (C1'), 85.6 (C 1) , 85.5 (C3), 79.3 (C 5), 76.3 (C5'), 73.5 (C3'), 71.0 (C2'), 70.9 (C 4) , 68.7 (C4'), 61.1 (C6'), 55.4 ( $\underline{\mathrm{CH}}_{3}, 3 \mathrm{M} \mathrm{eOPh}$ ), 53.6 ( C2), $53.1\left(\underline{\mathrm{CH}}_{2}, \mathrm{NH} \underline{\mathrm{CH}}_{2}\right), 40.7$ (C6), $23.5\left(\mathrm{CO} \underline{\mathrm{C}} \mathrm{H}_{3}\right) ; \mathrm{HRMS}$ (ESITOF) $\mathrm{m} / \mathrm{z}:[\mathrm{M}+\mathrm{Na}]^{+} \mathrm{Calcd}$ for $\mathrm{C}_{28} \mathrm{H}_{39} \mathrm{~N}_{2} \mathrm{O}_{10} \mathrm{SN}$ a 595.2325; Found 595.2352 .

\section{Phenyl $\beta$-D-galactopyranosyl- $(1 \rightarrow 3)$-2-acetamido-6-N,N'-di- (3-methoxybenzyl) amino-2,6-dideoxy-1-thio- $\beta$-D-glucopyra- noside 25}

Amine 13 was dissolved in anhydrous DM F ( $2 \mathrm{ml})$ and treated with 3-methoxybenzaldehyde ( $29.0 \mu \mathrm{L}, 0.24 \mathrm{mmol}, 2.4 \mathrm{eq})$ and $\mathrm{Et}_{3} \mathrm{~N}$ ( $\left.28 \mu \mathrm{L}, 0.2 \mathrm{mmol}, 2 \mathrm{eq}\right)$. T he mixture was stirred for $12 \mathrm{~h}$ at $60^{\circ} \mathrm{C}$ and the reaction was monitored by tlc. When all starting product was consumed the mixture was cooled to rt, then $\mathrm{NaBH}_{3} \mathrm{CN}$ ( $12.6 \mathrm{mg}, 0.2 \mathrm{mmol}, 2 \mathrm{eq}$ ) and A CO H ( $11.4 \mu \mathrm{L}, 0.2 \mathrm{mmol}, 2 \mathrm{eq}$ ) were added. After $2 \mathrm{~h}$, the reaction mixture was concentrated under reduced pressure. The residue was first purified by flash chromatography $\left(\mathrm{CH}_{2} \mathrm{Cl}_{2} / \mathrm{MeOH} 8 / 2\right)$ then by reverse phase $\mathrm{C}$-18 flash chromatography using $\mathrm{aH}_{2} \mathrm{O} / \mathrm{M} \mathrm{eOH}$ gradient mixture to give derivative 25 as a white solid (26.6 mg, 37\%); $\mathrm{R}_{\mathrm{f}} 0.85$ $\left(\mathrm{CHCl}_{3} / \mathrm{MeOH} / \mathrm{H}_{2} \mathrm{O} / \mathrm{CH}_{3} \mathrm{COOH} 60 / 30 / 5 / 3\right) ;{ }^{1} \mathrm{H} \mathrm{NMR}(400$ $\left.\mathrm{MHz}, \mathrm{DMSO}-\mathrm{d}_{6}\right) \delta 7.93(\mathrm{~d}, \mathrm{~J}=7.8 \mathrm{~Hz}, 1 \mathrm{H}, \mathrm{N} \underline{\mathrm{HAC}}), 7.48-7.43(\mathrm{~m}$, $2 \mathrm{H}, \mathrm{C} \underline{\mathrm{H}} \mathrm{SPh}), 7.29-7.22$ ( $\mathrm{m}, 2 \mathrm{H}, \mathrm{C} \underline{\mathrm{H}} \mathrm{SPh}), 7.22-7.13(\mathrm{~m}, 3 \mathrm{H}, \mathrm{C} \underline{\mathrm{H}}$ $\mathrm{SPh}, 3 \mathrm{M} \mathrm{eOPh}), 6.90-6.84$ ( $\mathrm{m}, 4 \mathrm{H}, \mathrm{CH} 3 \mathrm{M} \mathrm{eO} \mathrm{Ph}), 6.79-6.73$ (m, $2 \mathrm{H}, \mathrm{C} \underline{\mathrm{H}} 3 \mathrm{M} \mathrm{eOPh}), 5.06(\mathrm{~d}, \mathrm{~J}=8.6 \mathrm{~Hz}, 1 \mathrm{H}, \mathrm{H} 1), 4.83(\mathrm{br} \mathrm{s}, 1 \mathrm{H}$, $\mathrm{OH}), 4.72(\mathrm{~s}, 1 \mathrm{H}, \mathrm{OH}), 4.63(\mathrm{~d}, \mathrm{~J}=7.6 \mathrm{~Hz}, 1 \mathrm{H}, \mathrm{O} \underline{\mathrm{H}}), 4.54-4.51(\mathrm{br}$ $\mathrm{s}, 2 \mathrm{H}, 2 \times 0 \underline{\mathrm{H}}), 4.18\left(\mathrm{~d}, \mathrm{~J}=6.4 \mathrm{~Hz}, 1 \mathrm{H}, \mathrm{H} 1^{\prime}\right), 3.69\left(\mathrm{~s}, 6 \mathrm{H}, 2 \times \mathrm{C}_{3}\right.$ $3 \mathrm{M} \mathrm{eO} \mathrm{Ph}), 3.66-3.58\left(\mathrm{~m}, 6 \mathrm{H}, \mathrm{N}\left(\mathrm{C}_{2}\right)_{2}, \mathrm{H} 2, \mathrm{H} 3, \mathrm{H} 5, \mathrm{H} 4{ }^{\prime}\right), 3.53$ 3.41 ( $\mathrm{m}, 5 \mathrm{H}, \mathrm{N}\left(\mathrm{C}_{2}\right)_{2}$, H6' a, H6'b, H5'), 3.39-3.26 (m, 2H, H2', H3'), 3.16-3.08 ( $m, 1 \mathrm{H}, \mathrm{H} 4), 2.91(\mathrm{~d}, \mathrm{~J}=13.8 \mathrm{~Hz}, 1 \mathrm{H}, \mathrm{H}$ 6a) , 2.58 $(\mathrm{dd}, \mathrm{J}=8.1,14.1 \mathrm{~Hz}, \mathrm{H} 6 \mathrm{~b}, 1 \mathrm{H}), 1.84\left(\mathrm{~s}, 3 \mathrm{H} \mathrm{COC} \underline{\mathrm{H}}_{3}\right) ;{ }^{13} \mathrm{C}\left\{{ }^{1} \mathrm{H}\right\}$

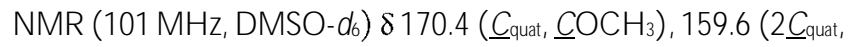

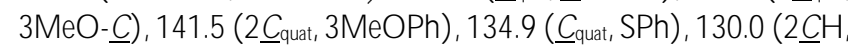
$\mathrm{SPh}), 129.5$ ( $2 \underline{\mathrm{CH}}, 3 \mathrm{M} \mathrm{eOPh}), 129.4$ (2다, $\mathrm{SPh}), 127.0$ ( $\underline{\mathrm{CH}}, \mathrm{SPh})$, 121.0 (2다 , 3M eO Ph), 114.1 ( $2 \underline{\mathrm{CH}}, 3 \mathrm{M} \mathrm{eO} \mathrm{Ph}), 112.7$ ( $2 \underline{\mathrm{CH}}, 3 \mathrm{M} \mathrm{e}-$ OPh), 104.2 (C1'), 85.7 (C1), 85.4 (C3), 78.8 (C5), 76.2 (C5'), 73.5 (C3'), 71.0 (C2'), 71.0 (C4), 68.7 (C4'), 61.0 (C6'), 58.1 $\left(2 \mathrm{CH}_{2}, \mathrm{~N}\left(\underline{\mathrm{CH}}_{2}\right)_{2}\right), 55.3\left(2 \underline{\mathrm{CH}}_{3}, 3 \mathrm{M} \mathrm{eOPh}\right), 55.1$ (C2) , 40.7 (C6), $23.5\left(\mathrm{COCH}_{3}\right)$; HRMS (ESI-TOF) m/ $\mathrm{z}:[\mathrm{M}+\mathrm{Na}]^{+} \mathrm{Calcd}$ for $\mathrm{C}_{36} \mathrm{H}_{47} \mathrm{~N}_{2} \mathrm{O}_{11} \mathrm{SN}$ a 715.2901; Found 715.2868.

\section{Phenyl $\quad \beta$-D-galactopyranosyl- $(1 \rightarrow 3)$-2-acetylamino-2,6- dideoxy-6-[4-(3-methoxyphenyl)-1H-1,2,3-triazol-1-yl]-1- thio- $\beta$-D-glucopyranoside 26}

To a solution of azide 11 ( $20 \mathrm{mg}, 0.04 \mathrm{mmol}$ ) in $\mathrm{H}_{2} \mathrm{O} /{ }^{\mathrm{t}} \mathrm{BuOH}$ (1/ $12 \mathrm{~mL}$ ) were added 3-methoxyphenylacetylene ( $11.4 \mu \mathrm{L}, 0.08$ mmol, 2 eq.) , o-phenylenediamine ( $16 \mu \mathrm{L}$ of a $375 \mathrm{mM}$ solution in $\mathrm{H}_{2} \mathrm{O}, 6 \mu \mathrm{mol}, 0.15 \mathrm{eq}$ ), sodium ascorbate ( $16 \mu \mathrm{L}$ of a $250 \mathrm{mM}$ solution in $\mathrm{H}_{2} \mathrm{O}, 4 \mu \mathrm{mol}, 0.1 \mathrm{eq}$ ) and copper sulfate pentahydrate ( $16 \mu \mathrm{L}$ of a $125 \mathrm{mM}$ solution in $\left.\mathrm{H}_{2} \mathrm{O}, 2.0 \mu \mathrm{mol}, 0.05 \mathrm{eq}\right)$. The reaction mixture was stirred at rt under an argon atmosphere for $12 \mathrm{~h}$, by which time TLC (Cyclohexane/ EtOAC 9/1) showed complete conversion. Then activated charcoal was added to the reaction mixture, which was stirred for $16 \mathrm{~h}$. The reaction mixture was then filtered through a Celite® plug, eluted with water, and the solvent evaporated. The residue was purified by flash chromatography $\left(\mathrm{CH}_{2} \mathrm{Cl}_{2} / \mathrm{MeOH} \mathrm{1/0} \mathrm{to} \mathrm{5/5)} \mathrm{to} \mathrm{give} \mathrm{derivative} 26\right.$ as a white solid (6.7 mg, 23\%); $\mathrm{R}_{\mathrm{f}} 0.52\left(\mathrm{CH}_{2} \mathrm{Cl}_{2} / \mathrm{MeOH} 85 / 15\right) ;{ }^{1} \mathrm{H} \mathrm{NMR}(400$ $\left.\mathrm{MHz}, \mathrm{DMSO}-\mathrm{d}_{6}\right) \delta 8.51(\mathrm{~s}, 1 \mathrm{H}, \mathrm{C}=\mathrm{C} \underline{\mathrm{H}}$ triazol), $7.95(\mathrm{~d}, \mathrm{~J}=8.0 \mathrm{~Hz}$, $1 \mathrm{H}, \mathrm{N} \underline{\mathrm{H}}(3 \mathrm{M} \mathrm{eO} \mathrm{Bz})), 7.44-7.34$ ( $\mathrm{m}, 3 \mathrm{H}, \mathrm{C} \underline{\mathrm{H}} 3 \mathrm{M} \mathrm{eO} \mathrm{Bz}), 7.05-7.00$ ( $\mathrm{m}, 2 \mathrm{H}, \mathrm{C} \underline{\mathrm{H}} \mathrm{SPh}), 6.99-6.90(\mathrm{~m}, 4 \mathrm{H}, \mathrm{C} \underline{\mathrm{H}} 3 \mathrm{M} \mathrm{eOBz}, 3 \mathrm{CH} \mathrm{SPh})$, 5.13 (br s, $1 \mathrm{H}, 0 \underline{\mathrm{H}}), 4.894 .77(\mathrm{~m}, 3 \mathrm{H}, \mathrm{H} \mathrm{1}, \mathrm{H} 6 \mathrm{a}, \mathrm{OH}), 4.71$ (t, J = $5.0 \mathrm{~Hz}, 1 \mathrm{H}, \mathrm{O} \underline{\mathrm{H}}), 4.58-4.52(\mathrm{~m}, 3 \mathrm{H}, \mathrm{H} 6 \mathrm{~b}, 2 \mathrm{OH}), 4.21(\mathrm{~d}, \mathrm{~J}=5.9$ $\left.\mathrm{Hz}, 1 \mathrm{H}, \mathrm{H} 1^{\prime}\right), 3.89-3.82(\mathrm{~m}, 1 \mathrm{H}, \mathrm{H} 5), 3.81$ ( $\left.\mathrm{s}, 3 \mathrm{H}, \mathrm{CH}_{3} 3 \mathrm{M} \mathrm{eO} \mathrm{Bz}\right)$, $3.74-3.64(\mathrm{~m}, 2 \mathrm{H}, \mathrm{H} 2, \mathrm{H} 3), 3.62\left(\mathrm{~d}, \mathrm{~J}=3.7 \mathrm{~Hz}, 1 \mathrm{H}, \mathrm{H} 4^{\prime}\right), 3.58-3.51$ (m, 2H, H6a', H6b'), 3.51-3.46 (m, 1H, H5) , 3.40-3.29 (m, 3H, $\mathrm{H} 2$ ', H3', H4), 1.82 (s, 3H, $\left.\mathrm{COC}_{3} 3\right) . ;{ }^{13} \mathrm{C}\left\{{ }^{1} \mathrm{H}\right\} \mathrm{NMR}(101 \mathrm{M} \mathrm{Hz}$, DMSO $\left.-\mathrm{d}_{6}\right) \delta 170.4\left(\underline{\mathrm{C}}_{\text {quat }}, \underline{\mathrm{COCH}}_{3}\right), 160.1$ ( $\underline{\mathrm{C}}_{\text {quat, }} 3 \mathrm{M} \mathrm{eO}-\underline{\mathrm{C}}$ ) , 146.6 ( $\underline{\mathrm{C}}=\mathrm{CH}$ triazol) , 134.6 ( $\left.\underline{\mathrm{C}}_{\text {quat, }} 3 \mathrm{M} \mathrm{eO} \mathrm{Bz}\right), 132.6$ ( $\left.\underline{\mathrm{C}}_{\text {quat }}, \mathrm{SPh}\right), 130.5$

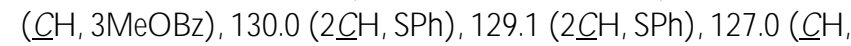
$\mathrm{SPh}), 123.0(\mathrm{C}=\underline{\mathrm{C}} \mathrm{H}$ triazol) , $118.0(\underline{\mathrm{CH}}, 3 \mathrm{M} \mathrm{eOBz}), 114.0(\underline{\mathrm{CH}}$, 3M eO Bz), 110.9 ( $\underline{\mathrm{CH}}, 3 \mathrm{M} \mathrm{eO} \mathrm{Bz}), 104.5$ ( C1'), 86.1 (C1), 85.1 (C3), 78.2 (C5), 76.3 (C5), 73.5 (C3'), 71.0 and 70.6 (C2' and C4) , 68.7 (C4'), 61.1 (C6) $, 55.6\left(\underline{\mathrm{CH}}_{3}, 3 \mathrm{M} \mathrm{eO} \mathrm{Bz}\right), 53.2$ (C2) , 51.6 (C6), 23.5 ( $\left.\mathrm{COCH}_{3}\right) ; \mathrm{HRMS}(\mathrm{ESI}-\mathrm{TOF}) \mathrm{m} / \mathrm{z}:[\mathrm{M}+\mathrm{Na}]^{+} \mathrm{Calcd}$ for $\mathrm{C}_{29} \mathrm{H}_{36} \mathrm{~N}_{4} \mathrm{O}_{10} \mathrm{SN}$ a 655.2050; Found 655.2053.

\section{General procedure for the reduction of azide derivative 12}

To a solution of disaccharide $\mathbf{1 2}$ ( $30 \mathrm{mg}, 0.065 \mathrm{mmol}, 1 \mathrm{eq}$ ) in TH F ( $3 \mathrm{ml}$ ), under an atmosphere of argon, PM $\mathrm{e}_{3} 1 \mathrm{M}$ in TH F ( 130 $\mu \mathrm{L}, 0.13 \mathrm{mmol}, 2 \mathrm{eq})$ was added. The reaction was stirred at rt and monitored by $\mathrm{TLC} \quad\left(\mathrm{CHCl}_{3} / \mathrm{MeOH} / \mathrm{H}_{2} \mathrm{O} / \mathrm{CH}_{3} \mathrm{COOH}\right.$ $60 / 30 / 5 / 3)$. After completion, $\mathrm{H}_{2} \mathrm{O}(60 \mu \mathrm{L})$ was added and the mixture was heated to $60^{\circ} \mathrm{C}$ in an oil bath for $16 \mathrm{~h}$. T hen solvent was removed under reduced pressure to give crude phenyl $\beta$-D-galactopyranosyl-( $1 \rightarrow 3$ )-6-amino-6-deoxy-1-thio- $\beta$-D-glucopyranoside $\mathbf{2 8}$ used without further purification; $\mathrm{R}_{\mathrm{f}} \quad 0.60$ ( $\mathrm{CHCl}_{3} / \mathrm{MeOH} / \mathrm{H}_{2} \mathrm{O} / \mathrm{CH}_{3} \mathrm{COOH} \mathrm{60/30/5/3).}$

\section{Phenyl $\beta$-D-galactopyranosyl-( $1 \rightarrow 3)$-6-deoxy-6-(3-methox- ybenzamido)-1-thio- $\beta$-D-glucopyranoside 29}

Amine 28 was dissolved in anhydrous DM F $(1.5 \mathrm{ml})$ at $0^{\circ} \mathrm{C}$ and treated with 3-methoxybenzoyl chloride ( $11 \mu \mathrm{L}, 0.08 \mathrm{mmol}, 1.2 \mathrm{eq}$ ) and $\mathrm{Et}_{3} \mathrm{~N}$ ( $11 \mu \mathrm{L}, 0.08 \mathrm{mmol}, 1.2 \mathrm{eq}$ ). The mixture was stirred $12 \mathrm{~h}$ and concentrated under reduced pressure. The residue was purified by flash chromatography $\left(\mathrm{CH}_{2} \mathrm{Cl}_{2} / \mathrm{MeOH} 9 / 1\right)$ then by reverse phase $\mathrm{C}$-18 flash chromatography using a $\mathrm{H}_{2} \mathrm{O} / \mathrm{M} \mathrm{eOH}$ gradient mixture to give derivative 29 as a white solid ( $21.2 \mathrm{mg}, 57 \%$ ); $\mathrm{R}_{\mathrm{f}} 0.42$ $\left(\mathrm{CH}_{2} \mathrm{Cl}_{2} / \mathrm{MeOH} \mathrm{9/1)} ;{ }^{1} \mathrm{H} \mathrm{NMR}(400 \mathrm{M} \mathrm{Hz}\right.$, DMSO-d $) \delta 8.51(\mathrm{t}, \mathrm{J}$ $=5.8 \mathrm{~Hz}, 1 \mathrm{H}, \mathrm{N} \underline{\mathrm{H}}(3 \mathrm{M} \mathrm{eO} \mathrm{Bz})), 7.51-7.35(\mathrm{~m}, 5 \mathrm{H}, 3 \mathrm{C} \underline{\mathrm{H}} 3 \mathrm{M} \mathrm{eO} \mathrm{Bz}, 2$ Cㅂ SPh) , 7.16-7.11 ( $\mathrm{m}, 1 \mathrm{H}, \mathrm{CH} 3 \mathrm{M} \mathrm{eOBz}), 7.08(\mathrm{~m}, 1 \mathrm{H}, \mathrm{CH} \mathrm{SPh})$, $7.00-6.93(\mathrm{~m}, 2 \mathrm{H}, \mathrm{C} \underline{\mathrm{H}} \mathrm{SPh}), 5.49(\mathrm{~d}, \mathrm{~J}=4.6 \mathrm{~Hz}, 1 \mathrm{H}, 0 \underline{\mathrm{H}}), 5.01$ (d, $\mathrm{J}=3.3 \mathrm{~Hz}, 1 \mathrm{H}, \mathrm{O} \underline{\mathrm{H}}), 4.97(\mathrm{~d}, \mathrm{~J}=2.5 \mathrm{~Hz}, 1 \mathrm{H}, \mathrm{O} \underline{\mathrm{H}}), 4.83(\mathrm{~d}, \mathrm{~J}=5.5$ $\mathrm{Hz}, 1 \mathrm{H}, \mathrm{O} \underline{\mathrm{H}}), 4.72-4.68(\mathrm{~m}, 1 \mathrm{H}, \mathrm{O} \underline{\mathrm{H}}), 4.68(\mathrm{~d}, \mathrm{~J}=9.6 \mathrm{~Hz}, 1 \mathrm{H}, \mathrm{H} 1)$, $\left.4.53(\mathrm{~d}, \mathrm{~J}=4.5 \mathrm{~Hz}, 1 \mathrm{H}, \mathrm{O} \underline{\mathrm{H}}), 4.31(\mathrm{~d}, \mathrm{~J}=7.5 \mathrm{~Hz}, 1 \mathrm{H}, \mathrm{Hl})^{\prime}\right), 3.87$ 3.80 ( $\mathrm{m}, 1 \mathrm{H}, \mathrm{H} 6 \mathrm{a}), 3.80$ ( $\left.\mathrm{s}, 3 \mathrm{H}, \mathrm{C}_{3} 3 \mathrm{M} \mathrm{eO} \mathrm{Bz}\right), 3.64-3.54(\mathrm{~m}, 2 \mathrm{H}$, H4', H5), 3.51 (m, 2H, H6a', H6b'), 3.50-3.38 (m, 3H, H3, H5', H2'), 3.38-3.29 (m, 2H, H3', H2), 3.28-3.15 ( $\mathrm{m}, 2 \mathrm{H}, \mathrm{H} 6 \mathrm{~b}, \mathrm{H} 4)$; 
${ }^{13} \mathrm{C}\left\{{ }^{1} \mathrm{H}\right\}$ N M R ( $101 \mathrm{M} \mathrm{H}$ z, D M SO $\left.-\mathrm{d}_{6}\right) \delta 166.3$ ( $\left.\underline{\mathrm{C}}_{\text {quat, }} \underline{\mathrm{C} O P h}\right), 159.6$ ( $\underline{C}_{\text {quat, }} 3 \mathrm{M} \mathrm{eO}-\underline{C}$ ), 136.2 ( $\underline{\mathrm{C}}_{\text {quat, }} 3 \mathrm{MP} \mathrm{eOBz}$ ), 134.9 ( $\underline{\mathrm{C}}_{\text {quat, }} \mathrm{SPh}$ ), 130.3 $(\underline{\mathrm{C}} \mathrm{H}, 3 \mathrm{M} \mathrm{eO} \mathrm{Bz}), 129.8(2 \underline{\mathrm{C}} \mathrm{H}, \mathrm{SPh}), 129.1(2 \underline{\mathrm{CH}}, \mathrm{SPh}), 126.9(\underline{\mathrm{CH}}$, $\mathrm{SPh}), 120.0(\underline{\mathrm{C}} \mathrm{H}, 3 \mathrm{M} \mathrm{eOBz}), 117.5(\underline{\mathrm{C}} \mathrm{H}, 3 \mathrm{M} \mathrm{eO} \mathrm{Bz}), 113.0(\underline{\mathrm{C}} \mathrm{H}$, $3 \mathrm{MeOBz}$ ), 104.6 (C1'), 89.2 (C3), 86.6 (C1), 78.0 (C5), 76.1 (C5'), $73.3\left(\mathrm{C}^{\prime}\right), 71.6$ and $71.5\left(\mathrm{C} 2\right.$ and $\left.\mathrm{C}^{\prime}\right), 71.1$ (C4), 68.5 (C4), 60.9 (C6'), 55.8 ( $\mathrm{CH}_{3}, 3 \mathrm{M} \mathrm{eO} \mathrm{Bz}$ ), 41.7 (C6); HRM S (ESITOF) $\mathrm{m} / \mathrm{z}:[\mathrm{M}+\mathrm{Na}]^{+} \mathrm{C}$ alcd for $\mathrm{C}_{26} \mathrm{H}_{33} \mathrm{~N} \mathrm{O}_{11} \mathrm{SN}$ a 590.1672; Found 590.1671.

\section{Phenyl $\beta$-D-galactopyranosyl-( $1 \rightarrow 3$ )-6-deoxy-6-(3-methoxy- phenylureido)-1-thio- $\beta$-D-glucopyranoside 30}

Amine 28 was dissolved in anhydrous D M F $(1.5 \mathrm{ml})$ at $0^{\circ} \mathrm{C}$ and treated with 3-methoxyphenyl isocyanate ( $10 \mu \mathrm{L}, 0.08 \mathrm{mmol}, 1.2$ eq) and $\mathrm{Et}_{3} \mathrm{~N}$ ( $10 \mu \mathrm{L}, 0.08 \mathrm{mmol}, 1.2 \mathrm{eq}$ ). The mixture was stirred 12 $\mathrm{h}$ and concentrated under reduced pressure. The residue was first purified by I phase flash chromatography $\left(\mathrm{CH}_{2} \mathrm{Cl}_{2} / \mathrm{MeOH} \mathrm{9/1)}\right.$ then by reverse phase $\mathrm{C}-18$ flash chromatography using a $\mathrm{H}_{2} \mathrm{O} / \mathrm{M} \mathrm{eOH}$ gradient mixture to give derivative 30 as a white solid ( $24.3 \mathrm{mg}, 65 \%) ; \mathrm{Rf}_{\mathrm{f}} 0.40\left(\mathrm{CH}_{2} \mathrm{Cl}_{2} / \mathrm{MeOH} 9 / 1\right) ;{ }^{1} \mathrm{H} \mathrm{NMR}(400 \mathrm{M} \mathrm{Hz}$, DMSO) $\delta 8.69(\mathrm{~s}, 1 \mathrm{H}, \mathrm{N} \underline{\mathrm{H}}(3 \mathrm{M} \mathrm{eO} \mathrm{Ph})), 7.53-7.44(\mathrm{~m}, 2 \mathrm{H}, \mathrm{C} \underline{\mathrm{H}}$ $\mathrm{SPh}), 7.32-7.07(\mathrm{~m}, 5 \mathrm{H}, 3 \mathrm{CH} \mathrm{SPh}, 2 \mathrm{CH} 3 \mathrm{M} \mathrm{eO} \mathrm{Ph}), 6.90-6.82(\mathrm{~m}$, $1 \mathrm{H}, \mathrm{C} \underline{H} 3 \mathrm{M} \mathrm{eO} \mathrm{Ph}), 6.52-6.44(\mathrm{~m}, 1 \mathrm{H}, \mathrm{C} \underline{H} 3 \mathrm{M} \mathrm{eO} \mathrm{Ph}), 6.22(\mathrm{t}, \mathrm{J}=$ $6.2 \mathrm{~Hz}, 1 \mathrm{H}, \mathrm{N} \underline{\mathrm{HCONH}}), 5.44(\mathrm{~d}, \mathrm{~J}=4.5 \mathrm{~Hz}, 1 \mathrm{H}, \mathrm{OH}), 4.98(\mathrm{~d}, \mathrm{~J}=$ $3.3 \mathrm{~Hz}, 1 \mathrm{H}), 4.91(\mathrm{br} \mathrm{s}, 1 \mathrm{H}, \mathrm{OH}), 4.82(\mathrm{~d}, \mathrm{~J}=5.3 \mathrm{~Hz}, 1 \mathrm{H}, \mathrm{O} \underline{\mathrm{H}}), 4.74$ $(\mathrm{d}, J=9.7 \mathrm{~Hz}, 1 \mathrm{H}, \mathrm{H} 1), 4.69(\mathrm{t}, \mathrm{J}=5.3 \mathrm{~Hz}, 1 \mathrm{H}, \mathrm{OH}), 4.50(\mathrm{~d}, \mathrm{~J}=4.6$ $\mathrm{Hz}, 1 \mathrm{H}, \mathrm{OH}), 4.28\left(\mathrm{~d}, \mathrm{~J}=7.4 \mathrm{~Hz}, 1 \mathrm{H}, \mathrm{H} 1^{\prime}\right), 3.71\left(\mathrm{~s}, 3 \mathrm{H}, \mathrm{CH}_{3} 3 \mathrm{M} \mathrm{e}-\right.$ OPh), 3.69-3.57 (m, 2H, H4', H6a), 3.52-3.50 (m, 2H, H6a', H6b'), 3.49-3.39 (m, 4H, H5', H3, H5, H2'), 3.39-3.25 ( $\mathrm{m}, 2 \mathrm{H}$, $\left.\mathrm{H} 3^{\prime}, \mathrm{H2}\right), 3.21-3.06(\mathrm{~m}, 2 \mathrm{H}, \mathrm{H} 4, \mathrm{H} 6 \mathrm{~b}) ;{ }^{13} \mathrm{C}\left\{{ }^{1} \mathrm{H}\right\}$ N M R ( $101 \mathrm{MHz}$,

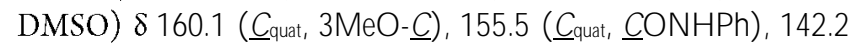
( $\underline{\mathrm{C}}_{\text {quat, }} 3 \mathrm{M}$ eO Ph), 134.4 ( $\left.\underline{\mathrm{C}}_{\text {quat, }} \mathrm{SPh}\right), 130.9(2 \mathrm{CH}, \mathrm{SPh}), 129.9$ ( $\mathrm{CH}$,

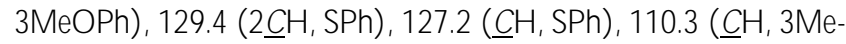
OPh), $106.9(\underline{\mathrm{CH}}, 3 \mathrm{M} \mathrm{eOPh}), 105.1\left(\mathrm{C} 1^{\prime}\right), 103.7(\underline{\mathrm{CH}}, 3 \mathrm{M} \mathrm{eO} \mathrm{Ph})$, 89.2 (C 3), 86.5 (C 1), 78.6 (C5), 76.1 (C5'), 73.3 (C3'), 71.5 and $71.3\left(\mathrm{C} 2\right.$ and $\left.\mathrm{C}^{\prime}\right), 70.3(\mathrm{C} 4), 68.6\left(\mathrm{C}^{\prime}\right), 61.0\left(\mathrm{C}^{\prime}\right), 55.3\left(\mathrm{CH}_{3}\right.$, $3 \mathrm{M} \mathrm{eO} \mathrm{Ph}$ ), 40.9 (C6);H RM S (ESI-T OF) $\mathrm{m} / \mathrm{z}:[\mathrm{M}+\mathrm{Na}]^{+} \mathrm{C}$ alcd for $\mathrm{C}_{26} \mathrm{H}_{34} \mathrm{~N}_{2} \mathrm{O}_{11} \mathrm{SN}$ a $605.1781 ;$ Found 605.1785.

\section{Phenyl $\beta$-D-galactopyranosyl-( $1 \rightarrow 3)$-6-deoxy-6-N-(3-meth- oxybenzyl)-1-thio- $\beta$-D-glucopyranoside 31}

Amine $\mathbf{2 8}$ was dissolved in anhydrous D M F ( $1.5 \mathrm{ml})$ and treated with 3-methoxybenzaldehyde ( $9.6 \mu \mathrm{L}, 0.08 \mathrm{mmol}, 1.2 \mathrm{eq}$ ) $\mathrm{Et}_{3} \mathrm{~N}$ (11 $\mu \mathrm{L}, 0.08 \mathrm{mmol}, 1.2 \mathrm{eq}$ ). The mixture was stirred $12 \mathrm{~h}$ at $60^{\circ} \mathrm{C}$ and the reaction was followed by tlc. When all starting product was consumed, the mixture was cooled to rt and $\mathrm{NaBH}_{4}(5.9 \mathrm{mg}, 0.16 \mathrm{mmol}$, $2.4 \mathrm{eq}$ ) was added. After $2 \mathrm{~h}$, the reaction mixture was concentrated under reduced pressure. The residue was first purified by flash chromatography $\left(\mathrm{CH}_{2} \mathrm{Cl}_{2} / \mathrm{M} \mathrm{eO} \mathrm{H} \mathrm{9/1)}\right.$ then by reverse phase $\mathrm{C}$ - 18 flash chromatography using a $\mathrm{H}_{2} \mathrm{O} / \mathrm{M} \mathrm{eOH}$ gradient mixture to give derivative 31 as a white solid (22.1 $\mathrm{mg}, 61 \%) ; \mathrm{R}_{\mathrm{f}} 0.75$ $\left(\mathrm{CHCl}_{3} / \mathrm{MeOH} / \mathrm{H}_{2} \mathrm{O} / \mathrm{CH}_{3} \mathrm{COOH} 60 / 30 / 5 / 3\right) ;{ }^{1} \mathrm{H} \mathrm{NMR}(400$ $\left.\mathrm{MHz}, \mathrm{CD}_{3} \mathrm{OD}\right) \delta 7.56-7.50$ (m, 2H, CH SPh), 7.29-7.22 (m, 4H, $\mathrm{CH} \mathrm{SPh}, 3 \mathrm{M} \mathrm{eO} \mathrm{Ph}), 6.92-6.84(\mathrm{~m}, 1 \mathrm{H}, 3 \mathrm{H}, \mathrm{CH} 3 \mathrm{M} \mathrm{eO} \mathrm{Ph}), 4.67$ (d, $\left.J=9.8 \mathrm{~Hz}, 1 \mathrm{H}, \mathrm{H} 1), 4.53(\mathrm{~d}, \mathrm{~J}=7.6 \mathrm{~Hz}, 1 \mathrm{H}, \mathrm{H1})^{\prime}\right), 3.86-3.73(\mathrm{~m}, 7 \mathrm{H}$, H6a', $\mathrm{H}_{4}{ }^{\prime} \mathrm{CH}_{3} 3 \mathrm{M} \mathrm{eO} \mathrm{Ph}, \mathrm{N} \mathrm{HCH}_{2}$ ) , 3.69 (dd, J = 4.5, $11.4 \mathrm{~Hz}, 1 \mathrm{H}$, H6b'), 3.65-3.54 (m, 3H, H2', H5', H3), 3.5-3.45 (m, 2H, H3', $\mathrm{H} 5), 3.43(\mathrm{dd}, J=8.5,9.9 \mathrm{~Hz}, 1 \mathrm{H}, \mathrm{H} 2), 3.26(\mathrm{t}, J=9.2 \mathrm{~Hz}, 1 \mathrm{H}, \mathrm{H} 4)$, $3.11(\mathrm{dd}, \mathrm{J}=2.0,12.9 \mathrm{~Hz}, 1 \mathrm{H}, \mathrm{H} \mathrm{6a}), 2.78(\mathrm{dd}, \mathrm{J}=8.6,12.7 \mathrm{~Hz}, 1 \mathrm{H}$,
H 6b) $;{ }^{13} \mathrm{C}\left\{{ }^{1} \mathrm{H}\right\}$ N M R (101 M Hz, CD $\left.3 \mathrm{OD}\right) \delta, 160.0$ ( $\underline{\mathrm{C}}_{\text {quat, }} 3 \mathrm{M} \mathrm{eO}$ $\underline{\mathrm{C}}$ ), 139.3 ( $\left.\underline{\mathrm{C}}_{\text {quat, }} 3 \mathrm{M} \mathrm{eO} \mathrm{Ph}\right), 132.6$ (2다, $\left.\mathrm{SPh}\right), 132.5$ ( $\underline{\mathrm{C}}_{\text {quat, }} \mathrm{SPh}$ ), 129.3 ( $\underline{\mathrm{CH}}, 3 \mathrm{M} \mathrm{eOPh}), 128.6(2 \underline{\mathrm{CH}}, \mathrm{SPh}), 127.5(\underline{\mathrm{C}} \mathrm{H}, \mathrm{SPh}), 120.5$ ( $\underline{\mathrm{CH}}, 3 \mathrm{M} \mathrm{eO} \mathrm{Ph}), 113.8(\underline{\mathrm{CH}}, 3 \mathrm{M} \mathrm{eO} \mathrm{Ph}), 112.7(\underline{\mathrm{CH}}, 3 \mathrm{M} \mathrm{eOPh})$, 104.2 (C1'), 87.3 (C3), 86.9 (C1), 77.6 (C5), 75.7 (C5), 73.3 (C3'), 71.6 and $71.6\left(\mathrm{C} 2\right.$ and $\left.\mathrm{C}^{\prime}\right), 70.6(\mathrm{C} 4), 68.9\left(\mathrm{C}^{\prime}\right), 61.2$ (C6), $54.3\left(\mathrm{CH}_{3}, 3 \mathrm{M} \mathrm{eO} \mathrm{Ph}\right), 53.4(\mathrm{C} 2), 52.3\left(\mathrm{CH}_{2}, \mathrm{~N} \mathrm{HCH}_{2}\right), 49.6$ (C6); HRM S (ESI-TOF) m/ z: [M + H ] ${ }^{+} \mathrm{Calcd}$ for $\mathrm{C}_{26} \mathrm{H}_{36} \mathrm{~N} \mathrm{O}_{10} \mathrm{~S}$ 554.2060; Found 554.2068.

Phenyl $\beta$-D-galactopyranosyl-( $1 \rightarrow 3$ )-6-deoxy-6-(3-methoxyphenylsulfonamido)-1-thio- $\beta$-D-glucopyranoside 32

Amine 28 was dissolved in anhydrous D M F $(1.5 \mathrm{ml})$ at $0^{\circ} \mathrm{C}$ and treated with 3-methoxyphenylsulfonyl chloride ( $12 \mu \mathrm{L}, 0.08 \mathrm{mmol}$, $1.2 \mathrm{eq})$ and $\mathrm{Et}_{3} \mathrm{~N}(12 \mu \mathrm{L}, 0.08 \mathrm{mmol}, 1.2 \mathrm{eq})$. The mixture was stirred for $8 \mathrm{~h}$ at $r$ and concentrated under reduced pressure. The residue was purified by flash chromatography $\left(\mathrm{CH}_{2} \mathrm{Cl}_{2} / \mathrm{M} \mathrm{eO} \mathrm{H} 88 / 12\right)$ then by reverse phase $\mathrm{C}-18$ flash chromatography using a $\mathrm{H}_{2} \mathrm{O} / \mathrm{M} \mathrm{eO} \mathrm{H}$ gradient mixture to give derivative 32 as a white solid $(27.8 \mathrm{mg}$, $70 \%) ; R_{f} 0.48\left(\mathrm{CH}_{2} \mathrm{Cl}_{2} / \mathrm{MeOH} 9 / 1\right) ;{ }^{1} \mathrm{H} N M R(400 \mathrm{MHz}$,

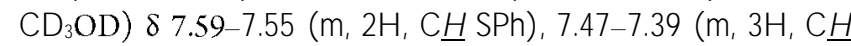
3M eO Ph), 7.37-7.29 (m, 3H, C $\underline{H ~ S P h), ~} 7.17$ (dt, J = 2.4, 7.2 Hz, $1 \mathrm{H}, \mathrm{CH} 3 \mathrm{M} \mathrm{eO} \mathrm{Ph}), 4.51\left(\mathrm{~d}, \mathrm{~J}=7.5 \mathrm{~Hz}, 1 \mathrm{H}, \mathrm{H} 1^{\prime}\right), 4.48(\mathrm{~d}, \mathrm{~J}=9.89$ $\mathrm{Hz}, 1 \mathrm{H}, \mathrm{H} 1), 3.86\left(\mathrm{~s}, 3 \mathrm{H}, \mathrm{C}_{3} 3 \mathrm{M} \mathrm{eO} \mathrm{Ph}\right), 3.80(\mathrm{dd}, \mathrm{J}=1.0,3.4 \mathrm{~Hz}$, $\left.1 \mathrm{H}, \mathrm{H} 4^{\prime}\right), 3.77\left(\mathrm{dd}, \mathrm{J}=7.2,10.9 \mathrm{~Hz}, 1 \mathrm{H}, \mathrm{H6a} \mathrm{a}^{\prime}\right), 3.69(\mathrm{dd}, \mathrm{J}=4.4$, $11.5 \mathrm{~Hz}, 1 \mathrm{H}, \mathrm{H} 6 \mathrm{~b}$ '), 3.61-3.47 (m, 4H, H2', H5', H3, H3'), 3.42 (dd, $\mathrm{J}=2.6,13.8 \mathrm{~Hz}, 1 \mathrm{H}, \mathrm{H}$ 6a) $, 3.38-3.29(\mathrm{~m}, 2 \mathrm{H}, \mathrm{H} 2, \mathrm{H} 5), 3.21(\mathrm{dd}, \mathrm{J}$ $=8.6,9.7 \mathrm{~Hz}, 1 \mathrm{H}, \mathrm{H} 4), 2.99(\mathrm{dd}, \mathrm{J}=7.7,13.8 \mathrm{~Hz}, 1 \mathrm{H}, \mathrm{H} 6 \mathrm{~b}) ;{ }^{13} \mathrm{C}\left\{{ }^{1} \mathrm{H}\right\}$ NMR ( $\left.101 \mathrm{M} \mathrm{Hz}, \mathrm{CD}_{3} \mathrm{OD}\right) \delta 160.1$ ( $\underline{\mathrm{C}}_{\text {quat }}, 3 \mathrm{M} \mathrm{eO}-\underline{\mathrm{C}}$ ), 141.8 ( $\underline{\mathrm{C}}_{\text {quat, }}$ 3M eO Ph), 132.9 ( $\left.\underline{\mathrm{C}}_{\text {quat }}, \mathrm{SPh}\right), 132.1$ (2 $\mathrm{CH}, \mathrm{SPh}$ ), 130.0 ( $\mathrm{CH}, 3 \mathrm{M} \mathrm{e}-$ OPh), $128.6(2 \underline{\mathrm{CH}}, \mathrm{SPh}), 127.3(\underline{\mathrm{C}} \mathrm{H}, \mathrm{SPh}), 118.7$ ( $\underline{\mathrm{CH}}, 3 \mathrm{M} \mathrm{eO} \mathrm{Ph})$, 118.2 ( $\underline{\mathrm{CH}}, 3 \mathrm{M} \mathrm{eO} \mathrm{Ph}), 111.5$ ( $\mathrm{CH}, 3 \mathrm{M} \mathrm{eO} \mathrm{Ph}), 104.2$ (C1'), 87.3 (C3), 87.1 (C1), 78.2 (C5), 75.7 (C5'), 73.3 (C3'), 71.6 and 71.3 (C2 and $\left.\mathrm{C}^{\prime}\right), 70.0(\mathrm{C} 4), 68.9\left(\mathrm{C}^{\prime}\right), 61.2\left(\mathrm{C}^{\prime}\right), 54.8\left(\mathrm{CH}_{3}, 3 \mathrm{M} \mathrm{e}-\right.$ OPh), 44.2 ( C6); HRMS (ESI-TOF) m/ z: [M $+\mathrm{Na}]^{+} \mathrm{Calcd}$ for $\mathrm{C}_{25} \mathrm{H}_{33} \mathrm{~N}_{12} \mathrm{~S}_{2} 626.1342$; Found 626.1337 .

\section{Phenyl $\beta$-D-galactopyranosyl-( $1 \rightarrow 3)$-6-deoxy-6-[(4-phe- noxy) phenylsulfonamido]-1-thio- $\beta$-D-glucopyranoside 33}

Amine 28 was dissolved in anhydrous DM F $(5 \mathrm{ml})$ at $0^{\circ} \mathrm{C}$ and treated with 4-phenoxyphenylsulfonyl chloride ( $35 \mathrm{mg}, 0.13 \mathrm{mmol}$, $1.2 \mathrm{eq})$ and $\mathrm{Et}_{3} \mathrm{~N}(18 \mu \mathrm{L}, 0.13 \mathrm{mmol}, 1.2 \mathrm{eq})$. The mixture was stirred for $8 \mathrm{~h}$ at rt and concentrated under reduced pressure. The residue was purified by flash chromatography $\left(\mathrm{CH}_{2} \mathrm{Cl}_{2} / \mathrm{M} \mathrm{eOH} \mathrm{93/7)} \mathrm{then}\right.$ by reverse phase $\mathrm{C}$-18 flash chromatography using a $\mathrm{H}_{2} \mathrm{O} / \mathrm{M} \mathrm{eO} \mathrm{H}$ gradient mixture to give derivative $\mathbf{3} 3$ as a white solid $(38.9 \mathrm{mg}$, 54\%); Rf $0.31\left(\mathrm{CH}_{2} \mathrm{Cl}_{2} / \mathrm{MeOH}\right.$ 9/1); ${ }^{1} \mathrm{H} N M R(400 \mathrm{MHz}$, $\left.\mathrm{CD}_{3} \mathrm{OD}\right)$ 8 7.83-7.77 ( $\mathrm{m}, 2 \mathrm{H}, \mathrm{CH}$ PhenoxyPh), 7.58-7.56 (m, 2H, C $\underline{H}$ SPh), 7.47-7.42 (m, 2H, C프 PhenoxyPh), 7.35-7.27 (m, 3H, C $\underline{H}$ SPh), 7.27-7.22 (m, 1H, Cㅍ PhenoxyPh), 7.12-7.07 (m, 2H, $\mathrm{C} \underline{\mathrm{H}}$ PhenoxyPh), 7.03-6.98 ( $\mathrm{m}, 2 \mathrm{H}, \mathrm{C} \underline{\mathrm{H}}$ PhenoxyPh), $4.51(\mathrm{~d}, \mathrm{~J}=$ $\left.7.6 \mathrm{~Hz}, 1 \mathrm{H}, \mathrm{H} \mathrm{l}^{\prime}\right), 4.47(\mathrm{~d}, \mathrm{~J}=9.8 \mathrm{~Hz}, 1 \mathrm{H}, \mathrm{H} 1), 3.81-3.76(\mathrm{~m}, 2 \mathrm{H}$, $\left.\mathrm{H} 4^{\prime}, \mathrm{H} 6 \mathrm{a}^{\prime}\right), 3.70\left(\mathrm{dd}, \mathrm{J}=4.4,11.5 \mathrm{~Hz}, 1 \mathrm{H}, \mathrm{H} 6 \mathrm{~b}^{\prime}\right), 3.61-3.55(\mathrm{~m}, 2 \mathrm{H}$, $\mathrm{H} 2^{\prime}, \mathrm{H}^{\prime}$ ), 3.55-3.49 (m, 2H, H3, H3'), 3.45 (dd, J = 2.5, $13.9 \mathrm{~Hz}$, $1 \mathrm{H}, \mathrm{H} 6 \mathrm{a}), 3.37(\mathrm{dd}, \mathrm{J}=8.6,9.8 \mathrm{~Hz}, 1 \mathrm{H}, \mathrm{H} 2), 3.32-3.25(\mathrm{~m}, 1 \mathrm{H}$, H 5), $3.23(\mathrm{dd}, J=8.3,9.7 \mathrm{~Hz}, 1 \mathrm{H}, \mathrm{H}$ 4) , $3.02(\mathrm{dd}, \mathrm{J}=7.4,13.8 \mathrm{~Hz}$, $1 \mathrm{H}, \mathrm{H} 6 \mathrm{~b}) ;{ }^{13} \mathrm{C}\left\{{ }^{1 \mathrm{H}}\right\}$ N M R ( $\left.101 \mathrm{MHz}, \mathrm{CD}_{3} \mathrm{OD}\right) \delta 161.3$ and 155.4 (2C, 2ㅇquat, PhenoxyPh), 134.5 (1C, 1 $\underline{C}_{\text {quat, }}$ PhenoxyPh), 132.9 ( $\left.\underline{\mathrm{C}}_{\text {quat, }} \mathrm{SPh}\right), 132.3(2 \underline{\mathrm{CH}}, \mathrm{SPh}), 129.2(2 \underline{\mathrm{C}} \mathrm{H}, \mathrm{PhenoxyPh}), 128.9$ 


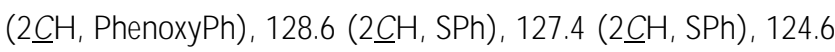
( $\underline{\mathrm{C}} \mathrm{H}, \mathrm{PhenoxyPh}), 119.9$ ( $2 \underline{\mathrm{C}} \mathrm{H}, \mathrm{PhenoxyPh}), 117.3$ (2 $\underline{\mathrm{C}} \mathrm{H}$, PhenoxyPh), 1074.2 (C1'), 87.4 (C3), 87.2 (C1), 78.0 (C5), 75.7 (C5'), 73.3 (C3'), 71.6 and 71.4 (C2' and C2), 70.0 (C4), $68.9\left(\mathrm{C}^{\prime}{ }^{\prime}\right), 61.2$ (C6), 44.2 (C6); HRM S (ESI-T OF) m/ $\mathrm{z}:[\mathrm{M}+\mathrm{Na}]^{+} \mathrm{Calcd}$ for $\mathrm{C}_{30} \mathrm{H}_{35} \mathrm{~N} \mathrm{O}_{12} \mathrm{~S}_{2} \mathrm{~N}$ a 688.1498; Found 688.1515.

Phenyl $\beta$-D-galactopyranosyl-(1-3)-6-deoxy-6-[4-(3-methoxyphenyl)-1H-1,2,3-triazol-1-yl]-1-thio- $\beta$-D-glucopyranoside 34

To a solution of azide $\mathbf{1 2}$ ( $30 \mathrm{mg}, 65 \mu \mathrm{mol}$ ) in DM F ( $5 \mathrm{~mL}$ ) were added 3-methoxyphenylacetylene ( $27.9 \mu \mathrm{L}, 0.20 \mathrm{mmol}, 3 \mathrm{eq}$.), copper iodide ( $1.24 \mathrm{mg}, 6.5 \mu \mathrm{mol}, 0.1 \mathrm{eq})$ and $\mathrm{Et}_{3} \mathrm{~N}(9.1 \mu \mathrm{L}, 65 \mu \mathrm{mol}, 1$ eq). The reaction mixture was stirred at rt under an argon atmosphere for $12 \mathrm{~h}$. After completion the mixture was concentrated under reduced pressure and purified by flash chromatography $\left(\mathrm{CH}_{2} \mathrm{Cl}_{2} / \mathrm{M} \mathrm{eOH} \mathrm{1/0}\right.$ to 9/1) to give derivative $\mathbf{3 4}$ as a white solid (13.9 mg, 36\%); Rf $0.31\left(\mathrm{CH}_{2} \mathrm{Cl}_{2} / \mathrm{MeOH}\right.$ 9/1); ${ }^{1} \mathrm{H} \mathrm{NMR}(400$ $\left.\mathrm{MHz}, \mathrm{CD}_{3} \mathrm{OD}\right) \delta 8.22(\mathrm{~s}, 1 \mathrm{H}, \mathrm{C}=\mathrm{C} \underline{\mathrm{H}}$ triazol), $7.40-7.32(\mathrm{~m}, 3 \mathrm{H}$, $\mathrm{CH} 3 \mathrm{M} \mathrm{eOBz}), 7.28-7.20(\mathrm{~m}, 2 \mathrm{H}, \mathrm{C} \underline{\mathrm{H}} \mathrm{SPh}), 7.05-6.97(\mathrm{~m}, 3 \mathrm{H}, \mathrm{C} \underline{\mathrm{H}}$ $\mathrm{SPh}), 6.97-6.93(\mathrm{~m}, 1 \mathrm{H}, \mathrm{CH} 3 \mathrm{M} \mathrm{eO} \mathrm{Bz}), 4.96(\mathrm{dd}, \mathrm{J}=2.4,14.4 \mathrm{~Hz}$, $1 \mathrm{H}, \mathrm{H} 6 \mathrm{a}), 4.64(\mathrm{~d}, \mathrm{~J}=9.9 \mathrm{~Hz}, 1 \mathrm{H}, \mathrm{H} \mathrm{1}), 4.62-4.54(\mathrm{~m}, 2 \mathrm{H}, \mathrm{H} 6 \mathrm{~b}$ and $\mathrm{H1}$ ), $3.87\left(\mathrm{~s}, 3 \mathrm{H}, \mathrm{CH}_{3} 3 \mathrm{M} \mathrm{eO} \mathrm{Bz}\right), 3.87-3.78(\mathrm{~m}, 3 \mathrm{H}, \mathrm{H6a}, \mathrm{H} 4$, H5), $3.74\left(d d, J=4.4,11.4 \mathrm{~Hz}, 1 \mathrm{H}, \mathrm{H} 6 \mathrm{~b}^{\prime}\right), 3.68(\mathrm{t}, \mathrm{J}=8.7 \mathrm{~Hz}, 1 \mathrm{H}$, H3), 3.65-3.60 (m, 2H, H2', H5'), 3.54 ( dd, J = 3.4, 9.7 Hz, $1 \mathrm{H}$, $\mathrm{H3}$ '), $3.44(\mathrm{dd}, \mathrm{J}=8.7,9.9 \mathrm{~Hz}, 1 \mathrm{H}, \mathrm{H} 2), 3.40-3.34(\mathrm{~m}, 1 \mathrm{H}, \mathrm{H} 4)$; ${ }^{13} \mathrm{C}\left\{{ }^{1} \mathrm{H}\right\}$ N M R ( $\left.101 \mathrm{M} \mathrm{H}, \mathrm{CD}_{3} \mathrm{OD}\right) \delta 160.2$ ( $\underline{\mathrm{C}}_{\text {quat }}, 3 \mathrm{M} \mathrm{eO}-\underline{\mathrm{C}}$ ), 147.2 $\left(\underline{\mathrm{C}}=\mathrm{CH}\right.$ triazol), 132.6 ( $\left.\underline{\mathrm{C}}_{\text {quat, }}, 3 \mathrm{M} \mathrm{eO} \mathrm{Bz}\right), 131.5$ ( $\left.\underline{\mathrm{C}}_{\text {quat }}, \mathrm{SPh}\right), 131.5$ (2마 , SPh), 129.7 ( $\underline{\mathrm{C}}, 3 \mathrm{M} \mathrm{eO} \mathrm{Bz}), 128.5(2 \underline{\mathrm{CH}}, \mathrm{SPh}), 127.1(\underline{\mathrm{C}} \mathrm{H}$, $\mathrm{SPh}), 122.4(\mathrm{C}=\underline{\mathrm{CH}}$ triazol) , $117.8(\mathrm{CH}, 3 \mathrm{M} \mathrm{eO} \mathrm{Bz}), 113.7(\underline{\mathrm{CH}}$, $3 \mathrm{M} \mathrm{eO} \mathrm{Bz}$ ), 110.7 ( $\underline{\mathrm{CH}}, 3 \mathrm{M} \mathrm{eO} \mathrm{Bz}$ ), 104.3 (C1'), 87.2 ( $\mathrm{C} 1$ and $\mathrm{C} 3$ ), $77.8(\mathrm{C} 5), 75.7\left(\mathrm{C}^{\prime}\right), 73.3\left(\mathrm{C}^{\prime}\right), 71.6$ and $71.5\left(\mathrm{C}^{\prime}\right.$ and $\left.\mathrm{C} 2\right), 69.9$ (C4), 68.9 (C4'), 61.2 (C6'), $54.5\left(\mathrm{CH}_{3}, 3 \mathrm{M} \mathrm{eOBz}\right), 51.4$ (C6); HRMS (ESI-TOF) m/z: [M + Na] ${ }^{+} \mathrm{Calcd}$ for $\mathrm{C}_{27} \mathrm{H}_{33} \mathrm{~N}_{3} \mathrm{O}{ }_{10} \mathrm{SNa}$ 614.1784; Found 614.1803.

Phenyl $\beta$-D-galactopyranosyl-(1 $\rightarrow 3)$-6-deoxy-6-(4-phenyl1H-1,2,3-triazol-1-yl)-1-thio- $\beta$-D-glucopyranoside 35

To a solution of azide $\mathbf{1 2}$ ( $30 \mathrm{mg}, 65 \mu \mathrm{mol}$ ) in DM F ( $1 \mathrm{~mL}$ ) were added phenylacetylene ( $28.0 \mu \mathrm{L}, 0.20 \mathrm{mmol}, 3$ eq.) , copper iodide ( $12.45 \mathrm{mg}, 65.4 \mu \mathrm{mol}, 1 \mathrm{eq})$ and $\mathrm{Et}_{3} \mathrm{~N}(10 \mu \mathrm{L}, 72 \mu \mathrm{mol}, 1.1 \mathrm{eq})$. The reaction mixture was stirred at rt under an argon atmosphere for 12 h. After completion the mixture was concentrated under reduced pressure and purified by flash chromatography $\left(\mathrm{CH}_{2} \mathrm{Cl}_{2} / \mathrm{M} \mathrm{eOH}\right.$ $1 / 0$ to $9 / 1$ ) then by reverse phase $C$ - 18 flash chromatography using $\mathrm{aH}_{2} \mathrm{O} / \mathrm{M} \mathrm{eO} \mathrm{H}$ gradient mixture to give derivative 35 as a white solid ( $30 \mathrm{mg}, 85 \%) ; \mathrm{R}_{\mathrm{f}} 0.18\left(\mathrm{CH}_{2} \mathrm{Cl}_{2} / \mathrm{M} \mathrm{eOH} \mathrm{9/1);}{ }^{1 \mathrm{H} \mathrm{NMR}}\right.$ ( $400 \mathrm{MHz}$, DM SO $\left.-\mathrm{d}_{6}\right) \delta 8.38(\mathrm{~s}, 1 \mathrm{H}, \mathrm{C}=\mathrm{C} \underline{\mathrm{H}}$ triazol), $7.82-7.79(\mathrm{~m}, 2 \mathrm{H}, \mathrm{C} \underline{\mathrm{H}}$ $\mathrm{Ph}), 7.46(\mathrm{t}, \mathrm{J}=7.6 \mathrm{~Hz}, 2 \mathrm{H}, \mathrm{C} \underline{\mathrm{H}} \mathrm{Ph}), 7.35(\mathrm{t}, \mathrm{J}=7.4 \mathrm{~Hz}, 1 \mathrm{H}, \mathrm{C} \underline{\mathrm{H}} \mathrm{Ph})$, 7.17-7.12 ( $\mathrm{m}, 2 \mathrm{H}, \mathrm{C} \underline{\mathrm{H}} \mathrm{SPh}), 7.00-6.95$ ( $\mathrm{m}, 3 \mathrm{H}, \mathrm{C} \underline{\mathrm{H}} \mathrm{SPh}), 5.51$ (d, $\mathrm{J}=4.7 \mathrm{~Hz}, 1 \mathrm{H}, \underline{\mathrm{OH}}), 5.18(\mathrm{br} \mathrm{s}, 1 \mathrm{H}, \underline{\mathrm{OH}}), 4.98(\mathrm{br} \mathrm{s}, 1 \mathrm{H}, \mathrm{O} \underline{\mathrm{H}}), 4.84-$ $4.74(\mathrm{~m}, 3 \mathrm{H}, 2 \mathrm{O} \underline{\mathrm{H}}, \mathrm{H} 6 \mathrm{a}$ and $\mathrm{H} 1), 4.69(\mathrm{t}, \mathrm{J}=5.2 \mathrm{~Hz}, 1 \mathrm{H}, \mathrm{O} \underline{\mathrm{H}})$, 4.54-4.47 ( $\mathrm{m}, 2 \mathrm{H}, \mathrm{O} \underline{\mathrm{H}}, \mathrm{H}$ 6b), $4.31(\mathrm{~d}, \mathrm{~J}=7.4 \mathrm{~Hz}, 1 \mathrm{H}, \mathrm{H1}$ ), 3.90 3.84 ( $m, 1 \mathrm{H}, \mathrm{H} 5)$, 3.64-3.62 ( $\mathrm{m}, 1 \mathrm{H}, \mathrm{H} 4$ ) ), 3.59-3.46 ( $\mathrm{m}, 4 \mathrm{H}, \mathrm{H} 6 \mathrm{a}^{\prime}$, H6b', H3, H5'), 3.46-3.35 ( $\left.\mathrm{m}, 2 \mathrm{H}, \mathrm{H} 2^{\prime}, \mathrm{H}^{\prime}\right), 3.35-3.22$ ( $\mathrm{m}, 2 \mathrm{H}$, $\mathrm{H} 2, \mathrm{H} 4) ;{ }^{13} \mathrm{C}\left\{{ }^{1} \mathrm{H}\right\}$ NMR (101 M Hz, DM SO- $\left.\mathrm{d}_{6}\right) \delta 146.6(\underline{\mathrm{C}}=\mathrm{CH}$ triazol), 133.9 ( $\left.\underline{C}_{\text {quat, }} \mathrm{SPh}\right), 131.3$ ( $\left.\underline{\mathrm{C}}_{\text {quat, }} \mathrm{Ph}\right), 130.8(2 \underline{\mathrm{CH}}, \mathrm{SPh})$, 129.3 and $129.1(2 \times 2 \underline{\mathrm{C}} \mathrm{H}, \mathrm{SPh}$ and $\mathrm{Ph}), 128.3(\underline{\mathrm{CH}}, \mathrm{Ph}), 127.1$ $(\underline{\mathrm{CH}}, \mathrm{SPh}), 125.6(2 \underline{\mathrm{CH}}, \mathrm{Ph}), 122.7\left(\mathrm{C}=\underline{\mathrm{CH}}\right.$ triazol), $105.2\left(\mathrm{C} 1^{\prime}\right)$,
88.9 (C3), 86.3 (C1), 77.9 (C5), 76.2 (C5'), $73.3\left(\mathrm{C}^{\prime}\right), 71.5$ and 71.3 (C2' and C2), 70.2 (C4), $68.6\left(\mathrm{C}^{\prime}\right), 61.0$ (C6), 51.5 (C6); HRMS (ESI-TOF) m/ z: [M + Na] ${ }^{+} \mathrm{Calcd}$ for $\mathrm{C}_{26} \mathrm{H}_{31} \mathrm{~N}_{3} \mathrm{O}{ }_{9} \mathrm{SNa}$ 584.1679; Found 584.1684.

\section{Phenyl $\beta$-D-galactopyranosyl-( $1 \rightarrow 3)$-6-deoxy-6-[4-(4-phe- noxyphenyl)-1H-1,2,3-triazol-1-yl]-1-thio- $\beta$-D-glucopyra- noside 36}

To a solution of azide $\mathbf{1 2}$ ( $30 \mathrm{mg}, 65 \mu \mathrm{mol}$ ) in D M F ( $1 \mathrm{~mL}$ ) were added 4-phenoxyphenylacetylene ( $23.7 \mu \mathrm{L}, 0.13 \mathrm{mmol}, 2$ eq.) , copper iodide ( $12.45 \mathrm{mg}, 65.4 \mu \mathrm{mol}, 1 \mathrm{eq})$ and $\mathrm{Et}_{3} \mathrm{~N}(10 \mu \mathrm{L}, 72 \mu \mathrm{mol}$, $1.1 \mathrm{eq}$ ). The reaction mixture was stirred at rt under an argon atmosphere for $12 \mathrm{~h}$. After completion the mixture was concentrated under reduced pressure and purified by phase flash chromatography ( $\mathrm{DCM} / \mathrm{M} \mathrm{eOH} 1 / 0$ to $9 / 1$ ) then by reverse phase $\mathrm{C}$-18 flash chromatography using $\mathrm{H}_{2} \mathrm{O} / \mathrm{M} \mathrm{eOH}$ gradient mixture to give derivative

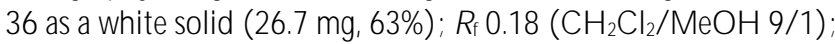
${ }^{1} \mathrm{H}$ N M R $\left(400 \mathrm{M} \mathrm{Hz}, \mathrm{DM} \mathrm{SO}-\mathrm{d}_{6}\right) \delta 8.33(\mathrm{~s}, 1 \mathrm{H}, \mathrm{C}=\mathrm{CH}$ triazol), 7.84 7.77 ( $\mathrm{m}, 2 \mathrm{H}, \mathrm{C} \underline{\mathrm{H}}$ PhenoxyPh), 7.45-7.38 ( $\mathrm{m}, 2 \mathrm{H}, \mathrm{C} \underline{\mathrm{H}}$ PhenoxyPh), 7.22-7.12 (m, 3H, Cㅂ SPh), 7.12-7.03 ( $\mathrm{m}, 4 \mathrm{H}, \mathrm{C} \underline{\mathrm{H}}$ PhenoxyPh),

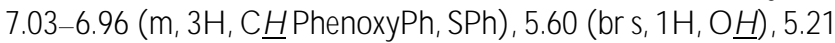
( br s, $1 \mathrm{H}, \mathrm{OH}), 4.83-4.71(\mathrm{~m}, 1 \mathrm{H}, \mathrm{H} \mathrm{6a}), 4.74(\mathrm{~d}, \mathrm{~J}=9.8 \mathrm{~Hz}, 1 \mathrm{H}$, H 1), $4.50(\mathrm{dd}, \mathrm{J}=8.8,14.4 \mathrm{~Hz}, 1 \mathrm{H}, \mathrm{H} \mathrm{6b}), 4.32(\mathrm{~d}, \mathrm{~J}=7.4 \mathrm{~Hz}, 1 \mathrm{H}$, $\mathrm{H} 1^{\prime}$ ), $3.86(\mathrm{ddd}, \mathrm{J}=1.9,6.0,11.1 \mathrm{~Hz}, 1 \mathrm{H}, \mathrm{H} 5), 3.64(\mathrm{dd}, \mathrm{J}=1.3,3.2$ Hz, 1H, H4'), 3.58-3.47 ( m, 4H, H6a', H6b', H5', H3), 3.47-3.34 $\left(\mathrm{m}, 2 \mathrm{H}, \mathrm{H2} 2^{\prime}, \mathrm{H} 3^{\prime}\right), 3.34-3.23(\mathrm{~m}, 2 \mathrm{H}, \mathrm{H} 2, \mathrm{H} 4) ;{ }^{13} \mathrm{C}\left\{{ }^{1} \mathrm{H}\right\} \mathrm{N} \mathrm{M} \mathrm{R}(101$ MHz, DM SO $\left.-\mathrm{d}_{6}\right) \delta 157.1$ and 156.7 (2 $\underline{\mathrm{C}}_{\text {quat, }}$ PhenoxyPh), 146.2 $\left(\underline{\mathrm{C}}=\mathrm{CH}\right.$ triazol), 134.0 ( $\left.\underline{\mathrm{C}}_{\text {quat, }} \mathrm{SPh}\right), 130.7(2 \underline{\mathrm{CH}}, \mathrm{SPh}), 130.6(2 \underline{\mathrm{CH}}$, PhenoxyPh), $129.1(2 \underline{\mathrm{C}} \mathrm{H}, \mathrm{SPh}), 127.4(2 \underline{\mathrm{C}} \mathrm{H}, \mathrm{PhenoxyPh}), 127.1$ ( $\underline{\mathrm{CH}}$, PhenoxyPh), 126.7 ( $\underline{\mathrm{C}}_{\text {quat, }}$ PhenoxyPh), $124.0(\underline{\mathrm{CH}}, \mathrm{SPh})$, $122.4(\mathrm{C}=\underline{\mathrm{C}} \mathrm{H}$ triazol), 119.5 and $119.14 \underline{\mathrm{C}} \mathrm{H}, \mathrm{PhenoxyPh}), 105.2$ (C1'), 89.0 (C3), 86.4 (C1), 77.9 (C5), 76.2 (C5'), 73.3 (C3'), 71.5 and 71.3 (C2' and $\mathrm{C} 2$ ), 70.2 (C4), 68.6 (C4'), 61.0 (C6'), 51.5 (C6); HRMS (ESI-TOF) $\mathrm{m} / \mathrm{z}:[\mathrm{M}+\mathrm{Na}]^{+}$Calcd for $\mathrm{C}_{32} \mathrm{H}_{35} \mathrm{~N}_{3} \mathrm{O}_{10} \mathrm{SN}$ a 676.1941; F ound 676.1918.

Molecular modelling. Lactosamine derivatives were built using Discovery Studio 4.1, Dassault Systèmes BIOVIA, San Diego or from the Glycam Web Server. ${ }^{46}$ The docking experiments were performed using the CDOCKER protocol ${ }^{47}$ as previously described. ${ }^{30,29}$ Briefly, the lactosamine binding domain of the 3ZSJ structure ${ }^{48}$ was defined as the center of a 18 Angstrom sphere where the ligand could freely explore the protein hypersurface. The protocol has a two-step procedure, the first one involves a rapid ligand-protein evaluation with limited precision for interaction energy evaluation, and a second phase where a full molecular dynamics simulation using the CHARMm force field is performed. During the first phase, 250 binding modes were evaluated then 25 poses were refined in the second full potential phase, and the 10 best poses were kept. The best pose for each compound was selected as presenting the best binding interaction energy in the CDOCKER protocol and the lowest deviation of the galactose moiety from the location found in the original crystal structure. The root mean square deviation (RMSD) of the galactose location compared to the crystallographic galactose was assessed using the Find Most Common Sub-Structure (MCSS) implemented in rdkit. ${ }^{49}$ Poses analysis and illustrations were performed in Discovery Studio and PyMol. ${ }^{50}$ Detailed ligand-receptor interaction analysis were done with LigPlot+. ${ }^{51}$ 


\section{ASSOCIATED CONTENT}

Supporting Information. Experimental part for compound 1 precursors, fluorescence anisotropy experiment, ${ }^{1} \mathrm{H},{ }^{13} \mathrm{C}, \mathrm{COSY}$ and $\mathrm{HSQ} \mathrm{C}$ N M R spectra for compounds 2, 4-12, 14-27 and 29-36 "This material is available free of charge via the Internet at http://pubs.acs.org."

\section{AUTHOR INFORMATION}

\section{Corresponding Author}

*E-mail: cyrille.grandjean@univ-nantes.fr

ORCID : Cyrille Grandjean: 0000-0002-9775-6917

\section{Author Contributions}

The manuscript was written through contributions of all authors. / All authors have given approval to the final version of the manuscript.

\section{ACKNOWLEDGMENT}

Les $L$ aboratoires Servier are acknowledged for a post-doctoral fellowship to C.D. and research funding. Wealso thank the mass spectrometry core facility of $\mathrm{CRN} H$ for exact mass determinations.

\section{REFERENCES}

(1) Zhang, J.; Chen, C.; Gadi, M. R.; Gibbons, C.; Guo, Y.; Cao, X.; Edmunds, G.; Wang, S.; Liu, D.; Yu, J.; Wen, L.; Wang, P. G. M achine-Driven Enzymatic Oligosaccharide Synthesis by Using a Peptide Synthesizer. Angew. Chem. Int. Ed Engl. 2018, 57 (51), 16638-16642. https:// doi.org/ 10.1002/ anie.201810661.

(2) Wen, L.; Edmunds, G.; Gibbons, C.; Zhang, J.; Gadi, M . R.; Zhu, H .; Fang, J.; Liu, X.; K ong, Y.; Wang, P. G . T oward Automated Enzymatic Synthesis of O ligosaccharides. Chem. Rev. 2018, 118 (17), 8151-8187. https:// doi.org/ 10.1021/ acs.chemrev.8b00066.

(3) Chen, X.; Kowal, P.; Wang, P. G. Large-Scale Enzymatic Synthesis of O ligosaccharides. Curr. O pin. D rug D iscov. D evel. 2000, 3 (6), 756-763.

(4) Yu, H.; Santra, A.; Li, Y.; M cArthur, J. B.; Ghosh, T .; Yang, X.; Wang, P. G.; Chen, X. Streamlined Chemoenzymatic T otal Synthesis of Prioritized Ganglioside C ancer Antigens. Org. Biomol. Chem. 2018, 16 (22), 4076-4080 https:/ / doi.org/ 10.1039/ c8ob01087k.

(5) Dube, D.H.; Bertozzi, C. R. M etabolic O ligosaccharide Engineering as a T ool for Glycobiology. Curr. O pin. Chem. Biol. 2003, 7 ( 5), 616-625. https:// doi.org/10.1016/ j.cbpa.2003.08.006

(6) Büll, C.; H eise, T .; van H ilten, N .; Pijnenborg, J. F. A.; Bloemendal, V.R.L. .; Gerrits, L.; Kers-Rebel, E. D.; Ritschel, T .; den Brok, M. H.; A dema, G. J.; Boltje, T. J. Steering Siglec-Sialic Acid Interactions on Living Cells U sing Bioorthogonal Chemistry. Angew. Chem. Int. Ed Engl. 2017, 56 (12), 3309-3313. https:/ / doi.org/ 10.1002/ anie.201612193.

(7) Briard, J. G.; Jiang, H.; M oremen, K. W.; M acauley, M. S.; Wu, P. Cell-Based Glycan Arrays for Probing Glycan-Glycan Binding Protein Interactions. $N$ at. Commun. 2018, 9 (1), 880 https:// doi.org/ 10.1038/ s41467-018-03245-5.

(8) Santra, A.; Xiao, A.; Yu, H .; Li, W .; Li, Y.; N go, L.; M CArthur, J. B.; Chen, $X$. A Diazido Mannose Analogue as a Chemoenzymatic Synthon for Synthesizing Di-N-A cetyllegionaminic Acid-Containing Glycosides. Angew. Chem. Int. Ed Engl. 2018, 57 (11), 2929-2933. https:/ / doi.org/ 10.1002/ anie.201712022.

(9) Kupper, C. E.; Rosencrantz, R. R.; Henßen, B.; Pelantová, H .; Thönes, S.; Drozdová, A.; Křen, V.; Elling, L. Chemo-Enzymatic M odification of Poly- $\mathrm{N}$-Acetyllactosamine ( $\mathrm{LaCN} A \mathrm{AC}$ ) O ligomers and N,N -Diacetyllactosamine (LacDiNAC) Based on Galactose
Oxidase Treatment. Beilstein J. Org. Chem. 2012, 8, 712-725. https:// doi.org/ 10.3762/ bjoc.8.80.

Li, T .; H uang, M .; Liu, L.; Wang, S.; M oremen, K. W .; Boons, G .J. Divergent Chemoenzymatic Synthesis of Asymmetrical-C oreFucosylated and Core-U nmodified N-Glycans. Chem. W einh Bergstr. Ger. 2016, 22 (52), 18742-18746. https:// doi.org/ 10.1002/ chem.201604999.

(11) Gagarinov, I. A.; Li, T .; Wei, N.; Sastre T oraño, J.; de Vries, R. P.; Wolfert, M . A.; Boons, G.-J. Protecting-Group-C ontrolled Enzymatic Glycosylation of Oligo-N -Acetyllactosamine Derivatives. Angew. Chem. Int. Ed Engl. 2019, 58 (31), 10547-10552. https:// doi.org/ 10.1002/ anie.201903140.

M einke, S.; Thiem, J. Trypanosomal Trans-Sialidases: Valuable Synthetic T ools and T argets for M edicinal C hemistry. Top. Curr. Chem. 2015, 367, 231-250 https:// doi.org/ 10.1007/ $128 \quad 2012 \quad 330$.

(13) Wang, L.-X.; H uang, W. Enzymatic T ransglycosylation for Glycoconjugate Synthesis. Curr. Opin. Chem. Biol. 2009, 13 (5-6), 592-600. https:// doi.org/10.1016/ j.cbpa.2009.08.014.

David, B.; I rague, R.; Jouanneau, D.; Daligault, F.; C zjzek, M .; Sanejouand, Y.-H .; T ellier, C. Internal Water Dynamics Control the $\mathrm{Transglycosylation/Hydrolysis} \mathrm{Balance} \mathrm{in} \mathrm{the} \mathrm{Agarase}$ (AgaD) of Zobellia Galactanivorans. ACS Catal. 2017, 7 (5), 3357-3367. https:// doi.org/ 10.1021/ acscatal.7b00348.

(15) Shaikh, F. A.; Withers, S. G. T eaching O Id Enzymes N ew Tricks: Engineering and Evolution of G lycosidases and $\mathrm{G}$ lycosyl $\mathrm{T}$ ransferasesfor Improved G lycoside Synthesis. Biochem. Cell Biol. Biochim. Biol. Cell. 2008, 86 (2) , 169-177. https:// doi.org/ 10.1139/007149.

(16) André-M iral, C.; Koné, F. M.; Solleux, C.; Grandjean, C.; Dion, $M$.; T ran, V.; T ellier, C. De N ovo Design of a T rans- $\beta-N$-A cetylglucosaminidase Activity from a GH1 $\beta$-Glycosidase by Mechanism Engineering. Glycobiology 2015, 25 (4), 394-402. https:/ / doi.org/ 10.1093/ glycob/ cwu121.

(17) M ackenzie, L. F.; Wang, Q .; Warren, R. A.J.; Withers, S. G. Glycosynthases: M utant Glycosidases for O ligosaccharide Synthesis. J. Am. Chem. Soc. 1998, 120 (22), 5583-5584. https:// doi.org/ 10.1021/ ja980833d.

(18) Armstrong, Z.; Liu, F.; Chen, H .-M .; H allam, S. J.; Withers, S. G. Systematic Screening of Synthetic Gene-Encoded Enzymes for Synthesis of M odified G lycosides. ACS Catal. 2019, 9 (4) , 3219 3227. https:// doi.org/ 10.1021/ acscatal.8b05179.

(19) Jahn, M.; M arles, J.; Warren, R. A. J.; Withers, S. G. T hioglycoligases: Mutant Glycosidases for Thioglycoside Synthesis. Angew. Chem. Int. Ed Engl. 2003, 42 (3), 352-354. https:// doi.org/ 10.1002/ anie.200390114.

(20) Salamone, S.; Guerreiro, C.; Cambon, E.; André, I.; Remaud-Siméon, M .; M ulard, L. A. Programmed Chemo-Enzymatic Synthesis of the O ligosaccharide Component of a C arbohydrate-Based Antibacterial Vaccine Candidate. Chem. Commun. Camb. Engl. 2015, $51 \quad$ (13), 2581-2584. https:// doi.org/ 10.1039/ c4cc08805k.

(21) Barondes, S. H.; Cooper, D. N .; Gitt, M. A.; L effler, H. Galectins. Structure and Function of a Large Family of A nimal Lectins. J. Biol. Chem. 1994, 269 (33) , 20807-20810.

(22) Dumic, J.; Dabelic, S.; Flögel, M. Galectin-3: An O pen-Ended Story. Biochim. Biophys. Acta 2006, 1760 (4), 616-635. https:// doi.org/ 10.1016/ j.bbagen.2005.12.020.

(23) Johannes, L.; Jacob, R.; L effler, H . G alectins at a Glance. J. Cell Sci. 2018, 131 (9). https:// doi.org/10.1242/ jcs.208884.

(24) H sieh, T .-J.; Lin, H .-Y.; T u, Z.; H uang, B.-S.; Wu, S.-C.; Lin, C.-H . Structural Basis U nderlying the Binding Preference of $\mathrm{H}$ uman $\mathrm{Ga}$ lectins-1, -3 and -7 for Galß1-3/ 4G IcN Ac. PloS O ne 2015, 10 (5), e0125946. https:// doi.org/ 10.1371/ journal.pone.0125946. 
(25) Delaine, T .; Collins, P.; M acKinnon, A.; Sharma, G .; Stegmayr, J.; Rajput, V.K.; M andal, S.; C umpstey, I.; Larumbe, A.; Salameh, B. A.; Kahl-K nutsson, B.; van H attum, $\mathrm{H}$.; van Scherpenzeel, M .; Pieters, R. J.; Sethi, T.; Schambye, H.; O redsson, S.; Leffler, H.; Blanchard, H.; Nilsson, U. J. Galectin-3-Binding Glycomimetics That Strongly Reduce Bleomycin-Induced Lung Fibrosis and Modulate Intracellular Glycan Recognition. Chembiochem Eur. J. Chem. Biol. 2016, 17 (18), 1759-1770. https:/ / doi.org/ 10.1002/ cbic.201600285.

(26) H sieh, T.-J.; Lin, H .-Y.; T u, Z.; Lin, T .-C.; Wu, S.-C.; T seng, Y.-Y.; Liu, F.-T.; H su, S.-T. D.; Lin, C.-H . Dual Thio-DigalactosideBinding M odes of $\mathrm{H}$ uman $\mathrm{G}$ alectins as the Structural Basis for the Design of Potent and Selective I nhibitors. Sci. Rep. 2016, 6, 29457. https:/ / doi.org/ 10.1038/ srep29457.

(27) Sörme, P.; Arnoux, P.; Kahl-Knutsson, B.; Leffler, H .; Rini, J. M .; $\mathrm{N}$ ilsson, U .J. Structural and Thermodynamic Studies on CationPi Interactions in Lectin-Ligand Complexes: H igh-Affinity Galectin-3 I nhibitors through Fine-T uning of an Arginine-Arene Interaction. J. Am. Chem. Soc. 2005, 127 (6), 1737-1743. https:/ / doi.org/ 10.1021/ ja043475p.

(28) O berg, C.T.; Leffler, H .; N ilsson, U.J. Inhibition of $G$ alectins with Small Molecules. Chimia 2011, 65 (1-2), 18-23. https:/ / doi.org/ 10.2533/ chimia.2011.18.

(29) Dion, J.; Advedissian, T .; Storozhylova, N .; D ahbi, S.; Lambert, A.; Deshayes, F.; Viguier, M .; T ellier, C.; Poirier, F.; T életchéa, S.; Dussouy, C.; T ateno, H .; H irabayashi, J.; Grandjean, C. Development of a Sensitive M icroarray Platform for the Ranking of $G$ alectin Inhibitors: Identification of a Selective Galectin-3 Inhibitor. Chembiochem Eur. J. Chem. Biol. 2017, 18 (24), 2428-2440. https:/ / doi.org/ 10.1002/ cbic.201700544.

(30) Atmanene, C.; Ronin, C.; T életchéa, S.; Gautier, F.-M .; DjedaïniPilard, F.; Ciesielski, F.; Vivat, V.; Grandjean, C. Biophysical and Structural Characterization of M ono/Di-Arylated Lactosamine Derivatives Interaction with $\mathrm{H}$ uman $\mathrm{G}$ alectin-3. Biochem. Biophys. $\begin{array}{llll}\text { Res. Commun. 2017, } 489 & \text { (3), 281-286. }\end{array}$ https:/ / doi.org/ 10.1016/ j.bbrc.2017.05.150.

(31) Fischöder, T .; Laaf, D.; D ey, C.; Elling, L. Enzymatic Synthesis of $\mathrm{N}$-Acetyllactosamine (LacNAC) Type 1 Oligomers and Characterization as M ultivalent Galectin Ligands. M ol. Basel Switz. 2017, 22 (8). https:// doi.org/ 10.3390/ molecules22081320.

(32) Fort, S.; K im, H .-S.; H indsgaul, O Screening for G alectin-3 Inhibitorsfrom Synthetic Lacto-N -Biose Libraries U sing M icroscale Affinity Chromatography Coupled to M ass Spectrometry. J. O rg. Chem. 2006, 71 (19), 7146-7154. https:/ / doi.org/ 10.1021/ j0060485v.

(33) D'Almeida, A.; Ionata, M.; Tran, V.; Tellier, C.; Dion, M.; Rabiller, C. An Expeditious and Efficient Synthesis of $\beta$-d-Galactopyranosyl-( $1 \rightarrow 3)-\mathrm{d}-\mathrm{N}$-A cetylglucosamine (Lacto-N-Biose) Using a Glycosynthase from $T$ hermus T hermophilus as a C atalyst. T etrahedron Asymmetry 2009, 20 (11), 1243-1246. https:/ / doi.org/ 10.1016/ j.tetasy.2009.05.007.

(34) O gunsina, M .; Samadder, P.; I dowu, T .; Arthur, G.; Schweizer, F. Design, Synthesis and Evaluation of $C$ ytotoxic Properties of Bisamino G lucosylated Antitumor Ether Lipids against $C$ ancer Cells and Cancer Stem Cells. M edChemComm 2016, 7 (11), 2100 2110. https:// doi.org/ 10.1039/ C6M D 00328A.

(35) Cai, L.; Guan, W.; Kitaoka, M .; Shen, J.; Xia, C .; Chen, W.; Wang, P. G. A Chemoenzymatic Route to N-Acetylglucosamine-1-Phosphate Analogues: Substrate Specificity Investigations of $\mathrm{N}$ Acetylhexosamine 1-Kinase. Chem. Commun. Camb. Engl. 2009, N 0. 20, 2944-2946. https:// doi.org/10.1039/ b904853g.

(36) Teze, D.; Dion, M.; Daligault, F.; Tran, V.; André-M iral, C.; Tellier, C. Alkoxyamino Glycoside Acceptors for the Regioselective Synthesis of Oligosaccharides U sing Glycosynthases and
T ransglycosidases. Bioorg. M ed. Chem. Lett. 2013, 23 (2), 448 451. https:// doi.org/ 10.1016/ j.bmcl.2012.11.065.

(37) Alpe, M.; O scarson, S. Synthesis of O ligosaccharides Corresponding to StreptococcusPneumoniae Type 9 C apsular Polysaccharide Structures. Carbohydr. Res. 2002, 337 (19), 1715-1722. https:/ / doi.org/ 10.1016/ s0008-6215( 02) 00263-X.

(38) Cumpstey, I.; Salomonsson, E.; Sundin, A.; Leffler, H .; N ilsson, U . J. Studies of A rginine-A rene Interactions through Synthesis and Evaluation of a Series of Galectin-Binding Aromatic L actose Esters. Chembiochem Eur. J. Chem. Biol. 2007, 8 (12), 1389-1398. https:// doi.org/ 10.1002/ cbic.200700040.

(39) Cumpstey, I.; Salomonsson, E.; Sundin, A.; L effler, H .; N ilsson, U . J. D ouble Affinity Amplification of Galectin-Ligand Interactions through Arginine-Arene Interactions: Synthetic, Thermodynamic, and Computational Studies with Aromatic Diamido Thiodigalactosides. Chem. W einh. Bergstr. G er. 2008, 14 (14), 4233 4245. https:// doi.org/ 10.1002/ chem.200701932.

(40) Baron, A.; Blériot, Y.; Sollogoub, M.; Vauzeilles, B. Phenylenediamine Catalysis of "Click Glycosylations" in Water: Practical and Direct Access to Unprotected N eoglycoconjugates. O rg. Biomol. Chem. 2008, 6 (11), 1898-1901. https:// doi.org/ 10.1039/ b805528a.

(41) van H attum, H.; Branderhorst, H. M .; M oret, E. E.; N ilsson, U. J.; Leffler, $H$.; Pieters, R. J. T uning the Preference of Thiodigalactoside- and Lactosamine-Based Ligands to G alectin-3 over G alectin1. J. Med. Chem. 2013, 56 (3), 1350-1354. https:// doi.org/ 10.1021/jm301677r.

(42) Dion, J.; Deshayes, F .; Storozhylova, N .; Advedissian, T .; Lambert, A.; Viguier, M.; T ellier, C.; Dussouy, C.; Poirier, F.; Grandjean, C. Lactosamine-Based D erivatives as T ools to D elineate the Biological Functions of Galectins: Application to Skin Tissue Repair. Chembiochem Eur. J. Chem. Biol. 2017, 18 (8), 782-789. https:// doi.org/ 10.1002/ cbic.201600673.

(43) Nambiar, S.; Daeuble, J. F.; D oyle, R. J.; Grant Taylor, K. Facile Synthesis of Silylated T hioglycosides. T etrahedron Lett. 1989, 30 (17), 2179-2182. https:// doi.org/ 10.1016/ S00404039(00) 99642-4.

(44) M ehta, S.; M eldal, M.; Ferro, V.; Duus, J. Ø.; Bock, K. Internally Quenched Fluorogenic, $a$-H elical Dimeric Peptides Andglycopeptides for the Evaluation of the Effect of G lycosylation on T heconformation of Peptides. J. Chem. Soc. Perkin 1 1997, N 0. 9, 1365 1374. https:// doi.org/ 10.1039/ A607624F.

(45) Airoldi, C.; Palmioli, A.; D'Urzo, A.; Colombo, S.; Vanoni, M.; M artegani, E.; Peri, F. Glucose-D erived Ras Pathway Inhibitors: Evidence of Ras-Ligand Binding and Ras-GEF (C dc25) Interaction Inhibition. Chembiochem Eur. J. Chem. Biol. 2007, 8 (12), 1376-1379. https:// doi.org/ 10.1002/ cbic.200700185.

(46) Kirschner, K. N.; Yongye, A. B.; T schampel, S. M.; GonzálezOuteiriño, J.; Daniels, C. R.; Foley, B. L.; Woods, R. J. GLYCAM 06: A Generalizable Biomolecular Force Field. C arbohydrates. J. Comput. Chem. 2008, 29 (4), 622-655. https:// doi.org/ 10.1002/ jcc.20820.

(47) Wu, G.; Robertson, D. H .; Brooks, C. L.; Vieth, M . D etailed Analysis of Grid-Based Molecular Docking: A Case Study of CDOCKER-A CH ARM m-Based M D D ockingAlgorithm. J. Comput. Chem. 2003, 24 (13), 1549-1562. https:/ / doi.org/ 10.1002/ jcc.10306.

(48) Saraboji, K.; H åkansson, M .; Genheden, S.; Diehl, C.; Q vist, J.; Weininger, U.; N ilsson, U . J.; Leffler, H .; Ryde, U .; Akke, M .; L ogan, D. T . The Carbohydrate-Binding Site in G alectin-3 Is Preorganized to Recognize a Sugarlike Framework of Oxygens: U Itra$\mathrm{High}$-Resolution Structures and Water Dynamics. Biochemistry 2012, 51 (1), 296-306. https:// doi.org/ 10.1021/ bi201459p.

(49) RDKit https:/ / www.rdkit.org/ ( accessed Jul 24, 2020). 
(50) The PyM OL M olecular Graphics System, Version 1.8 Schrödinger, LLC.
(51) Laskowski, R. A.; Swindells, M . B. LigPlott: M ultiple Ligand-Protein Interaction Diagrams for D rug Discovery. J. Chem. Inf. M odel. 2011, 51 (10) , 2778-2786. https:// doi.org/ 10.1021/ ci200227u. 